Florida International University FIU Digital Commons

FIU Electronic Theses and Dissertations

University Graduate School

7-9-2013

\title{
An Ethnographic Study: Becoming a Physics Expert in a Biophysics Research Group
}

Idaykis Rodriguez

Florida International University, irodr020@fiu.edu

DOI: $10.25148 /$ etd.FI13080915

Follow this and additional works at: https://digitalcommons.fiu.edu/etd

Part of the Biological and Chemical Physics Commons, Higher Education Commons, Other Physics Commons, and the Science and Mathematics Education Commons

\section{Recommended Citation}

Rodriguez, Idaykis, "An Ethnographic Study: Becoming a Physics Expert in a Biophysics Research Group" (2013). FIU Electronic Theses and Dissertations. 938.

https://digitalcommons.fiu.edu/etd/938

This work is brought to you for free and open access by the University Graduate School at FIU Digital Commons. It has been accepted for inclusion in FIU Electronic Theses and Dissertations by an authorized administrator of FIU Digital Commons. For more information, please contact dcc@fiu.edu. 


\section{FLORIDA INTERNATIONAL UNIVERSITY}

Miami, Florida

\section{AN ETHNOGRAPHIC STUDY: BECOMING A PHYSICS EXPERT IN A BIOPHYSICS RESEARCH GROUP}

A dissertation submitted in partial fulfillment of

the requirements for the degree of

DOCTOR OF PHILOSOPHY

in

PHYSICS

by

Idaykis Rodriguez

2013 
To: Dean Kenneth G. Furton

College of Arts and Sciences

This dissertation, written by Idaykis Rodriguez, and entitled An Ethnographic Study: Becoming a Physics Expert in a Biophysics Research Group, having been approved in respect to style and intellectual content, is referred to you for judgment.

We have read this dissertation and recommend that it be approved.

David Brookes

Laird H. Kramer

Brian Raue

Eric Brewe, Major Professor

Date of Defense: July 9, 2013

The dissertation of Idaykis Rodriguez is approved.

Dean Kenneth G. Furton

College of Arts and Sciences

Dean Lakshmi N. Reddi

University Graduate School

Florida International University, 2013 


\section{ACKNOWLEDGMENTS}

It has been a truly amazing journey to reach my life goal of finishing my physics Ph.D. But I could not have done it alone.

I would first like to acknowledge the man that started it all, my high school physics professor, David Jones. Without his extraordinary teaching and passion for physics I would not have thought I could succeed in physics. To my great advisor Eric Brewe, I thank him for challenging me to always do my best and for not freaking out when I cried from frustration. Understanding the ways of women is the first step in helping them succeed. I would like to acknowledge Laird H. Kramer for never giving up on any student. As a true advocate for students, his dedication has touched many, especially me. I also thank Laird for helping me improve my writing. I acknowledge my committee member David Brookes for his insightful knowledge of physics education literature and for inspiring me to think deeply about teaching. I thank Brian Raue for being a great mentor. Without his challenging remarks I would not have been so driven to pursue the answers. I thank Brian for all those afternoon meetings where he just sits and listens to me.

I am so fortunate to be a part of an amazing Physics Education Research group at FIU where I have met incredible people made true friendships over the years. I thank Renee Michelle Goertzen, whom without which I would not been able to properly decipher all of my data and build strong arguments. I would like to acknowledge my incredible mentor and true friend, Vashti Sawtelle for being someone I can always talk to. I will never forget our carpooling days on the mysterious Palmetto or her notes of encouragement to never quit believing in myself. 
Finally, none of this work could have been accomplished without the great support of my family. I thank my amazing husband Vicente for supporting me in every way and giving me the confidence to reach any goal. I thank my mother Triana for having the courage to risk our lives for a better life in the United States. I am grateful to both my parents Triana and Omar for always letting me know how proud they are of me. I am grateful to my Dad, Renato and my in-laws, Vicente and Emma, for their support and amazing cooking.

This work was supported by the National Science Foundation Grant No. 03120038, and No. 0802184 and by Florida International University Graduate School Dissertation Year Fellowship for 2012. Any opinions, findings, conclusions, or recommendations expressed in this dissertation are those of the author and do not necessarily reflect the views of the National Science Foundation or Florida International University Graduate School.

Chapter 2 has been reprinted with the permission from I. Rodriguez, E. Brewe, and Laird H. Kramer, "Constructing a Model of Physics Expertise," in Proceedings of the 2010 Physics Education Research Conference, Portland, OR (AIP, Melville, NY, 2010), p. 277. Copyright 2010, American Institute of Physics.

Chapter 3 has also been reprinted with the permission from I. Rodriguez, R. M. Goertzen, E. Brewe, and Laird H. Kramer, "Communicating Scientific Ideas: One Element of Physics Expertise," in Proceedings of the 2011 Physics Education Research Conference, Omaha, NE (AIP, Melville, NY, 2010), p. 319. Copyright 2011, American Institute of Physics. 


\title{
ABSTRACT OF THE DISSERTATION
}

\section{AN ETHNOGRAPHIC STUDY: BECOMING A PHYSICS EXPERT IN A BIOPHYSICS RESEARCH GROUP}

\author{
by
}

Idaykis Rodriguez

Florida International University, 2013

Miami, Florida

\section{Professor Eric Brewe, Major Professor}

Expertise in physics has been traditionally studied in cognitive science, where physics expertise is understood through the difference between novice and expert problem solving skills. The cognitive perspective of physics experts only create a partial model of physics expertise and does not take into account the development of physics experts in the natural context of research. My dissertation takes a social and cultural perspective of learning through apprenticeship to model the development of physics expertise of physics graduate students in a research group. I use a qualitative methodological approach of an ethnographic case study to observe and video record the common practices of graduate students in their biophysics weekly research group meetings. I recorded notes on observations and conduct interviews with all participants of the biophysics research group for a period of eight months. I apply the theoretical framework of Communities of Practice to distinguish the cultural norms of the group that cultivate physics expert practices. Results indicate that physics expertise is specific to a topic or subfield and it is established through effectively publishing research in the larger biophysics research community. The participant biophysics research group follows a learning trajectory for its 
students to contribute to research and learn to communicate their research in the larger biophysics community. In this learning trajectory students develop expert member competencies to learn to communicate their research and to learn the standards and trends of research in the larger research community. Findings from my dissertation expand the model of physics expertise beyond the cognitive realm and add the social and cultural nature of physics expertise development. The research also addresses ways to increase physics graduate student success towards their $\mathrm{PhD}$. and decrease the $48 \%$ attrition rate for physics graduate students. Cultivating effective research experiences that give graduate students agency and autonomy beyond their research groups gives students the motivation to finish graduate school and establish their physics expert identity. 


\section{TABLE OF CONTENTS}

CHAPTER

PAGE

CHAPTER I. INTRODUCTION

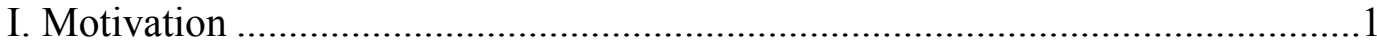

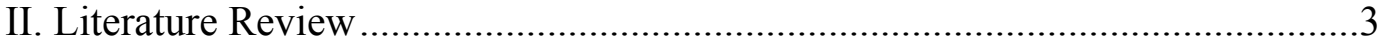

A. Expertise Research .........................................................................

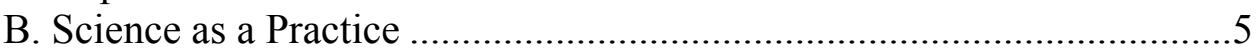

C. Graduate Student Socialization ..............................................................

III. Theoretical Framework …………….........................................................

A. Apprenticeship Theory of Learning …………………….....................

B. Legitimate Peripheral Participation.........................................................

C. Communities of Practice ……………………………….....................10

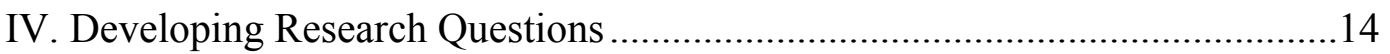

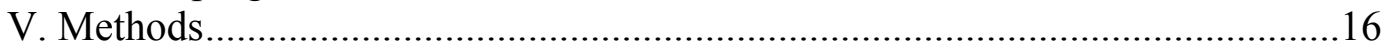

A. Data Collection .......................................................................... 16

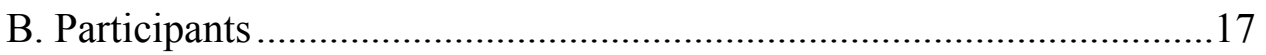

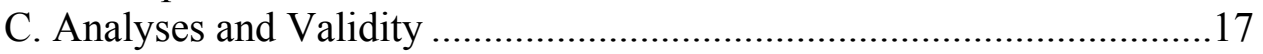

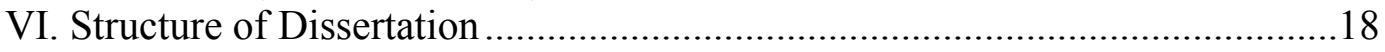

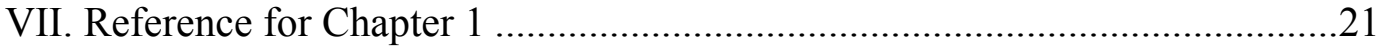

CHAPTER II. CONSTRUCTING A MODEL OF PHYSICS EXPERTISE .....................25

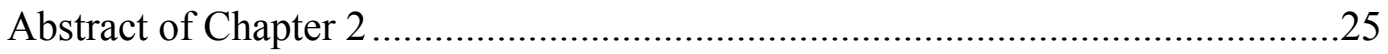

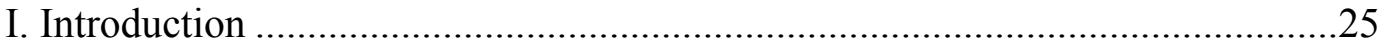

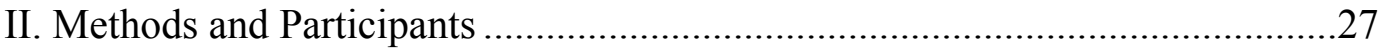

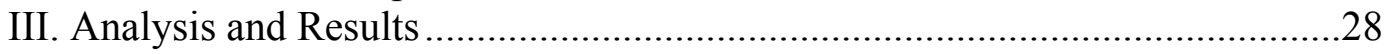

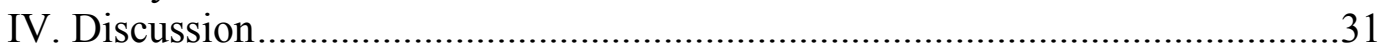

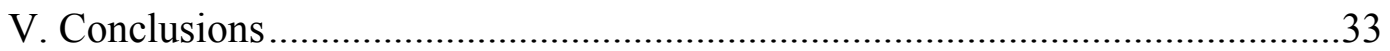

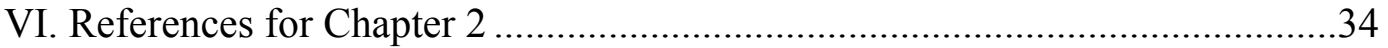

CHAPTER III. COMMUNICATING SCIENTIFIC IDEAS: ONE ELEMENT OF

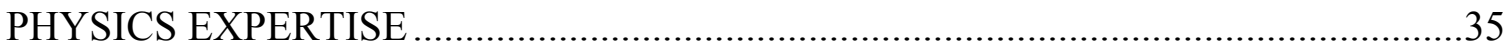

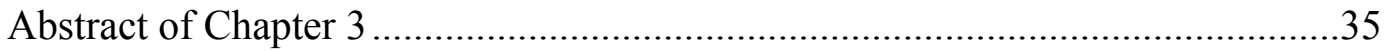

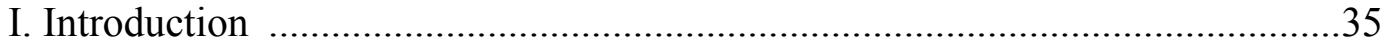

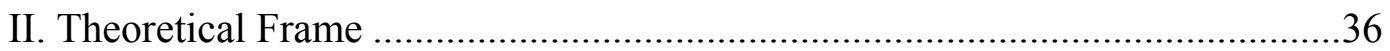

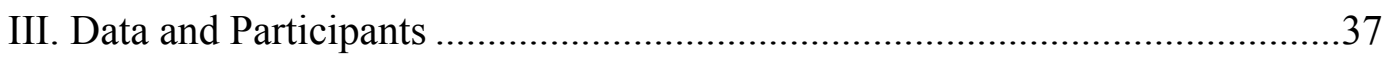

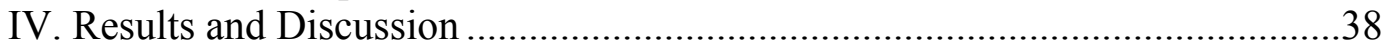

A. Contributing as a marker of expertise .....................................................38

B. Apprenticed to communicate in the field ..................................................39

1. Members assimilate the socialization process …………………......40

2. Communicating with graphical representations...............................41

C. Apparent Contradiction ........................................................................4

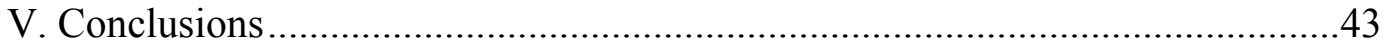

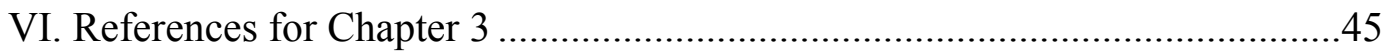




\section{CHAPTER IV. DEVELOPING A PHYSICS EXPERT IDENTITY IN A BIOPHYSICS}

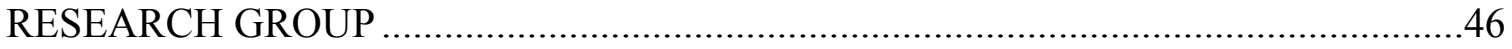

Abstract of Chapter 4 ...................................................................................46

I. Introduction .........................................................................................

II. Social Learning in a Community of Practice ................................................50

III. Identity Framework.......................................................................................51

A. Defining identity ..............................................................................51

B. Identity as community membership ………………………………......53

C. Identity formation as a trajectory .........................................................56

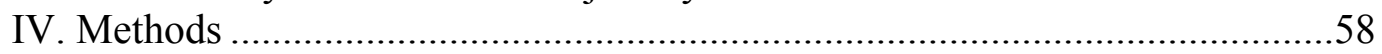

A. Data collection of group dynamics ………………………………......60

B. Interviews with individual members ......................................................60

C. Analysis of video episodes..................................................................61

V. Identity Development Through Membership..................................................63

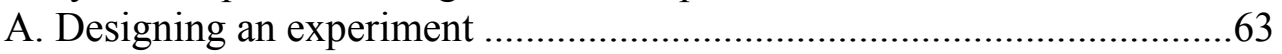

B. Testing factors of the experiment.......................................................68

C. Communicating ideas........................................................................72

VI. Trajectory Towards Expert Member Identity ………......................................

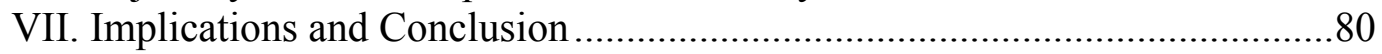

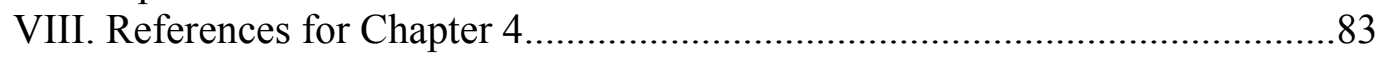

CHAPTER V. THE GLOBAL COMMUNITY OF PHYSICS INFLUENCE ON A BIOPHYSICS RESEARCH GROUP'S CULTURAL SHIFT AND INDIVIDUAL

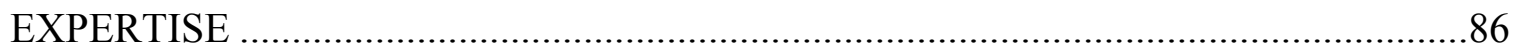

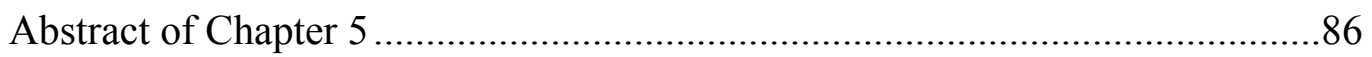

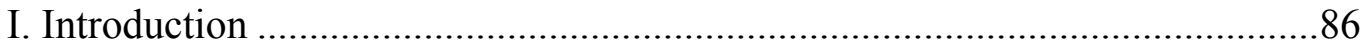

II. Research Group and Graduate Students ......................................................89

III. Knowledge in a Community of Practice.....................................................92

IV. Boundaries of a Community of Practice........................................................94

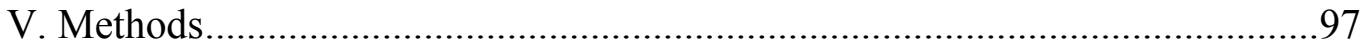

A. Data Collection .............................................................................

B. Researcher and Validity Measures.......................................................98

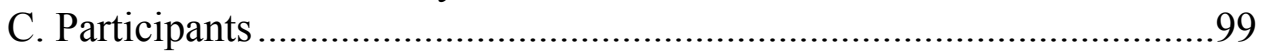

D. Structure of Chapter ..................................................................100

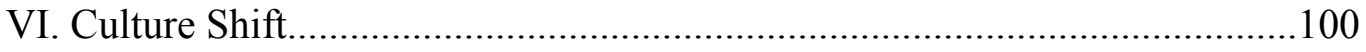

A. Research meetings..........................................................................100

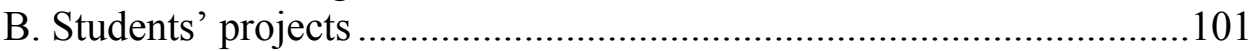

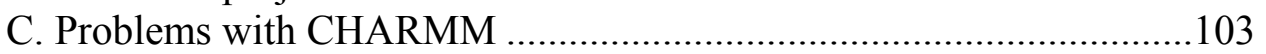

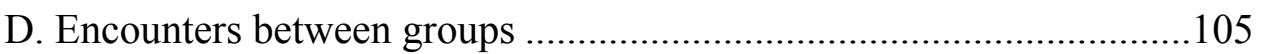

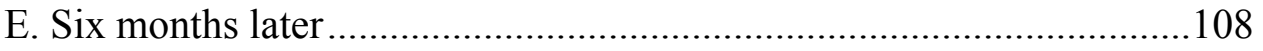

F. Matthew's perspective on the cultural shift.........................................109

VII. Role of Boundary Connections on Culture Shift........................................111

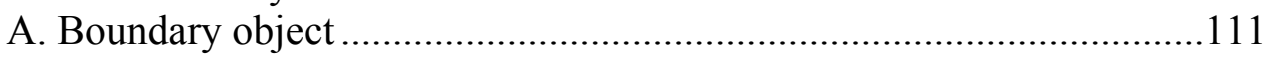

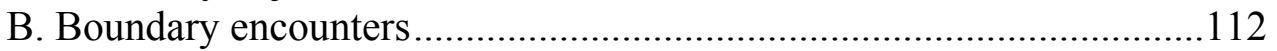

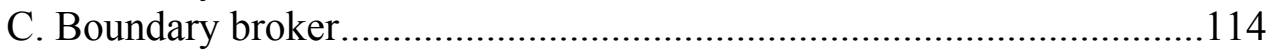


VIII. Influence of Larger Enterprise on Individual Expertise...........................117

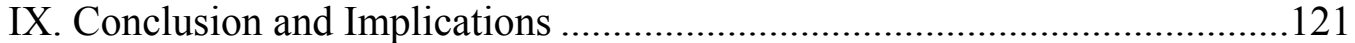

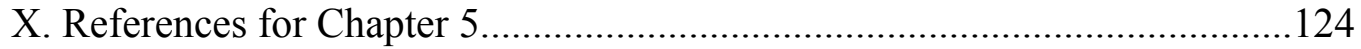

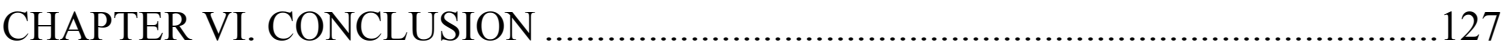

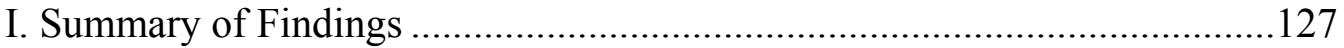

A. Chapter 2: Constructing a Model of Physics Expertise ....................128

B. Chapter 3: Communicating Scientific Ideas: One Element of Physics

Expertise ...................................................................................130

C. Chapter 4: Developing a Physics Expert Identity in a Biophysics Research Group.

D. Chapter 5: The Global Community of Physics Influence on a Biophysics Research Groups' Cultural Shift and Individual Expertise

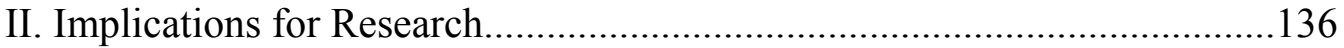

III. Implications for Instructors and Graduate Students..............................138

IV. Directions for Future Research............................................................140

V. References for Chapter 6........................................................... 142

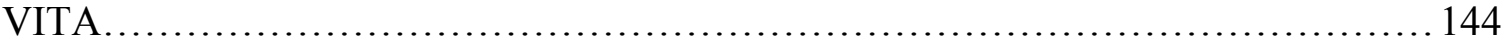




\section{CHAPTER I}

\section{INTRODUCTION}

\section{MOTIVATION}

Research on the nature of physics experts is mostly limited to their cognitive abilities to strategically solve introductory physics problems [1-3], effectively categorize introductory physics problems by physics principles [4,5] and to efficiently use representations to solve problems [6-8]. In these studies, expertise is defined by the differences in problem solving skills and knowledge to their novice counterparts [8]. Cognitive studies choose the expert to be physics professors or graduate students and the novices to be the students they teach $[9,10]$. Although research on the cognitive abilities of physics experts has explained a great deal about how people learn and how knowledge is stored in memory and retrieved [11], the research fails to examine how expertise is developed in natural contexts. The current model of physics experts is served only by research of expert-novice differences in laboratory-controlled tasks [12] and thus is unable to explain how someone becomes an expert. Questions of expertise development in the real world require an expansion of theoretical and methodological perspective beyond the cognitive realm and into social and cultural theories of learning and development.

My dissertation addresses the gap in the physics expertise literature and investigates how physics expertise is developed from a social and cultural perspective. I also use the alternative perspective on physics expertise as a way of understanding physics graduate student retention in their research career. Statistical data surveyed over all physics graduate programs in the United States reveal that about half (48\%) of the students 
enrolled in graduate $\mathrm{Ph} . \mathrm{D}$. programs do not graduate with their physics $\mathrm{Ph}$.D. within nine years [13]. Of those that don't finish their Ph.D. some switch and finish with a terminal Master's degree and of those that do receive their Ph.D. in physics, only $2 \%$ of United States graduates are Hispanic or African American [13]. Low participation from students of diverse cultures and high attrition rate of physics graduate students is alarming, given the substantial amount of time and resources invested by the students, faculty, and departments $[14,15]$. Research has found several factors influence doctoral completion and attrition. Factors include disciplinary and departmental issues such as mismatched expectations between students and their departments [16-18] poor advising [16-18] structural isolation of students $[15,17]$ and the misunderstanding of departmental research cultures [18]. Although research on physics graduate students and the Physics Graduate Education Task Force, [19,20] promote the improvement of placement tests, communication skills, mentoring of students, professional development opportunities, and productive participation in the department, attrition in graduate school remains a problem. I argue that investigating the problem of graduate student attrition from a perspective of developing expertise in their natural research context will inform graduate student research and stakeholders how to reduce attrition and increase diverse participation of physics graduate students.

My study focuses on describing what a physics expert is and the process to develop into a physics expert from a social and cultural perspective of participation. Using the theoretical perspective of learning as transforming one's participation in a community of practice [21-26], I take the apprenticeship theory of learning of Legitimate Peripheral Participation in a Community of Practice [22], to describe physics expertise development 
in physics graduate students. In the following sections I review the background literature on physics expertise, science laboratory research, and graduate student enculturation and explain how my study adds to this literature and differs from previous research. In the theoretical framework section I give a detailed overview of Legitimate Peripheral Participation [22] and Communities of Practice [23] theoretical frameworks. These sections set up my research questions and methods section. I also give an overview of how chapters in this dissertation are structured.

\section{LITERATURE REVIEW}

In this section I summarize research relating to expertise research, science research laboratory studies, and graduate school experience for science students. I propose how to reframe the discussion of graduate student experience from the perspective of developing expertise in natural social context of the physics research community. A more detailed review of relevant literature is provided in subsequent chapters.

\section{A. Expertise Research}

Research on experts stems form the seminal works on chess masters effectively simplifying patterns of play [27], having large amounts of content knowledge with superior memory and retrieval mechanism [11]. Since then, expertise has been studied in different settings using a variety of methods. Expertise has been studied in areas such as sports, games, arts, sciences, and mathematics from the perspectives of decision-making, strategy building, and cognitive abilities $[3,10,28,29]$. In domains such as physics, experts solve textbook problems with an automated process derived from physics principles unlike novices whom work backwards when solving problems [2,4]. Chi, et al.'s [4] seminal work on expert-novice differences in problem solving sets a foundation 
on investigating physics hierarchical knowledge structures built on physics laws and principles. The study of Chi et al. categorizes introductory mechanics problems on the basis of similarity of solution. Solutions by experts, or the physics professors, were categorized on the basis of physical principles involved in solving the problem. Novices, or introductory physics students, solutions were categorized on the basis of the surface features of the problem. For example, all inclined plane problems were categorized similarly even if one problem uses Newtonian force concepts and another uses energy conservation to solve the problem. In the specific context of physics problem solving, categorization tasks such as these have lead to further investigation of expert problem solving strategies $[5,30]$. Others argue that problems solved in these categorization studies are problems for the novices but only mere exercises for experts and do not challenge expert level cognition $[8,10]$.

Research on physics experts that focus around expert-novice differences in specific problem solving skills specialize in clinically controlled methods as their research approach and methodology. They use methods such as verbal protocols, cognitive walkthroughs, and knowledge elicitation techniques such as card sorting and task analysis $[4,5,10,12,29,30]$. The cognitive research on physics experts has made contributions to understanding how people learn and has created tasks that evaluate cognitive learning. Yet, there is more to be learned about physics experts' performance in natural contexts where the tasks are challenging enough to demonstrate expert performance beyond novice comparison and, more importantly, to demonstrate how experts develop $[8,10]$. For physics experts, their natural learning context would be a research laboratory, solving research problems, and working together with their research group. 


\section{B. Science as a Practice}

Research on scientific reasoning in practice emerged as a way of understanding how scientists reason within their research group settings. Landmark studies in sociology have investigated scientists working in laboratories on their day-to-day practices [31-37].

Given the assumption that science takes place in a social context of research laboratories, these researchers have used ethnographic methodologies to describe the processes by which scientists interact in a social context to create or generate knowledge. KnorrCetina's [34] ethnographic studies of high-energy physics laboratories and molecular biology laboratories fuse both cognitive and social perspectives of knowledge to understand the mechanisms of knowledge creation in research settings. She found stark epistemic cultural differences between the high-energy physics and molecular biology research cultures especially in how they perceive measurable data, theoretical and experimental models of analysis, and knowledge developed collectively or individually.

Similar studies incorporating both cognitive and social cultural perspectives of knowledge in science research group have reframed knowledge creation to be a social practice of scientist [35-37]. Analysis of science practice ranged from describing interactions between members of a research group to how laboratory equipment is a pivotal actor in knowledge formation [34,38,39]. Dunbar's [35] work with molecular biologist research laboratories research investigated cognitive processes the scientists use in modeling organisms in their natural environments in comparison to experimentally controlled environments. Dunbar's findings are related in nature with how expert physicists function in research group settings and working together to resolve problems. Dunbar's research approach focused on the evolution of ideas and concepts between 
individuals and artifacts. The literature on science laboratories in both a cognitive and social context of knowledge creation explains how scientists' epistemic cultures influence their own knowledge communities. The above referenced research on science research group does little to address an individual's process of enculturation into the practice of science.

\section{Graduate Student Socialization}

Literature in graduate student socialization explores how a student becomes a member of an academic community. Models of socialization outline different stages of development through a graduate program $[17,40]$. Their research focuses on using a socialization framework to understand questions of graduate student attrition $[40,41]$ and career choice [42]. Further, research using socialization models for graduate students are limited to development within a program department and do not include student development into the larger enterprise of the discipline. Gardner's [41] study of the socialization process of graduate students in the chemistry and history disciplines finds that disciplinary culture impacts student socialization but she does not outline how. Stucky [43] studied organic chemistry graduate students in research groups and found that social aspects of acceptance into the community needed to be adopted by the student, such as language, culture, and norm practices to communicate research. Many of the studies on graduate student socialization suggest identity development is an important concept in understanding graduate student socialization, yet studies on physics socialization and identity development are conducted with undergraduate students $[44,45]$ or retrospective interviews of past physics students $[46,47]$. There is a dearth of research 
on physics graduate student identity development as it is developing and my dissertation fills the research gap.

\section{THEORETICAL FRAMEWORK}

\section{A. Apprenticeship theory of learning}

To study the development of physics expertise in physics graduate students from a social perspective, I assume an apprenticeship theory of learning where students are enculturated into authentic practices through participation in the community of practice $[22,24,48]$. Brown, Collins, and Duguid [48] summarize the apprenticeship theory to be learning that incorporates authentic activity, concept, and culture simultaneously. They claim that learning happens by doing, specifically through participation in the practices of the culture or community of which one is a part. Brown et al. [48] give the example that an authentic activity in a classroom context would be considered part of school culture. Enculturation into the physics community would then require the student to learn authentic practice beyond the classroom and into their research communities.

As the apprenticeship theory of learning has been practiced since the times of blacksmith masters passing their knowledge to new generations, apprenticeship is a natural way of perceiving expertise development. In the next section I review a modern theory of apprenticeship that explains how novice members of a group or community become expert participants.

\section{B. Legitimate Peripheral Participation}

Lave and Wenger's [22] Legitimate Peripheral Participation (LPP) theory describes the process of becoming an expert through transformation of participation in the community of practice. Legitimate Peripheral Participation is an apprenticeship theory of 
learning that proposes learning occurs as part of a social practice and learning is demonstrated by a newcomer's change in participation in the community of practice. A newcomer or novice in the community starts off as a legitimate peripheral participant, which is simply defined as a member participating in work that is not critical but valued by others in the group. Authors of the theory point out that LPP should be thought of as a whole and not in its separate parts. There is no "illegitimate" versus legitimate, or "central" versus peripheral or "nonparticipation" versus participation. Peripheral participation would indicate the multiple ways to be more or less engaged in the practices of the community and a way to grow in involvement. Lave and Wenger describe interpret peripheral participation in the case of tailors. Apprentice tailors of suits would begin to learn making clothing by first sewing on the buttons where indicated. The small yet valuable task allows the newcomer to participate in the practice and be accepted as a contributing member of the community. As the apprentice observes from master tailors and is acquainted with the entire process of making a suit, his or her participation evolves to more critical aspects of making a suit. Figure 1 gives a representation of the learning process and changes in participation within the community. 


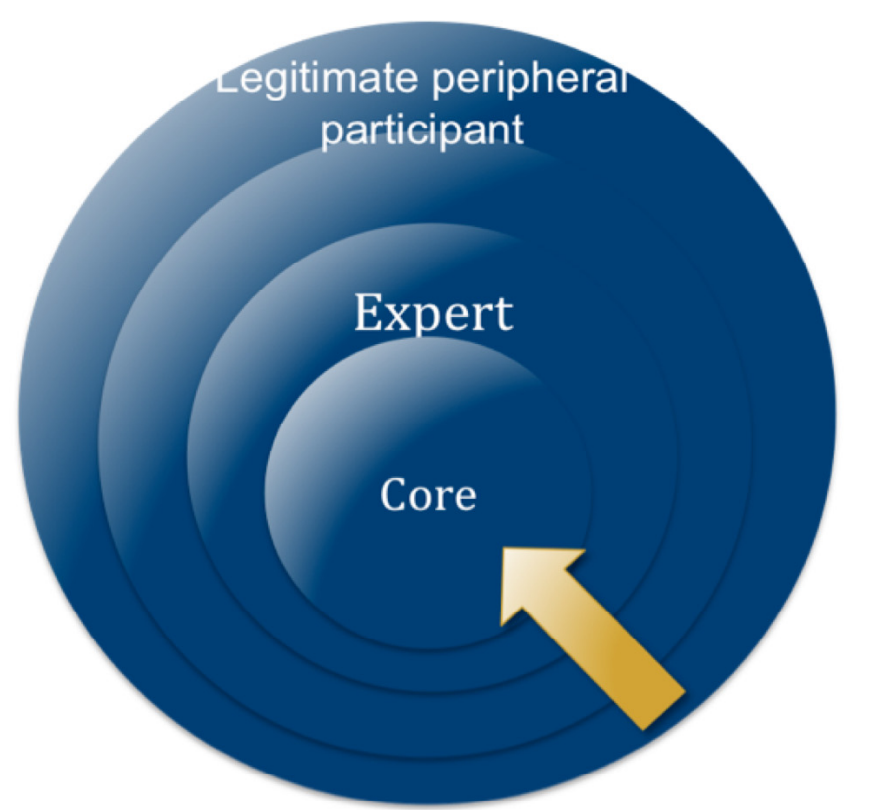

Figure 1. Representation of learning trajectory within a community of practice.

The learning trajectory depicted in Figure 1 serves as a representation of how a novice becomes an expert in the group or practice. The community is bounded by norm practices. A novice starts at the periphery of these practices and performs small tasks. As they acquire the skills and knowledge to perform more difficult tasks in the community, their participation changes and along the way they become more expert in the practice. This learning trajectory occurs in the context of the social world where the newcomer learns to be a member or the community. To understand how the individual becomes an expert is also a matter of understanding how they develop identities in the community of practice. To better understand the concept of identity development in a community of practice, I turn to the extension of the LPP theory to Wenger's theoretical framework of Communities of Practice [23]. 


\section{Communities of Practice}

A community of practice (COP) in simplest terms is a group of people that share a common practice. A person can belong to many communities of practice. A family that shares routines, artifacts, traditions, stories, and histories is a COP. A profession such as being a doctor or scientist is also a COP. The main purpose of a COP is to have its members learn and create knowledge about the common practice they share. Secondly, a COP must regenerate itself through the socialization process of novices becoming experts. To understand how the theory of $\mathrm{COP}$ explains learning and developing expertise I break down the theoretical concepts of COP that I use in this dissertation.

Figure 2 presents the flowchart of concepts that explains the relationships and interactions of these concepts with each other.

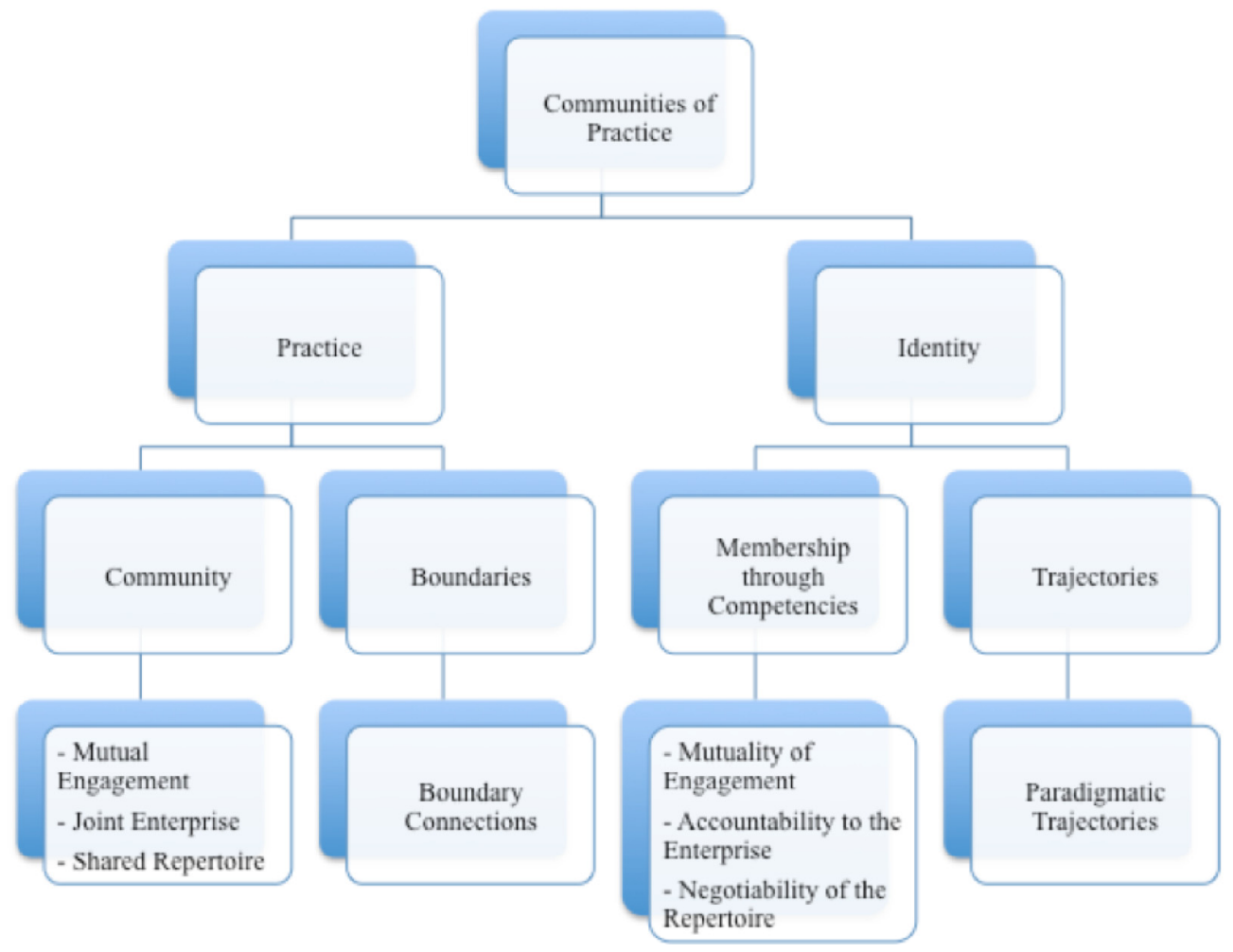

Figure 2. Flowchart of concepts in Communities of Practice 
Communities of Practice (COP) can be broken up into two main theoretical concepts; Practice and Identity. Practice encompasses the historical and social context of what the community does. The practice refers to the work people do but also holds the meanings and knowledge of the community. For example, a physics research group as a COP shares the practices of doing physics research. Practice depicts the larger group structures and activities while identity sets the frame for understanding individuals in the COP. The difference between practice and identity is best understood through the unit of analysis. Practice is the way to analyze the collective group as a whole and Identity is used to analyze the individuals that make up the group. Following along the left side of Figure 2 under Practice, I use the concepts of Community and Boundaries in the subsequent chapters of this dissertation to understand the group structures of a research group.

Community is defined by three components, mutual engagement, joint enterprise, and the shared repertoire. The first component, mutual engagement defines the patterns of interaction among the members of the group. Without the mutual engagement of members in the practice, there is no community coherence. Member's interactions with each other also shape the group's culture and norm practices. The second component of community is the joint enterprise. The enterprise explains the why in the practice, a unifying goal that binds the people in the practice to share a common purpose. The physics practice is driven by the search for the meaning of the universe, what it's made of, and how it was created. Scientist and physicists that practice physics negotiate the purpose of doing physics; conversely the physics enterprise holds its members accountable to the purpose of the practice. The third component of community is the shared repertoire. The repertoire includes "routine, words, tools, ways of doing things, 
stories, gestures, symbols, actions, or concepts that the community has produced or adopted in the course of its existence" (p.83) [23]. A community of physics researchers in the same research group will share a repertoire that has long been established in the group as communal resources. Learning to use the tools of the group is an important aspect of developing expertise in the COP.

Along the flowchart of Practice, the second theoretical concept explored in this dissertation is boundaries. Boundary as a collective structure of practice defines what belongs and does not belong within the COP. Boundaries are created by the norm practices in the community and outline how members behave and participate within the COP. For example, biophysics research group is bounded by the kinds of research questions they investigate, the tools and analysis techniques they perform, and how they organize their culture within the group. As general boundaries define what is in the group, it can also define what is not in the group. A biophysics group does not do the same kind of research as a nuclear physics group since they might not share the same tools, research interest, or research techniques. Yet, the concept of boundaries does lend itself to consider how COP such as a biophysics group can be related or connected to the practices of a nuclear physics research group. The concept of boundaries is then used as a way of looking at the COP as a whole in relation to other COPs and the entire discipline itself. Detailed explanations of connections between COPs are explored in chapter 5.

To the right side of the COP flowchart is the theoretical concept of identity. As previously mentioned, identity is the way to understand the individuals developing in the COP. The first component of identity is membership developed through competencies. In order to learn in a social practice of a COP one needs to become a member of that COP. 
Competencies learned through participation in the COP is what makes up the kind of person and member one becomes within the COP. A member of the COP learns to interact and work with other member of the group, they learn the reasons and purposes of the things they do, and they learn how to do what they do through the use of tools, artifacts and following routines in the group. Each of these membership competencies, being mutually engaged, being held accountable to enterprise, and negotiating the group's repertoire are developed through continuous participation in the COP. Notice that each of the membership competencies are directly parallel to the components of a community. In the same way that there is no community without the individuals that belong to it, individuals that are not competent members of the community do not belong in the community. Individuals that become members of a physics research group, for example, must learn to conduct themselves in the group. There are certain ways to work together with researchers and become a valuable contributor to the group. The purpose of performing certain tasks within the research group is learned with the guidance and interactions of more advanced research members. A competent member of the physics research practice is also able to negotiate the tools, norms, and standards of communication in the COP.

The second component of identity explored in this dissertation is one's trajectory. A person's identity is fundamentally changing as one interacts with social contexts. Identity in COP is not only internalized by the individual but also affected by interactions with the social world. Trajectories explain the temporal nature of identities and suggest a path towards the kind of person one wishes to be. For physics graduate students in a physics research group, a trajectory towards becoming an expert member of the group is not 
necessarily a set course. Experiences of past members, current engagement in legitimate participation, and aspirations of the future practice are what make up one's identity as a trajectory. Paradigmatic trajectories of more advance members of the group serve to give newcomers a reference of how to develop in the COP. Paradigmatic trajectories are further explored in chapter 4.

The exploration of how physics graduate students develop physics expertise in a research group is understood with the guidance of Legitimate Peripheral Participation within a Community of Practice theoretical framework. Section IV gives an overview of how I approach the overall question of becoming a physics expert and how I develop my specific research questions for this dissertation.

\section{DEVELOPING RESEARCH QUESTIONS}

In order to investigate how one becomes a physics expert within a community of practice, I first need to understand what a physics expert is and how they are perceived within their own physics community. Expertise developed in the social and cultural context of communities of practice needs to be understood within the common practice of physics research. In order to understand the social aspects, community expectations, and valued attributes of physics experts, I conducted a pilot study on the perspectives of three university physics professors on physics expertise. The pilot study is fully described in chapter 2 of this dissertation but I give a brief summary here of the findings for they guide the development of my research questions.

In an in depth interview study of three physics professors at a university, I analyze their perspectives on what makes up a physics expert. Their collective response is synthesized into three main aspects of a physics expert creating a model of physics 
expertise. First, a physics expert is a specific expert in a subfield or topic of physics research. There is no overall expertise in all of physics, as an expert needs to know their topic of expertise in depth. Secondly, a physics expert also develops general physics expert characteristics, these being characteristic shared by practicing physics experts regardless of their specific subfield. Lastly, once specific expertise is established, a physics expert can become a boundary crosser and apply what they have learned in one subfield or topic to another subfield or topic. When the expert crosses boundaries to a different topic or subfield, the process of becoming a specific expert begins all over again within the new field and the expert then evolves as the research community evolves. These findings compose a model of physics expertise as understood by the practicing experts in the field of physics; the university physics professors. From this physics expertise model I develop more focused research questions that I address in the case of physics graduate students developing expertise in a research group. My research questions are as follows:

Question 1: What makes a physics expert, from the perspective of university physics professors?

Question 2: How do graduate research students develop specific expert identities in a specific physics subfield, i.e., a specific expert trajectory?

Question 3: Within a specific physics research group, what are the general physics expert characteristics and how do they develop?

Question 4: How does the larger physics community interplay in the development of specific physics expertise? 


\section{METHODS}

\section{A. Data Collection and Validity}

To address questions of development and processes I use a qualitative research design. The present study is an ethnographic case study [49] of a biophysics research group. An ethnography is the study of a group's culture [49,50]. Traweek [50] explains ethnographies as a written account of a community's way of life. Ethnographies include information about a group's means of existence and shared environment. Ethnographies also give accounts of the social organization of the community and its developmental cycle. How the group teaches novices skills, values, and norms of the community. Lastly, ethnographies include information about the groups system of knowledge and beliefs. My dissertation study is also a case study [49] because it focuses on the culture of a biophysics research group as a specific case for understanding similar research groups.

To explore the culture of the specific biophysics research group I collect data from multiple sources. For the pilot study in Chapter 2 data were collected through in depth hour-long interviews [51] with each of the participant physics professors. Data collection methods for the rest of the chapters 3-5 are from ethnographic case study of the biophysics research group. I observed the biophysics research group's weekly research meetings for a period of six months from January 2011 through June 2011 and again for two months in January and February 2012. I participated in participant observations [49] where I am accepted to participate in the research meetings as I develop a rapport with the participants. Throughout the observations of their weekly research meetings I take extensive fieldnotes of their interactions, what is being talked about, and any interesting comments I believe are relevant to my research. As another source of data, each research 
meeting is also video-recorded with two cameras at different angles in the room. The third source of data is two video-recorded in depth interviews with each participant in the research group performed throughout the data collection period.

\section{B. Participants}

Participants in the present study are part of a computational biophysics research group. The research group is composed of two lead university physics professors, Matthew and Prakul (all names are pseudonyms), three graduate students, Udit, Hal, and Ike, and an undergraduate student, Louis. I assume that development from novice to expert is a developmental process that happens in stages; therefore students in the biophysics research group were at different stages of their development. There are also transitional stages of development depending on institutionally given title, i.e., first year or second year graduate student, etc. Collectively the group researches theoretical and computational models of protein structural fluctuations. Detailed descriptions of individual research projects and personal characteristics are included within the relevant chapters 3-5.

\section{Analyses and Validity}

Analyses for an ethnographic case study requires three aspects; description of the group and the setting they work in, analyses of patterns of interaction and meaning in video and interview data through triangulation, and interpretation of the culture through a theoretical frame [49]. As a participant observer in this study, I keep fieldnotes during my observations of the research meetings. These fieldnotes are time stamped notes and comments on the interactions I observe and therefore become a first order analysis of information I find to be relevant to the research topic. As the primary researcher I keep a 
researchers' reflective journal to practice reflexivity [52] and record any biased feelings or judgments I may experience throughout my observations. These reflections are acknowledged and bracketed [52] as an internal validity measure. To maintain validity through analyses of video data or interview data, I practice peer debriefing [49] where peer physics education researchers review my claims on the data and asks specific questions of meaning, methods, and interpretations to make sure the interpretation is supported by the evidence in the data. Peer debriefing also keeps the researcher honest and objective. Specific analyses through interpretations of the theoretical framework are also thoroughly reviewed in each chapter when relevant.

\section{STRUCTURE OF DISSERTATION}

The organization of this dissertation is written in a format where chapters $2-5$ are either accepted, submitted, or in preparation manuscripts to submit to journals. In this section I give an overview of how each chapter is written on the basis of the formatting requirements for the journals that each chapter is published in or submitted to.

Chapter 2 is the initial pilot study of three physics professors' perception of physics expertise. This chapter creates a model of physics expertise based on these professors' perceptions and guides the direction of research in the subsequent chapters. Chapter 2 is published in the Physics Education Research Conference proceedings of 2010. These proceedings follow a peer review process and follow the American Institute of Physics (AIP) publication guidelines.

Chapter 3 is an analysis of the physics expertise perspectives shared by the participant biophysics research group. The study explores how the group views experts to have certain attributes, the most important attribute of physics experts being able to 
communicate research through publications. Chapter 3 explores how this biophysics research group prepares their graduate students to develop expert attributes and learn to contribute research through publications. Chapter 3 is published in the Physics Education Research Conference of 2011 [53] and like chapter 2 follows AIP publication guidelines.

Chapter 4 takes a more in depth look at the development of individual graduate students in this research group using identity in a community of practice as the guiding theoretical perspective. Learning to become a specific physics expert by contributing research in the field allows for the development of an expert identity. The mechanisms by which this biophysics research group enculturates their graduate students to develop expert identities is explored in this chapter. Chapter 4 is currently under peer review and waiting acceptance to be published in AIP's Physical Review Special Topics - Physics Education Research journal publication.

Chapter 5 takes the entire biophysics research group as a unit of analysis and investigates how trends in the larger biophysics research community influences the research culture of the entire group and individual members. The analysis focuses on specific encounters the biophysics research had with a neighboring chemistry research group that shares similar computation techniques in research. Through an analysis of the theoretical concept of boundaries and boundary connections between communities of practice, I evaluate how the biophysics group research culture and individuals' research interests shifts after the encounters with the chemistry group. Chapter 5 is in preparation to be submitted to the Journal of Science Education and follows the American Psychological Association reference format for publications. 
Chapter 6 is the conclusion chapter where I summarize finding of each study and relate them to each other to answer the overarching questions of how one becomes a physics expert. The summary also addresses how each of my research questions are answered. Chapter 6 also reviews the implications of findings for research, instructors, and graduate students. Lastly, chapter 6 identifies some of the directions of future research in physics expertise and graduate student education. 


\section{REFERENCES}

[1] F. Reif and J. I. Heller, Educational psychologist 17, 102 (1982).

[2] J. Larkin, J. McDermott, D. P. Simon, and H. A. Simon, Science 208, 1335 (1980).

[3] J. D. Bransford, A. L. Brown, and R. R. Cocking, How people learn: Brain, mind, experience, and school (National Academies Press, Washington, D.C., 2000).

[4] M. T. H. Chi, P. J. Feltovich, and R. Glaser, Cognitive Science 5, 121 (1981).

[5] A. Mason and C. Singh, Phys Rev. STPER 7 (2011).

[6] Y. Anzai, Learning and use of representations for physics expertise, New York, NY, 1991), p. 64.

[7] J. H. Larkin, The role of problem representations in physics (Lawrence Erlbaum Associates, Inc., Hillsdale, NJ, 1983).

[8] G. Taasoobshirazi and M. Carr, Educational Psychology Review 20, 149 (2008).

[9] G. Taasoobshirazi and M. Carr, J. Educ. Psychol. 101, 630 (2009).

[10] T. Farrington-Darby and J. R. Wilson, Appl. Ergon. 37, 17 (2006).

[11] W. G. Chase and H. A. Simon, Cognit. Psychol. 4, 55 (1973).

[12] Ericsson, K. Anders, Jacqui Smith, Prospects and limits of the empirical study of expertise: an introduction (Cambridge University Press, Cambridge, 1991), p. 1.

[13] AIP Statistical Research Center, (Graduate Student Statistics 2013), 2013.

[14] G. Potvin, Thinking Seriously about Doctoral Education in Physics, 2012), 21, p. Back Page.

[15] G. Potvin and R. H. Tai, Journal of Chemical Education 89, 21 (2012).

[16] C. M. Golde and T. M. Dore, At Cross Purposes: What the Experiences $f$ Today's Doctoral Students Reveal about Doctoral Education (A report prepared for the Pew Charitable Trust, Philadelphia, PA, 2001).

[17] C. M. Golde, Beginning graduate school: Explaining first-year doctoral attrition (Wiley Online Library, San Francisco, 1998), 1998, p. 55. 
[18] B. E. Lovitts, Leaving the Ivory Tower: The causes and consequences of departure from doctoral study (Rowman \& Littlefield Publishers, Inc, Lanham, MD, 2001).

[19] R. Diehl, T. Hodapp, C. Singh, M. Thoennessen, S. Turley, and L. Wolf, Graduate Education Conference 2013 (APS, College Park, MD, 2013).

[20] J. Tate, T. Hodapp, M. Thoennessen, and C. Singh, Gradaute Education if Physics: Which Way Forward. A Conference to Discuss the Status and Future of Gradaute Education in Physics (APS, College Park, MD, 2008).

[21] J. Lave, Situating learning in communities of practice (American Psychological Association, 1991), 2, p. 63.

[22] J. Lave and E. Wenger, Situated Learning; Legitimate Peripheral Participation (Cambridge University Press, 1991).

[23] E. Wenger, Communities of practice: Learning, meaning, and identity (Cambridge University Press, New York, 1998).

[24] B. Rogoff, E. Matusov, and C. White, Models of Teaching and Learning: Participation in a Community of Learners (Blackwell, Oxford, UK, 1996).

[25] A. Sfard, Educational Researcher 22, 4 (1998).

[26] E. Brewe, V. Sawtelle, L. H. Kramer, G. O'Brien, I. Rodriguez, and P. Pamela, Phys Rev. STPER 6 (2010).

[27] A. D. De Groot, Thought and choice in chess (Mouton De Gruyter, 1978), 4.

[28] K. A. Ericsson, The road to excellence: The acquisition of expert performance in the arts and sciences, sports, and games. (Lawrence Erlbaum Associates, Inc, Mahwah, NJ, 1996).

[29] J. Shanteau, The Psychology of Experts An Alternative View (Springer, New York, 1992), p. 11.

[30] C. Singh, Am. J. Phys. 77 (2009).

[31] B. Latour and S. Woolgar, Laboratory Life: The Social Construction of Scientific Facts (Sage Publications, Inc., Beverly Hills, California, 1979), 80, p. 271.

[32] K. Knorr-Cetina, The ethnographic study of scientific work: Towards a constructivist interpretation of science (Sage, Beverly Hills, CA, 1983). 
[33] A. Pickering, Science as practice and culture (University of Chicago Press, Chicago, 1992).

[34] K. Knorr-Cetina, Epistemic Cultures: How the Sceincs Make Knowledge (Harvard University Press, Cambridge, MA, 1999).

[35] K. Dunbar, How scientists really reason: Scientific reasoning in real-world laboratories. (MIT Press, Cambridge, MA, 1995), p. 365.

[36] N. J. Nersessian, Interpreting scientific and engineering practices: Integrating the cognitive, social, and cultural dimensions. (New York, Erlbaum Press, 2005), p. 17.

[37] N. J. Nersessian, Organization Studies 27, 125 (2006).

[38] D. Gooding, Putting agency back into experiment (The University of Chicago Press, 1991), p. 65.

[39] K. Knorr-Cetina, The couch, the cathedralm and the laboratory: on the relationship between experiment and laboratory in science (The University of Chicago Press, 1991), p. 113.

[40] J. C. Weidman, D. J. Twale, and E. L. Stein, Socialization of Graduate and Professional Students in Higher Education: A Perilous Passage? (Jossey-Bass, Publishers, Inc., 350 Sansome Street, San Francisco, CA 2001)

[41] S. K. Gardner, High Educ. 54, 723 (2007).

[42] A. E. Austin, JHE 73, 94 (2001).

[43] A. P. Stucky, Empiral grounding of the nature of scientific inquiry: A study of developing researchers (University of Kansas, Lawrence KS, 2005).

[44] Z. Hazari, G. Sonnert, P. M. Sadler, and M. Shanahan, Journal of Research in Science Teaching 47, 978 (2010).

[45] J. Nespor, Knowledge in Motion: Space, Time and Curriculum in Undergraduate Physics and Management (Falmer Press, Taylor \& Francis, Inc., Bristol, PA, 1994), p. 176.

[46] H. B. Carlone, Journal of Research in Science Teaching 41, 392 (2004).

[47] H. B. Carlone and A. Johnson, JRST 44, 1187 (2007).

[48] J. S. Brown, A. Collins, and P. Duguid, ER 18, 32-41 (1989). 
[49] J. W. Creswell, Qualitative inquiry \& research design: Choosing among five approaches (Sage Publications, Inc, Thousand Oaks, CA, 2007).

[50] S. Traweek, Beamtimes and Lifetimes: The World of High Energy Physicists (Harvard University Press, Cambridge, MA, 1988).

[51] R. C. Bogdan and S. K. Biklen, Qualitative Research for Education: An introduction to theory and methods (Pearson Education, Inc, Boston, MA, 2007).

[52] S. B. Merriam, Qualitative Reserach in Practice; Examples for discussion and analysis (Jossey-Bass, San Francisco, CA, 2002).

[53] I. Rodriguez, R. M. Goertzen, E. Brewe, and L. H. Kramer, in Physics Education Research Conference 2011, Omaha, NE, 2011), p. 319. 


\title{
CHAPTER II
}

\section{CONSTRUCTING A MODEL OF PHYSICS EXPERTISE}

\begin{abstract}
Research on physics expertise has predominantly focused on cognitive differences between physics experts and novices where the novices are high school or introductory college students and the experts are university physics professors or graduate doctoral students. Most physics expertise studies declare the experts to be physics faculty without justifying this decision. To establish more clearly the characteristics of physics experts, I conducted a qualitative interview pilot study of three university physics professors. The professors each had an hour-long interview where they describe their experiences of becoming a physics expert. This chapter presents the analysis of the specific interview question, 'What makes a physics expert?' Analysis of the data resulted in the construction of a model of physics expertise, which indicates that one is a specific physics expert first, acquires general physics expert characteristics and then becomes an expert in physics or a boundary crosser.
\end{abstract}

\section{INTRODUCTION}

Expertise research has provided insights about characteristics of experts in many domains and has projected these findings to speculate about how people learn and what educators could do to move students toward greater expertise [1]. Research on physics expertise, particularly, has shown how physics experts differ from novices in their problem solving skills, pictorial representation, problem categorization, and metacognitive skills [2-5]. However, physics expertise research thus far has focused on cognitive differences between novices and physics experts where the experts are typically 
university physics professors, or graduate doctoral students and the novices are typically high school students or introductory physics students in college [5-7]. It is common in these studies to declare physics faculty to be the experts without justifying the rationale for considering them experts. While the literature is very descriptive of expert-novice cognitive aspects, it is not sufficient to describe the nature of physics experts.

To understand more about the nature of physics experts we will build upon cognitivist and individual learning perspectives by integrating more participationist views on learning [8-9]. I propose using situated cognition as portrayed by Lave and Wenger's [1011] model of communities of practice to frame our understanding of the nature of physics experts. A community of practice in its simplest definition is a group of people engaged in a shared practice that 'binds' the community together. Physics as a community of practice is a very complex community consisting of many interrelated communities [9]. For example, the nuclear physics community exists within the larger physics community and shares features with the elementary particle physics community.

In conjunction with the model of communities of practice, Lave and Wenger [10] introduce the idea of legitimate peripheral participation, which describes how a newcomer develops his or her expertise through transformation of participation in the community of practice. I argue that university physics professors have transformed their participation in the physics community from students to teachers, mentors and researchers. This trajectory is one of developing expertise and thus, these professors have much to offer about their interpretation of the nature of physics expertise. The purpose is to describe university physics professors' perceptions of what makes a physics expert. To 
investigate, I conducted a qualitative in-depth interview pilot study of three university physics professors.

\section{METHOD AND PARTICIPANTS}

Participants for this study were White males, full physics professors that received their Ph.D. in physics from research universities across the United States. The three participants have gone through the customary undergraduate, graduate, and post-doctoral sequence in physics before assuming a faculty position at a research university. Leebob and Albert are experimental physicists, and Matthew is a theorist. Each professor chose his pseudonym. These three professors were purposely chosen for the researcher's established rapport with them and for their perspective on developing physics expertise $[12]$.

TABLE 1. Main questions used as an interview guide for all three physics professors.

\section{Main Questions}

1. Since I am now in the process of becoming a physicist, I can tell it takes a lot of work. Can you tell me about how you came to be a physicist?

2. What makes an expert physicist?

3. Considering the journey that got you to this point, what does a typical day look like for you?

4. Can you describe any defining moments in your physics career?

Data were gathered through one-hour individual qualitative in-depth interviews. All participants gave informed consent and agreed to be videotaped. The participants were interviewed not only about their perceptions of physics experts but also about the process of becoming a physics expert. The interview guide had four main questions (see Table 1) 
followed by subsidiary questions. The three interviews were transcribed and proofread prior to an in-depth analysis. The analysis and results to follow are focused on data gathered from the second main question of the interview guide.

As a current physics graduate student, the first author's own attitudes and beliefs about being and becoming an expert certainly influenced the interpretation of the data. The first author practiced "reflexivity, the process of critically reflecting on the self as a researcher" [13] as an internal validity measure. A reflective research journal was kept throughout the research process to keep track of any biases toward the data and any choices and experiences that could influence the study.

\section{ANALYSIS AND RESULTS}

The answers to the main question of what makes a physics expert were analyzed for emergent themes. The analysis resulted in the construction of a model of physics expertise. The model of physics expertise consists of being a specific physics expert that helps achieve general physics expert characteristics to finally being an expert in physics.

The model of physics expertise starts with becoming a specific physics expert. This specificity can be seen in Albert's description of physics experts: "When we think of experts, we think of people who have taken a narrow specialty and learned all there is to learn about that narrow specialty." The narrow specialty refers to specific subfields in physics like nuclear or particle physics and within the specific subfields there are particular expertise. Leebob explains, "Well at one time, so I was a hardware guru. I was an expert. Alright? In what? In building wire chambers. Okay? That's really-a wire chamber expert." Leebob's particular expertise lies within the specific subfield of nuclear physics but specializes in wire chambers. 
Expertise specificity can also been seen from particular physics projects. For example, when Albert was asked if he considered himself an expert he answered, "Yes I do. In nuclear and particle physics. But more specifically I would say particularly electroproduction of strange quarks." Knowing all there is to know about the narrow specialty is foremost to being a physics expert because according to Matthew, "Being an expert physicist means by definition that you're an expert in one [sub]field of physics."

Though the participants consider themselves specific physics experts they also acknowledge that there are still a few generalized characteristics that apply across disciplines. As Albert explains,

First of all, they do know pretty much what's happening in their discipline... they know this by knowing what's happening with the theory of what's going on then and the experiment. [Also] what research is happening and especially what funded research is happening... So I'd say that the people who are experts they're experts because they can apply this type of thing to their specialty. --Albert

These general characteristics presented by Albert refer to what a physicist does in general. If you are an experimentalist, you must understand the theory that can fit the experimental data and if you are a theorist, you must understand the experiments to create theories for them. Knowing the relationship between theories and experiments is a characteristic of general physics experts because only then will one be able to be funded to do research.

Another general physics expert characteristics, Matthew points out, is the ability to ask the right question,

You've got to put in the effort to learn the basic physics first in the coursework. You should enjoy the process of doing the physics, not forgetting that you're aiming to answer a question... You also need to learn how to pick a good question to focus on. Find something you're 
interested in and then learn everything you can about it that other people have discovered, and that'll allow you to pick a good question.-- Matthew

Normally we think of experts as people that can answer questions and solve problems, but the participants of this study are not only claiming that experts answer questions, but also that they need to able to pose a good question.

Beyond acquiring the characteristics of a general physics expert, an established expert can institute expertise in other fields of physics. All of the participants in the study asserted physics expertise to be very specific at first, but most of them also asserted that one could carry their expertise into other areas in the field and become experts in that specific area. The ability to cross over into other specialized areas distinguished specific physics expert within a general physics expert community from expert in physics.

Recall that Leebob was a hardware guru in building wire chambers but when I asked if he considered himself an expert he said he had not built wire chambers in fourteen years. I asked him what he was an expert at now and he replied, "I am one of the few people doing kaon electroproduction," which he claims is his current area of expertise.

As an expert in physics one can transition from a very specific physics expertise to another expertise within the same physics subfield like Leebob who went from building wire chambers to kaon electroproduction, both areas within the subfield of nuclear physics. On the other hand, Matthew points out that an expert in physics can transition into completely different fields also. When the space shuttle Challenger exploded, Matthew explains the government created a panel of experts to investigate the situation.

They wanted a panel of experts including some people who had direct expertise in this kind of rocketry-type equipment. But they also brought in an expert in physics, knowing that they needed somebody with the type of expertise that a physicist could have, who knows all the things that a 
physicist knows, and though they may not have expertise in rockets, they'll learn it. --Matthew

In this situation the expert in physics transferred his physics expertise into a field of rocketry, which is a field of applied physics. Matthew adds that a physicist was very beneficial to such a panel of experts because "they could learn what the engineer already knows, but the physicist could learn it quite quickly and then take the basic knowledge that the field of physics gives you, which can be applied to anything."

The model of a physics expert drawn from these three qualitative interviews starts with acquiring expertise in a very specific area of physics to become a specific physics expert and as one is developing that specific expertise, they attain certain general characteristics that apply across disciplines. As the general physics expert characteristics are developed, one can transition to be an expert in physics.

\section{DISCUSSION}

The model constructed of a physics expert has transitory stages. The first stage of physics expertise is to be a specific physics expert where your research projects or the subfield within physics at large define the specificity. Taking the perspective of physics as a community of practice, it is understandable that specific subfields like nuclear or high energy physics are individual communities of practice that are interrelated within the encompassing physics community of practice. Even within the smaller subfield communities, smaller groups of people create their own communities of practice defined by the projects they are working on. For example, Leebob was not only part of a nuclear group but also the group of researchers studying electroproduction of kaons. 
Since the subfields of physics are nested within the larger physics community, it is through the development of specific physics expertise that one attains general physics expert characteristics. Wenger's [11] framework defines practice to have five main components, one of them being community. Community has three dimensions: mutual engagement, joint enterprise, and shared repertoire. Mutual engagement is the action of people working together; joint enterprise in this case is the physics that pulls them to work together; and the shared repertoire is the source of community coherence. The shared repertoire is the development of resources and norms that reflect the community's character and further engagement. The general physics community interconnects all the specific subfields of physics through their shared repertoire or the general physics expert characteristics. Characteristics that are common to all physicists like asking good research questions and understanding the connections between theories and experiments are elements of the shared repertoire of the larger physics community.

Attaining general physics expert characteristics through the development of specific physics expertise is then necessary to being an expert in physics. Within the communities of practice framework [11], another component of practice is boundaries. Boundaries can define what belongs to the community but also what does not belong and particularly how communities are related to one another [9]. A boundary crosser is one that one that can take elements and concepts from one community of practice into another; an expert in physics is a boundary crosser.

As mentioned earlier, a community of practice can be defined by the specificity of the project, subfield, or physics community at large. Leebob, for example, crossed the boundaries of the subfield of nuclear physics in working with wire chambers to working 
with electroproduction of kaons. Boundary crossing also extrapolates to crossings between subfields of physics because one attains general physics expert characteristics that are common within the general physics community. However, boundary crossing does not only occur within the general physics community but also outside the physics community to other general communities of practice such as engineering. Having an expert in physics on a panel to investigate why the space shuttle Challenger exploded demonstrates the applicability of general physics characteristics to another community of practice. An expert in physics can take what they know and span across boundaries.

\section{CONCLUSION}

Physics expertise models have thus far been developed from experimental cognitive studies of the difference between experts and novices. The model of physics expertise presented here builds upon the cognitive models and depicts a more authentic story. In contrast to cognitive models of physics expertise, which rely on controlled and limited laboratory experiments, the model of physics expertise constructed from interviews with three university physics professors is developed from within the community of physics experts.

As seen from the perspective of the physics experts themselves, physics expertise is much more than one's ability to solve physics problems. Within the communities of practice framework, physics expertise is developed through transforming participation within a community of practice and expanding to other communities. It is through this theoretical lens that we will also view novices developing physics expertise within a community of practice. 


\section{REFERENCES}

[1] National Research Council Brown, How people learn: Brain, mind, experience and school., Washington DC: National Academy Press., 2000.

[2] Reif, F., and Heller, J. I. Educ. Psychol. 17, 102-127 (1982).

[3] Anzai, Y., "Learning and use of representations for physics expertise," In Toward a general theory of expertise, edited by K. A. Anders, \& J. Smith, New York: Cambridge University Press, 1991, pp. 64-92.

[4] Larkin, J. H., Heller, J., and Greeno, G. New Directions for Teaching and Learning 2, 51-65 (1980).

[5] Chi, M. T. H., Feltovich, P. J., and Glaser, R., Cognitive Sci. 5, 121-152 (1981).

[6] Larkin, J. H., "The role of problem representations in physics," in Mental Models edited by D. Gentner, and A.L. Stevens, Hillsdale, NJ: Lawrence Erlbaum Associates, Inc. 1983, pp. 75-98.

[7] Taasoobshirazi, G. and Carr, M., Educ. Psychol Rev. 20, 149-169 (2008).

[8] Brewe, E., Sawtelle, V., Kramer, L.H., O’Brien, G., Rodriguez, I., and Pamela, P., Phy. Rev. ST Physics Ed. Research 6, 010106 (2010).

[9] Danielsson, A.T., and Linder C., Gender Educ. 21, 129-144 (2009).

[10] Lave, J., and Wenger, E., Situated learning. Legitimate peripheral participation, Cambridge: Cambridge University Press, 1991.

[11] Wenger, E., Communities of practice. Learning, meaning, and identity, New York: Cambridge University Press, 1998.

[12] Patton, M. Q., Qualitative research and evaluation methods, 3rd ed., California: Sage, 2002.

[13] Merriam, S. B., "Assessing and evaluating qualitative research," in Qualitative research in practice: Examples for discussion and analysis edited by S. B. Merriam, New York: John Wiley \& Sons, 2002, pp. 18-33. 


\title{
CHAPTER III
}

\section{COMMUNICATING SCIENTIFIC IDEAS: ONE ELEMENT OF PHYSICS EXPERTISE}

\begin{abstract}
In this chapter I present an alternative perspective to physics expertise research. Using Lave and Wenger's theoretical perspective of Legitimate Peripheral Participation [4] as a guide to understanding expertise development, I redefine expertise from the perspective of physicists. I analyze data from an ethnographic, qualitative study of a physics research group and draw data from multiple sources to triangulate a definition of expert. Results show that a very critical part of becoming a physics expert in this physics research group is communicating one's scientific ideas through writing. Students perceive scientific writing as an important aspect of participating in the research group and it is a significant discussion point in the research meetings. Thus, it appears that learning to write a scientific paper is a process congruent to developing physics expertise.
\end{abstract}

\section{INTRODUCTION}

Literature on experts in physics has been situated in the cognitive literature to distinguish experts from novice physics problem solvers [1-3]. In this paper, I take a different approach to physics expertise, and examine how one becomes a physics expert. To answer this question, I take the socialization model described by Lave and Wenger [4], legitimate peripheral participation, which is a framework to interpret the process of becoming an expert within a group. Legitimate peripheral participation within a community of practice describes how a newcomer will change their participation in a community to learn to do what experts do in that community. 
Previous studies that have researched the socialization process of graduate students into a science discipline have found that contributing to the scientific field formally through writing scientific papers and publishing in scientific journals is a large component of becoming a member of the community and establishing oneself within the community [5-6]. It is understood that publishing scientific journal articles in academia is an important part of one's career and has been used in factor analysis of career productivity and success in the discipline [6-7]. While publishing has been explicitly used as an indicator of expertise, this paper describes both the process of writing a scientific paper in a physics research group and how this process is associated with becoming a physics expert.

\section{THEORETICAL FRAME}

In describing the process of developing physics expertise, I take the perspective of the apprenticeship model of learning to explain the process of becoming a member of a community. Becoming a member of a community is a socialization process that involves learning about a group's culture, norms, expectations, and skills along with the values necessary to succeed in the community [8-10]. Lave and Wenger outline this process in their learning theory of legitimate peripheral participation within a community of practice, in which learners or novices increasingly participate in legitimate social practices.

In a community of physicists, those who aspire to become experts in this community find that language, and more specifically written language, is necessary to communicate with and inform other physicists of the physics knowledge constructed [2-3]. To learn a language (including written language) is also to learn a culture, because culture and social 
interaction are the only contexts in which a language has meaning [5]. Therefore, learning to write within the physics community becomes a crucial part of the socialization process from novice to expert. In this chapter I address how physicists socialize novices to contribute and communicate with the field by learning or participating in the process of writing scientific papers.

\section{DATA AND PARTICIPANTS}

This paper analyzes data as part of an ongoing ethnographic, qualitative study of a physics research group. The study involves six months of participant field observation and video recordings of the physics group weekly research meetings. I also collected video and audio recorded interviews with each regular member of the research group concurrently and subsequently to the six-month data collection period.

Participants in this ethnographic case study [11] are located within the physics department of an R1 American university with a student enrollment of about 44,000. The participant group carries out research in theoretical and computational biophysics. Two university physics professors, Matthew and Prakul (all names are pseudonyms), lead the research team. Omar is an adjunct professor with the university who spends time doing research with the group. There are three graduate students, Udit, Hal, and Ike, and an undergraduate physics student, Louis.

The group meets once a week in meetings that last on average about five hours to present the theoretical and computation findings to the research supervisors, Matthew and Prakul. During the presentations, the group discusses and evaluates the progress of the project's findings and plans the next steps of that particular project. It is an assumption that a project and its results will be written up into a scientific paper. This is the 
evidenced by the fact that the words "project" and "paper" are used interchangeably through the research meeting conversations on each project. Most notably, what are presented at these meetings are often graphical and pictorial representations of the physical phenomena the group members are researching.

\section{RESULTS AND DISCUSSION}

A triangulation analysis [11] of the data sources reveal that this physics research group shares the perception that experts contribute new knowledge to the field and communicate by writing and publishing in scientific journals. The study also shows how this particular research group explicitly socializes its members to write scientific papers. Specifically, the analysis shows how the lead professor divides the process into three stages or levels of participation that are congruent with the progress of the graduate students becoming experts.

\section{A. Contributing as a marker of expertise}

This physics research group was very much consistent in their perception of what an expert physicist is. Professor and student interview responses to the questions about what makes a physics expert and what they hope to learn and achieve in their career were consistently related to contributing to the field and publishing research. The interview segment below shows what Matthew perceives as the attributes of expertise: knowing what questions to ask, knowing how to approach the questions, and contributing to the field.

Matthew: What makes somebody an expert is knowing what the important question is, and knowing how to approach those important questions. The other aspect is having contributed new knowledge to the field... Interviewer: Out of your group members, who would you consider an expert? 
Matthew: The ones you might expect. Besides myself, Professor Prakul.

Dr. Omar has expertise in specific areas. Cause he has done all three of those things, his name is on a couple of papers.

Interviewer: So would you consider being published a very important aspect of that?

Matthew: That's the third part of it that you've contributed to the field...

Matthew later went on to describe some of his graduate students as experts and defined them as such if they had these attributes but most importantly, the third attribute of contributing to published research.

Other members of the group share the perception that experts in physics are people who publish their work. Graduate student Ike solely defined physics experts as people who have published quality research in physics journals. Before he graduates, Udit hopes to make this time the most "prolific" of his graduate career. He claims that "at the end what counts is your publication, how many publications you have and how good the paper is." Therefore, graduate students in this group view publications as signs that their contributed research is accepted in the field.

Since communicating one's research through publishing and writing papers is a critical part of achieving expertise, the question remains of how one learns to write and publish in scientific journals. Other research groups have students research and write the papers with the guidance of their mentor [5]. This biophysics research groups takes a scaffold approach to the writing process.

\section{B. Apprenticed to communicate in the field}

In this research group, the mentors have adopted a specific process of socializing students to contribute to physics research papers. Interestingly, this process of writing 
scientific papers is interdependent on developing expertise. Following is an outline of the process of contributing to scientific publications from Matthew's interview responses.

Matthew outlined how contributing to scientific papers in his group depended on the graduate students' progress. First, a beginning graduate student is not expected to write the paper but to contribute by doing the research. "They may just be doing a lot of the computer simulations and we will be saying 'we need the data point at $320^{\circ}$ because that looks like where the peak of the heat capacity curve might be."'

Later, as the students gets a feel for the topic, they may be instructed to write an outline for the paper where they should be deciding on what graphs and figures to include in the paper.

Matthew: A paper has to have a point, now how do you convey the point based upon your research? In other words, other physicists are going to be reading this paper, are they going to believe that you've proven your point... A good way to get them thinking about how to convey the logical argument that leads to the results, the point, is 'which graphs do you think that would be important?'

The final step in the process is when the students are actually ready to be "thinking about the discussion and the conclusion section and where else it might lead to." Matthew points out that none of his current students are at this last point; instead they are all where they can make good suggestions about graphs and figures that should be in the paper.

\section{Members assimilate the socialization process}

Members of the research group have assimilated the three levels of participation in scientific papers. Many of the weekly meetings revolve around changes and edits that need to be made to each of the ongoing projects or papers. In the setting created in the meetings, any student can learn from another student's progress or questions. Students 
give suggestions about the kind of language to use when describing the graphical representation of the protein folding time, for example. More specifically, at one meeting, the mentor, Matthew, requested that Hal review the manuscript on florescent proteins and focus on the methods and results section to check if what is written was a good representation of what was done. Matthew's request for Hal's input on the manuscript is evidence that Matthew accepts and values Hal as a participant in the writing of the paper.

The process of contributing to a paper has also been established as a group norm that the students learn to adopt. In the interview with Louis, the undergraduate, he delineated where he saw himself in the process. The interviewer asked him about what he learned in the group and he said "research papers." The interviewer understood that Louis learned to write research papers but he rectified this and said:

Louis: I am not going to write the paper. I don't think- I think Professor Matthew has an idea to include my work in the paper but I don't think I would be writing word by word. My English sucks. He would ask me to write like an outline with the important things, but I wouldn't be writing out the whole thing.

Louis identified his role in the writing process to be in the beginning stages. He was consistent with Matthew's expectations of a student just starting to do research.

\section{Communicating with graphical representations}

Matthew emphasized the second level of participation for students in the process of contributing to a paper. He gave specific examples of "outline the results section" by using graphs and figures to tell the story. Previous research [12] argues that figures and graphs are the language of physicists. This is consistent with the practices of this group, which spends significant amounts of time discussing graphical representations. 
Learning to interpret figures and graphs and to use them to build a scientific argument becomes an important socialization task as the students evolve as physics experts. In one research meeting, Matthew and Prakul purposefully spent the entire meeting going over editor comments on Udit's manuscript. They discussed changes that needed to be made to the figures and if they needed specific graphs to convince the reader of the point they were trying to make. Activities such as addressing reviewer comments, which are often dealt with privately between authors and coauthors, now became a social activity for the entire group to learn from. The showcase of editor comments to a manuscript in the meetings not only helps the student on the project receive feedback from all members of the group, it exemplifies the expectations of a student at the second level of participation in the writing process, and the activity becomes a learning opportunity of the norm practice in the biophysics research field.

\section{Apparent contradiction}

I wish to direct the reader back to Matthew's interview comments on what defines an expert. He listed three attributes that make an expert: asking the important questions, knowing how to approach the important questions and contributing to the field in the form of publishing the work he has done. Following his definition of an expert, the interviewer asked him whom in his group he considered an expert. He started to list the expected professors, but he continued to label some of his students as experts.

Matthew: Udit has expertise in a very narrow aspect of the computational molecular biophysics. I say that because his name is on a published paper. Hal is getting awfully close to having expertise in molecular dynamics calculations... Ike is like Hal, he's getting very close to having expertise in a specific area. 
In the previous excerpt, Matthew characterized his graduate student Udit as an expert, because he has all three attributes and has coauthored a paper.

However, this contradicts Matthew's statement that none of his students are at the last level of participation: "thinking about the discussion and conclusion section and where else it might lead to." There seems to be an apparent contradiction between what makes an expert and consequently whom he considers an expert, and where in the writing process his students are.

We can make sense of this apparent contradiction by interpreting Matthew as discussing different levels of expertise dependent on specificity. In a previous study [13], I introduced a model of physics expertise, which depends on specificity. The model describes how one becomes a specific physics expert in a very narrow field of physics or even a specific topic within a field. In developing that specific expertise, one attains the general physics expert characteristics common among many fields of physics.

I interpret Matthew's distinction between Udit's expertise in a "narrow aspect of the computational molecular biophysics" and his participation in the writing process not being in the final stages as a distinction between Udit being a specific physics expert and yet not having attained general physics expert characteristics. Being a student does not exclude one from the label of an expert; it is one's expertise that is narrow and specific to the topic of the published paper. At the same time, being a student identifies a certain "incomplete" aspect of the trajectory toward expertise.

\section{CONCLUSIONS}

This study suggests that physicists in this research group are partially socialized into becoming an expert through the process of contributing to writing a scientific paper. In 
this biophysics research group, writing a scientific paper is not only associated with the socialization process into the community of practice in physics, learning to write in the community is a process that one is apprenticed into and a social process itself. All members of the group can participate in giving feedback about the manuscript and thereby learn the expected norms of the group.

In this group, students participate in the writing of a manuscript in different stages. Beginners conduct research and observe how the paper is written, which gives them a reference of how a scientific paper is written. Later, they contribute in the form of an outline and identifying what graphical representation and figures should be included. The last stage is when students are ready to give insight to the discussion and conclusion section in the paper, because they have the knowledge to direct their own research and evolve as a general physics expert [13].

The process of developing physics expertise is complex, yet researchers can study in detail the practices one physics research group and identify the smaller processes that graduate students experience. Observing one group limits the ability to generalize to physics at large, but it serves as a guide to identifying the common skills and communication norms of the field so that we can later teach those specific skills to graduate students aspiring to become physics experts. 


\section{REFERENCES}

[1] M.T.H Chi, P. J. Feltovich, and R. Glaser, Cognitive Sci. 5, 121-152 (1981)

[2] F. Reif, \& J.I. Heller, Educ. Psychol. 17, 102-127 (1982).

[3] G. Taasoobshirazi, and M. Carr, Educ. Psychol Rev. 20, 149-169 (2008).

[4] J. Lave, and E. Wenger, Situated Learning. Legitimate Peripheral Participation, Cambridge: Cambridge University Press, (1991).

[5] M.K. Florence and L. D. Yore, J. Res. Sci. Teach. 41 (6) 637 (2004).

[6] L. D. Yore, B. M. Hand and M. K. Florence, J. Res. Sci. Teach. 41 (4) 338 (2004).

[7] Z. Hazari, G. Potvin, R. H, Tai and J. Almarode, Phys. Rev. Spec. Top-Ph. 6010107 (2010).

[8] S. Jacoby and P. Gonzalez, Issues in Applied Linguistics. 2 (2) 149 (1991).

[9] A. E. Austin, J. High. Educ. 73 (1) 94 (2002).

[10] C. M. Golde, New Direc. Higher Educ. 1998 (101) 55 (1998).

[11] M. D. LeCompte, W. L. Millroy and J. Preissle (eds), The Handbook of Qualitative Research in Education. (Academic Press, San Diego, 1992).

[12] E. Ochs, S. Jacoby and P. Gonzalez, Configurations. 1994 (1) 151 (1994).

[13] I. Rodriguez, E. Brewe and L. H. Kramer, Proceedings of 2010 PERC (PERC, Portland, OR, 2010), pp. 277-280. 


\title{
CHAPTER IV
}

\section{DEVELOPING A PHYSICS EXPERT IDENTITY IN A BIOPHYSICS RESEARCH GROUP}

\begin{abstract}
I investigate the development of expert identities through the use of the sociocultural perspective of learning as participating in a community of practice. An ethnographic case study of biophysics graduate students illuminates the experiences the students have in their research group meetings. The analysis focuses on the community of practice-based identity constructs of competencies and trajectory to characterize student expert membership. Results provide evidence that students at different stages of their individual projects develop different forms of mutual engagement, negotiability of the repertoire, and accountability to the enterprise competencies. These membership competencies are developed through direct participation in the research practice under the guidance of peers and mentors. The multi-generational interactions in the research meetings provide students with a range of paradigmatic trajectories to learn from and choose for their future. The leaders of the biophysics research group designed a paradigmatic trajectory that helps students contribute research to the larger biophysics field and develop their individual membership competencies. A fully developed expert identity may take multiple cycles of the group's designed pragmatic trajectory of contributing to the field. The present work expands research on physics expertise beyond the cognitive realm and has implications for how to design graduate learning experiences to promote expert identity development.
\end{abstract}




\section{INTRODUCTION}

The model of a physics expert is traditionally defined by the cognitive abilities of experts, namely having large amounts of content knowledge and having superior memory retrieval mechanisms when solving problems [1]. Particular studies have focused on the abilities of physics experts to solve textbook problems faster and more effectively than student novices [2-4]. The most salient feature of experts is that they acquired their expertise through 10 years of deliberate practice [5]. I deviate from this perspective and expand the model of physics expertise to be inclusive of the social and cultural aspects that develop expertise. I contend that being a physics expert carries certain social connotations about what kind of person one is and how one experiences and interacts within the community of physicists [6,7]. Taking the social-cultural perspective of learning as transforming participation in the social world, [8-12] I examine how participating in the natural context of a community of physicists develops physics expertise. I particularly analyze the enculturation process of biophysics graduate students into the larger biophysics community through their development of expert identities. I review theories of identity that support the social development of expertise of the individual as part of a community. My research study expands the model of physics expertise beyond the cognitive realm and includes the social factors that influence expertise development such as identity. The present study also addresses how these social factors affect the physics graduate student experience.

About half of the students enrolled in graduate Ph.D. programs do not graduate with their physics Ph.D. within nine years [13]. Although some of them may switch and finish with a terminal Master's degree, such high attrition rates of graduate students is alarming 
given the substantial amount of time and resources invested by the students, faculty, and departments $[14,15]$. Several factors influence doctoral completion and attrition, including disciplinary and departmental issues such as mismatched expectations between students and their departments, [16-18] poor advising, [16-18] structural isolation of students, $[15,16]$ and the misunderstanding of departmental research cultures [18]. Such research, as well as the Physics Graduate Education Task Force, $[19,20]$ promote the improvement of placement tests, communication skills, mentoring of students, professional development opportunities, and productive participation in the department; yet, attrition in graduate school remains a problem. Exploring the graduate education experience from the perspective of developing a physics identity provides an opportunity to see the influence of these factors from a student's perspective. An identity perspective can also suggest changes to graduate and mentoring experiences that would nourish students' individual expert identities.

Understanding the development of a physics expert identity requires examining how physicists learn from a social cognitive perspective [21]. Social cognitive theories of learning see learning as a social process of engagement in the world and transforming one's participation in the world [8-12]. For example, the apprenticeship theory of learning $[22,23]$ suggests that a novice learns to become a master at a trade by participating in the activities of the trade. As the apprentice develops their expertise within the trade, they change how they participate in the trade community. The apprentice becomes a unique member of the community and contributes a specific expertise. 
In physics, the socialization process of becoming an expert member of the community may start as early as the first introductory physics course in high school or college, but the experiences that help one become an expert member of the physics community, we argue, typically happen during graduate school [23,24]. Graduate school gives students the opportunity to select a field of study, a topic of interest, and a relevant question to investigate in the field. It is the place where the apprentices master the tools and skills to practice and evaluate relevant physics research. In Traweek's [25] seminal ethnographic study of high-energy physicists, she outlines three stages of being a legitimate and competent member of the high-energy physics community. The stages are undergraduate student, graduate student, and postdoctoral research assistant. Although Traweek claims the stage of postdoctoral research assistant is when one becomes a "full-fledged member"(p.75), it is during graduate school that students develop the skills, knowledge, and practice to conduct and evaluate physics research. Graduate school is often the time when students learn skills such as how to use a specific research method, how to operate the equipment, and how to document and present their work [26].

In the present ethnographic study, I observe graduate students for eight months in a biophysics research group in order to characterize their expert identity development. To frame our study, I first review the literature on communities of practice and development of identity in a community of practice. I then use the identity constructs of membership competencies and trajectory in a community of practice to analyze three episodes of student interaction with mentors with students at different stages of their individual projects. I discuss how physics graduate student develop competencies towards expert participation in the research group and argue for three socially constructed competencies 
that characterize the students' expert identities that develop after multiple cycles of a learning trajectory.

\section{SOCIAL LEARNING IN A COMMUNITY OF PRACTICE}

Expert identity development in physics can be understood from an apprenticeship model of learning [22,23]. Craft apprenticeships, as well as cognitive apprenticeships, enable the apprentice to acquire, develop and use the tools in an authentic work environment. Apprenticeships emphasize the importance of context-dependent activities that help the apprentice learn the culture of the trade [23]. As graduate students are socialized to become experts, they learn the skills, norms, and culture of the physics practice by doing the practice first hand. I take Lave and Wenger's theoretical construct of Legitimate Peripheral Participation in a Community of Practice as a guide in the understanding and interpretation of the graduate student socialization process from novice to expert $[9,27]$. Legitimate Peripheral Participation in a Community of Practice is a theory of learning derived from the context-dependent apprenticeship model of learning. The theory explains how newcomers to a trade, or practice are peripheral participants when they first join. Although they are peripheral because their work might not be too critical to the overall practice of the community, their work is legitimate and contributing to their individual development of the practice. The theoretical theory of learning sees learning as a social process of transforming one's participation along a learning trajectory within the community of practice $[9,28]$.

A community of practice is, in its simplest form, a group of people that share a common practice [10]. For example, physics as a community of practice, is wide and general in its pursuit of discovering the origins of the universe. Within physics there are 
subfields that also share their own specific goals and ways of approaching questions, and they too are communities of practice. In the chapter, I take a smaller unit of analysis as a community of practice: a physics research group. A physics research group is a community of practice as it has defining characteristics of a community [10]. A research group and its members are mutually engaged in the pursuit of negotiating meaning of their joint enterprise of research and share common repertoire of tools, standards, norms, and traditions to get the job done. Most importantly, a research group is the context in which physics graduate students are first introduced into the practice of physics research and therefore develop their specific expert identities.

\section{IDENTITY FRAMEWORK}

\section{A. Defining identity}

Identity plays a central role in the development of physics expertise, thus I first make it clear what is meant by identity. Identity is a concept that is well studied in various fields, including psychology, sociology, anthropology, and now in interdisciplinary fields such as science education. The concept of identity was introduced by the "father of identity," Erikson in his seminal work on adolescent identity formation [29]. Erikson's conceptualization of "ego identity" is characterized by the inner self interacting with outer social reality $[29,30]$. Some in the psychological fields treat identity to be a sole property of the individual, while the sociological view of identity is that identity circumstantially changes through social interaction [31]. In this work, I consider both the individual and social interaction aspects, since the concept of identity formation was always built on the premise that identities develop in social practice and interaction of the self with others $[29,30,32]$. 
The integrative perspective of context, culture, and historical influence on identity formation has brought theorist and researchers to consider selves as socially constructed through mediation of powerful discourses and practices $[9,21,32,33]$. In science education, most studies on identity focus on specific aspects of the individual or specific "worlds" an individual can belong to, for example, gender, race, ethnicity, nationality, and sexual orientation [34-38] can define where an individual belongs. Science education literature has taken particular interest in the critical perspective of the female gender participating in science and mathematical fields [36,37,39,40]. Carlone and Johnson [36] modeled what they call "science identity" to have three dimension; competence, performance, and recognition. Hazari [40] added to Carlone and Johnson's model of identity the dimension of interest. Both of these works on science and physics identity are not gender specific, but they research the interaction of identity with aspects of an individual's cultural identities such as gender and race. Their model for science identity is contextualized in the defining characteristics of a specific discursive community of which women are or aspire to be members. For example, the participation of females in science and mathematics fields can be affected by their gender.

In the present chapter I use identity as an analytical lens to view the process of learning as a process of change in participation in a social context $[9,10]$. I take the concept of identity to be comprised of multiple constructs and socially constructed worlds that individuals belong to: such as the social constructs of gender and the social frames of life like political views. However, I focus on a specific aspect of someone's identity as defined by participating in a community of practice of which one is a member. Wenger's [10] social theory of identity within a community of practice revolves around the 
individual, not as a lone object, but an individual as defined by the world to which they belong and with which they interact. Wenger's identity construct has many dimensions. To understand the development of a physics expert identity, I focus on two dimensions, identity as community membership and identity formation as a trajectory.

\section{B. Identity as community membership}

Expert identity in a community of practice is in part defined by full membership within the community. Membership within the community is a matter of experiencing competence and being recognized as a competent member of the community [10]. In contrast to the dimension of competence described in Carlone and Johnson's [36] model of "physics identity," Wenger does not limit the definition of competence to only content knowledge; he also includes the competence to be socially engaged with others to produce knowledge. Another study that defines constructs similar to competencies is Feldman et al.'s [41] study of chemistry graduate students gaining "proficiencies" (p. 234) during their graduate career. They find that their chemistry graduate students develop two kinds of proficiencies, methodological and intellectual, in their growth towards expertise. Feldman et al. describe three levels of methodological proficiencies the chemistry students develop at different stages of their career. The first level, methodological proficiency, is the ability to gather and analyze data effectively. In the second level, the student masters a technique or machine and is able to manage his/her research and mentor others. The third-level methodological proficiency is when the student, in this case a doctoral student, is able to innovate and develop new methods of research. The second kind of proficiency, intellectual proficiency, does not have distinct levels, but the student must be able to show the ability to create, disseminate, or defend 
new knowledge and research in the field. The ultimate goal for the student is to be aware and work towards becoming part of the larger field of research.

From the mentioned studies on competencies and proficiencies becoming part of one's identity we learn what the technical and content competencies are, but the studies do not discuss the importance of socially developed competencies from interacting with other members of the community. The two studies, Carlone and Johnson [36] and Feldman et al. [41] discuss some of the possible skills and abilities gained by science graduate students during their development of expert identities. The two studies define competencies and proficiencies through technical and content knowledge gained by the students. Neither study goes beyond performance and technical mastery abilities to distinguish interaction and social and interaction competencies that develop as well. Feldman et al.'s [41] intellectual proficiency does require the student to contribute work and publications to the field, which is essentially a social process of joining a community of researchers. However, they do not detail how intellectual proficiency develops or whether it is a defining characteristic of expertise. Wenger's [10] identity dimension of competent membership in a community expands beyond the content and technical competencies to explain the socially constructed competencies developed through participation in a community of practice. He distinguishes three types of competences; mutuality of engagement, accountability to the enterprise, and negotiability of the repertoire. In this context, competence is related to how well members engage with others in the community, how well they understand why they do the things they do, and learn to share the resources and tools that allows them to be successful in the community. 
The first type of competence, mutuality of engagement, is the ability to engage with other members of the group, respond in kind to their actions, and be able to establish relationships in which mutuality is the basis for participation. As part of identity formation, the community practices take a unique significance for each member. Each member finds a way to create a form of individuality in the practice and work together with others as well. It is through the value of one's competence, what one can individually bring to the practice, and the ability to connect with the competence of others that mutuality of engagement produces meaningful contributions and knowledge. "To be competent is to be able to engage with the community and be trusted as a partner in these interactions" (p. 229) [42].

The second type of competence in community membership is accountability to the enterprise. Accountability to the enterprise is the ability to understand the enterprise of a community of practice deeply enough to take some responsibility for it and contribute to its pursuits. For example, a nutritionist will think twice before eating a sugary doughnut. It is the actions, choices, and interpretations that nutritionists learn to value because they are accountable to the larger enterprise of healthy nutrition. Being accountable to the enterprise gives us a certain perspective of the world and how we should behave in it.

The third type of competence in community membership is negotiability of the repertoire. "The repertoire of a community of practice includes routines, words, tools, ways of doing things, stories, gestures, symbols, actions, or concepts that the community has produced or adopted in the course of its existence" (p.83) [10]. Negotiability of the repertoire pertains to our ability to interpret and make use of the repertoire. Negotiability of the repertoire requires enough participation (personal or vicarious) in a practice to 
recognize the elements of the repertoire. For example, a physics student learns the language, tools, and machines necessary to conduct research either by watching others or doing the practice themselves. One experiences the repertoire through sustained and continuous engagement in the community. "To be competent is to have access to the repertoire and be able to use it appropriately" (p. 229) [42].

Interpreting identity as competent membership defines knowing and learning within a community as what would be recognized to be competent participation in the practice. The definition of identity as membership does not take competencies to be static. For example, discovering something new and learning from it are considered acts of competence in the science community of practice. While developing membership competencies, identity also develops as a changing trajectory.

\section{Identity formation as a trajectory}

Expert identity development also involves the temporal and variable nature of one's identity interacting with the past, present, and future. The theoretical underpinnings of identity formation in the different fields of psychology, sociology, and anthropology share a view that identity development is expressed in the present as the continuous interaction of the past and aspirations of the future [10,29-32]. Erikson described the development of identity as, "the trust in mutual recognition, the will to be oneself, the anticipation of what one will become, and the knowledge of what one is in the process of becoming” (p.180) [29]. The temporal and variable nature of identity formation encourages researchers to consider identity formation as a trajectory [10]. Identity formation as a trajectory does not imply a charted course for newcomers to the community to follow. Instead it is a coherency between past, present, and future that 
helps sort out what can contribute to one's identity and what does not. Traweek [25] wrote of the "pilgrims' progress" (p. 74) to becoming a high-energy physicist through selective stages from undergraduate student to postdoctoral fellow. Undergraduate students, for example, have their past experiences to help them fulfill the present expectations to show intellectual skill in analogical thinking. From interactions with older generations of graduate students, post-docs, and mentors in high-energy physics, the undergraduate students see the kinds of trajectories taken by those generations and could anticipate what kind of trajectory would await them in the future. Wenger [10] calls these trajectories by previous generations, "paradigmatic trajectories" (p.154), where newcomers can learn about their career path from the path followed by others.

Aside from the "paradigmatic trajectories," participation is also characterized by the kind of trajectory students are on. Wenger [10] describes five types of trajectories: peripheral, inbound, insider, boundary, and outbound. Peripheral trajectories give access to the community but never lead to full participation. Graduate students developing an expert identity in a research group are on an inbound trajectory working towards full participation. Insider trajectories are attained when the evolution of practice and identity continues to meet new demands of the community. Boundary trajectories enable participants to span their identities across multiple communities of practice and outbound trajectories lead out of the community. For those students developing specific expert identities on inbound trajectories, one of the most influential factors in shaping their learning is their exposure to a variety of trajectories of past and current members in the community or what Wenger calls "old-timers" (p.156) [10]. The paradigmatic trajectories offered by old-timers give access to stories and narratives of the old-timer's own 
participation that are passed down to the new generation. It is through this cycle of mutual engagement of old and new generations that certain cultural and fundamental values of the community are jointly achieved.

\section{METHODS}

To investigate the development of expert identity in a biophysics research group, I take a sociocultural perspective of learning. The sociocultural perspective of learning and identity development as being socially constructed gives us the opportunity to design the study as an ethnographic case study [43] of a specific research group. Ethnography is a qualitative research design in which the researchers describe and interpret the shared and learned patterns of values, beliefs, behaviors, and language of a culture-sharing group (p.68) [43]. Ethnography gives us the opportunity to observe the ongoing process of change that is highly contextual in identity development in the social practice. The case study in the present chapter is an instrumental case study (p.74) [43] in which the researcher focuses on a specific question or phenomena and selects a bounded system that illustrates the issue. The case study focuses on a specific community of practice, a physics research group and its members and how newcomers are enculturated to become experts. To explore the patterns of this specific research group, I practiced participant observations, where I was granted access to the day-to-day activities of the research group.

Ethnographies historically are an outcome of anthropological fieldwork [25,43], and like anthropologists, I document observations in my fieldnotes, which are corroborated with video recordings of group interactions. Fieldnotes serve as the first analysis tool; they are where I record interesting interactions, quotes, and emerging feelings during the 
field observations. In this study, the fieldnotes are a collection of time-stamped notes and reflections made while I observe the group and their interactions.

I serve as the participant observer for this study. I am physics graduate student and I am gradually accepted and able to participate in the biophysics research group's activities. Although I do not participate on research projects, I am able to ask questions and make suggestions in the research group meetings. My experience with physics gives this study a unique perspective of student development and interaction that physics "outsiders" would have taken more time to acquire. Since I, as the researcher, am graduate student at the time of the study, I acknowledge my perspective is an integral part of the research project and influence how participants interact with me and conversely, how I interpret and analyze data in the study. This interaction is referred to as "reactivity" in qualitative research [44].

To address any validity threats related to researcher bias, I establish three validity measures throughout the research project. I as investigator, carry out the practice of "reflexivity," the process of reflecting in a journal how the researcher reacts to the data and analysis [45]. I also practice triangulation, the use of multiple data sources to confirm emergent findings [43-45]. In this case, the data are from the participant observation, fieldnotes, video recording of the research meetings, and interviews with participants. To further insure internal validity, I implement peer review of data analysis in which multiple physics education researchers review evidence for the claims made and check for multiple interpretations of the data [45]. 


\section{A. Data collection of group dynamics}

The research participants are part of a theoretical and computational biophysics research group at an American university. The research group is housed within the physics department and the members conduct research on models of protein structure formation. The participant group holds weekly research meetings every Friday afternoon. Research meetings last four to five hours on average. Their meetings are a time and a place where each student in the group has an opportunity to report on the week's progress and ask for the guidance and help from their peers and mentors if they come across issues or questions about their project.

The ethnographic case study includes participant observations and video recordings of each research meeting for the months of January 2011 through June 2011. After the first six months, I also collected two months of video data, one year later, in January and February 2012 to be able to evaluate the progress of the students and patterns of the research group. Data from the weekly research meetings allows me to observe the ongoing evolution of the participants' work in real time.

\section{B. Interviews with individual members}

To support observations taken in the weekly research meetings, I also conduct guided hour-long interviews with each member of the participant group. I collected two interviews per participant, one conducted during the first six-month period and the second interview the following year in January and February 2012.

The participant research group is composed of two university physics professors and four students. Matthew (all names are pseudonyms), founder of the research group, is a tenured professor and holds an administrative position in the department. Prakul is an 
associate professor and has been part of the group for about six years. Between the two of them, they mentor three graduate students and one undergraduate student at the time of the data collection. Udit, a fourth year graduate student, focuses his studies on structural fluctuations of proteins at different pressures and volumes. Hal, a third year graduate student, focuses on structural fluctuations of florescent proteins using molecular dynamics calculations. Both Hal and Udit learned English as a second language, they have the same native language as professor Prakul, and they all speak English fluently. The third graduate student Ike, a third year graduate student, models the structural transitions of proteins in random coil to beta structure, which is the prevalent structure of several brain disease such as Alzheimer's disease. The undergraduate student, Louis, works on theoretical models calculating the energy of amino acids in alpha helix protein chains, he also learned English as a second language but speaks English fluently. During the data collection period, interested undergraduate students, other experts in the field, and collaborators on projects, also visit the group research meetings.

\section{Analysis of video episodes}

I analyze data of everyday social interactions within the physics research group meetings. In order to create a kind of map that describes how typical graduate students in this research group developed expert physics identities, I select representative instances of social interaction between students and their mentors working on specific aspects of the students' project. Episodes of the students interacting with their mentors and other members of the group are chosen at points in the interaction when the participants are discussing suggestions and changes to the project and not just listening to presentations or explanations. This kind of discourse between students and mentors allows for 
participants to receive feedback from each other and is a great source for analysis of socially developed membership competencies.

I select three episodes of students interacting with their mentors when they are at different stages of their projects and graduate career. My choice is influenced by previous findings of the group's developmental cycle or learning trajectory, designed for the students to follow as a way of developing expertise in a specific topic [24]. In the previous study, the mentors, Matthew and Prakul, agree that the most important attribute of a physics expert is to "contribute to the scientific community" (p. 320) [24]. Therefore, they prepare their students to "contribute to the field" by having them go through a general learning cycle. The cycle involves students first contributing to the project by doing most of the research, simulations, and literature review. The second part of the cycle requires the students to think about how the results and graphical representations help build the point of the manuscript. Lastly, the students need to be thinking about how the project contributes to the field as a whole and what the future research implications are. I take this developmental cycle of expertise to be a kind of paradigmatic trajectory for students in this research group. It is through their participation on group projects that students develop membership competencies and learn to distinguish their individual success and negotiate their trajectory.

I select episodes that illustrate the paradigmatic trajectory at three points: when an project is being designed or new research is being done (Ike), when experimental factors are being tested to build a stronger manuscript (Hal), and when the project is ready to be presented to the scientific community (Udit). These three points are representative of the three stages of the developmental cycle described in the previous study [24]. When the 
project is first beginning the student is required to run preliminary simulations and read relevant literature. At the second stage, well into their project analysis, students are expected to produce and organize graphical representations of their experimental factors. Lastly, when the project is ready to be presented or written for the larger research community, the student is expected to understand the project and its implications for the research community. Within each episode, I analyze for the three kinds of competencies (mutuality of engagement, accountability to the enterprise, and negotiability of the repertoire) to establish the development of the competent membership of the student.

\section{IDENTITY DEVELOPMENT THROUGH MEMBERSHIP}

\section{A. Designing an experiment}

The first episode illustrates a typical discussion between mentors and a student determining the next steps in their analysis. The episode focuses on the work being done by Ike on the structural changes of a protein that is initially in alpha helix formation and transforms to beta fibrils. These protein structural changes are usually seen in proteins that are identified with Alzheimer's disease. The group has developed a theoretical model that explains and predicts how the protein structurally changes as a function of time. The group received reviewer comments regarding their first manuscript submission, which recommended that they include how the size and shape of the proteins change in the process. As part of the research and changes to the current theoretical model, Ike has read experimental papers that describe the changes in aggregate protein size and shape for this process. Ike is in a meeting where the group is discussing how the data about aggregate size and structure from the experimental studies will be included in their theoretical computational model. 
In this group meeting, Ike presents how he is able to convert the data about size of aggregates to an understanding of how it relates to rate of change in time. Ike has realized that the three experimental studies he has read are done in three different time scales and different initial conditions. In this episode Ike introduces the idea of changing the rate constants in their theoretical model in order to fit each of the three experimental data sets, Ike and his mentors then later conclude that the model stays the same even if the rate constant changes. The three experimental studies are referred to as "Lomaikin," Kirkatazi," and "Fetzui."

Transcript conventions include the following: the boundaries of overlapping talk are shown with square brackets at the beginning ( [ ) and end ( ] ) of the overlap, and emphasis in pronunciation is shown with underline. Gestures or actions are shown between carrot brackets ( $<$ action $>$ ). Dashes (-) represent an abrupt pause in conversation, while ellipses (...) represent long pauses of more than a second.

1. Ike: No. Well no- Well, what I am saying is... I don't- ...I...It's going to be really hard to compare... or to use the fits from any of the other papers for the Lomaikin data. Now what we could do is only fit to this here $<$ points to equation on board that says "monomers per aggregate $>$ That's I mean-

2. Prakul: for Kirkatazi you mean?

3. Ike: No, for, for, for Lomaikin. Fit, fit to the number of aggre- the number of monomers per aggregate and that's it.

4. Matthew: Because that is based upon the Lomaikin-

5. Ike: [Lomaikin data

6. Matthew: [data] the hydrodynamic radius. $<$ glances at Prakul $>$
7. Prakul: And what about ours? We have the fit for the Lomaikin data as well?

8. Ike: No, no. The, the Lomaikin data does not have any secondary structure content.

9. Prakul: So what is the connection to our model then?

10. Ike: It's this. It's this here $<$ Pointing at the monomer per aggregate equation on the board $>$. [number of monomers per aggregate.] 11. Matthew: [Using]. Using the rate constants that we go from the Kirkatazi fitted12. Ike: No. No. 13. Matthew: Don't you use the rate 
constants from fitting the Kirkatazi data to then produce this?

14. Ike: Uh. Well I- ok. This, this particular one that I have drawn < points to a graph on the board $>$ I use the rate constants from the Fetzui. 15. Matthew: [From the Fetzui.] 16. Ike: [What I'm saying is to get a whole different set of rate constants. 17. Matthew: To fit the Lomaikin. 18. Ike: To fit the Lomaikin. But we are only going to fit the number of monomers per aggregate. We are not going to fit any secondary structure data. 19. Matthew: From Lomaikin. There is none, right? There is none?

20. Ike: Yep, there is none.

21. Matthew: Ok.

22. Prakul: And?

23. Ike: Well I mean- $<$ Matthew chuckles>

24. Prakul: <looking at Matthew $>$ Is that what you were-

25. Matthew: [No. No. I was going to say] $<$ Prakul chuckles $>$ What we are doing is, we are using our model to fit various experimental data from different groups,

26. Ike: [Yes]

27. Matthew: We are going to end up having to use different rate constants. The same model though, that one thing that will be the point of the paper: This model fits the data from several different experimental groups but we have to use different sets of rate constants depending on which type of data we are fitting. $<$ Glances towards Ike $>$ So - I think that's what you are saying also. 28. Ike: Yes.

I now describe Ike's identity in terms of his membership in the interactions as defined by the three types of competencies: mutuality of engagement, accountability to the enterprise, and negotiability of the repertoire in this episode.

Mutuality of engagement is the competence to work effectively in a group. To analyze this type of competence I look at the entire interaction and show evidence of how Ike is mutually engaged with his mentors and is recognized as a trusted participant on the project. It is most evident that Ike is mutually engaged with his mentors on this project by the fact that they are discussing options and Ike's proposal in the research meeting. More specifically, as the conversation unfolds, Ike makes a proposal to use different rate constants when fitting the different experimental results. Ike's mentors, Matthew and Prakul, are trying to understand what Ike is proposing. Matthew tries to understand Ike by following his train of thought and finishing Ike's sentences in voice turns 4, 6, and 11. In 
the efforts to understand Ike proposal, the mentors also question Ike as a way of assessing the value and feasibility of Ike's proposal. Prakul offers challenging questions to Ike in voice turns 2, 7, 9, and 22 to make sure he correctly understands Ike. Matthew also attempts to clarify his own confusion in voice turns $13,15,17$, and 19 . Both mentors are formulating their own understanding of Ike's proposal and by the end Matthew summarizes his understanding of Ike's proposal. In voice turn 27, Matthew reviews the points of discussion and concludes that the model will fit the different experimental results if they change the rate constants. Mathew's conclusion is in agreement with Ike's proposal and confirmed by both Ike, in voice turn 27, and Prakul with a nod (not shown in transcript). The student and the mentors have mutually resolved to take Ike's proposal and, as a result change the point of the manuscript.

The second type of competence, accountability to the enterprise, is the ability to weigh one's actions and decisions against the purpose of the overall larger biophysics and sciences enterprises. The inclusion of aggregate size analysis into their model is a result of a reviewer comment on the first manuscript. It is important to the research group to take up the request of the community of scientists they belong to and adhere to the standards of the field. In this interaction, evidence of accountability to the enterprise is shown by professor Prakul when he asks Ike to connect his proposal of different rate constants to the theoretical computational model in voice turn 9 and is implied again in voice turn 22. Prakul asked Ike how the proposal connected with the established theoretical model in order to gauge Ike's understanding of the theoretical model and the change in the model that Ike is suggesting. Earlier in the meeting, Prakul had stated that the theoretical model was made to fit as many experiments as possible. Making sure that 
Ike understands the value of the theoretical model is the basis of being accountable to the enterprise. There is no evidence that Ike did not already understand the difference between the original intent of the theoretical model and his proposed change. It was obvious from the interaction that his mentors question Ike in order to find out his understanding of the theoretical model and research process.

For the third type of competence, negotiability of the repertoire, the participants must be able to use, manipulate and exercise the tools of the practice, such as the computational software used to fit theoretical models and experimental results. Participants must also be able to communicate their ideas with language and logic common to the practice. Ike has effectively used the fitting programs used by the group to compare theoretical models to experimental results and has used this competence to recommend how to improve the group manuscript. Ike has also reviewed the relevant literature and has evaluated how his readings inform his model. Effectively learning to use such tools like computer software and reading relevant literature are skills developed through individual practice and effort. Negotiating more abstract tools of the repertoire, such as normative argumentation and language, is acquired from the social interactions with mentors and other group members. Having the ability to use the resources such as argumentation and presentation skills during the meeting gives Ike the competence to clearly get his idea across to his group members.

From the analysis of the types of competencies displayed by Ike in this interaction, I characterize Ike as a member that has been given the opportunity to be mutually engaged with his mentors on this project and is still developing the competencies to be accountable to the enterprise and negotiate the repertoire within this interaction. Although 
Ike has shown he is competent in negotiating the repertoire by using the simulation programs to analyze his model, his procedures are thoroughly questioned by his mentors. In this interaction, Prakul challenges Ike's proposal of changing the rate constants to fit the different experiments against the previous intent of the computational model to fit as many experiments as possible without changing any variables. I do not intend to claim that Ike does not have the competence to be accountable to the enterprise, only that in this episode Prakul showed explicit evidence of accountability and Ike did not. Through the continuous participation in discussions like this, Ike will learn to distinguish the important decisions in physics research and the mentor will give less guidance.

\section{B. Testing factors of the experiment}

In the following episode, the graduate student $\mathrm{Hal}$ and his mentors are discussing his project on Green Florescent Proteins (GFP). Green Florescent Proteins are of particular interest because they absorb and emit green light that can be used as biochemical markers for studying cellular processes. The proteins have a barrel-like surface with an oxygen sensitive chromophore that emits light at its center. Hal focuses his research on understanding the molecular dynamics of the protein when it is exposed to water in order to study how and when the chromophore becomes "quenched" by the oxygen and no longer emits light. Hal runs molecular dynamic calculations on a simulation program called CHARMM (Chemistry at HARvard Molecular Mechanics) that is widely used by the biophysics field.

The episode starts in the middle of a four-hour-long research meeting when the group begins to discuss the progress of Hal's project. Hal is running simulations calculating the fluctuations in protein structure when the chromophore center interacts with water 
molecules. At the beginning of this episode, Hal is discussing what the program has been telling him about the location of the water molecules in the vicinity of the chromophore center. His mentors, Matthew and Prakul, inquire about the state of the interaction and how else to determine information about the location of the water molecules in relation to the chromophore center. In their discussion, they evaluate how the simulation program CHARMM is treating the water molecules under given circumstances, for example, if the water molecule is inside or outside the barrel.

1. Matthew: So there's a water molecule between beta seven and beta ten, can you tell that it is making a hydrogen bond to each one of them? Does CHARMM tell you if that is happening?

2. Hal: Hmm. In the sense of the distance, we can measure like, - choosing the amino acid from the beta strand and measuring the distance between the water molecule and the nearest hydrogen or oxygen.

3. Matthew: But CHARMM doesn't have any way to say, "is there a hydrogen bond between that water molecule and beta seven?"

4. Hal: Well either way it's measuring the distance.

5. Matthew: Just the distance

6. Hal: Yeah

7. Prakul: But maybe also the angle though.
8. Hal: For the CHARMM, they are not considering the angle...

9. Prakul: [what about?

10. Hal: [it doesn't matter.]

11. Prakul: what about the other program that looks at the orientation because it's such a specific interaction.

12. Matthew: So you run it in CHARMM and then after you've got the output then you put it through a different program, which see about the angle. 13. Hal: <nodding > we can, we can use the VMD for that.

14. Matthew: Is your impression that the water molecule not only stays there, but stays in the same orientation while its there? Or does it move... does it rotate 15. Hal: Hmmm. Maybe we can test that, if it is rotating or not.

In order to understand Hal's group membership development in this interaction, I discuss evidence of the three types of competencies for community membership. In this episode, Hal shows to be mutually engaged with his mentors Prakul and Matthew in understanding the next step in the project. The relationship between the three of them constitutes their group and legitimizes Hal as a group participant. Their interaction shows 
a synergy between "complementary forms of competence and overlapping competence" $[10]$ (p. 76) as they mutually engage. They are overlapping in that they all can visualize physically how the protein and the water interact and the structural changes that can possibly occur because of interactions. It is the complementary competence of the individuals; Hal's knowledge of the abilities and limits of the CHARMM program, Prakul's knowledge of the importance of orientation, and Matthew's ability to mediate the conversation, that bring the group forward into working effectively together to make meaningful decisions that create knowledge about the interactions between water and the protein. The episode shows how Matthew asks Hal how CHARMM functions to compute the information they need. The following sequence of events characterizes their overlapping competencies. In voice turn 2 , Hal responds to the best of his knowledge of the limits of the program, but it is not enough to make a compelling argument. In voice turn 7, Prakul makes a suggestion of analyzing for the angle between the protein and the water molecules, and while CHARMM is not able to calculate this, another program can. Matthew immediately understands and mediates the discussion by summarizing the task (voice turn 12). Hal also understands the task to test for rotation and sees how to complete it on the VMD program (voice turn 13). The display of complementary competencies between Hal and his mentors has created a flow of conversation where all participants clearly understand each other by the end of the conversation. It also shows Hal be a competent member of the team and an important contributor on the project.

For the second type of competence, I look for evidence of the participants being accountable to the enterprise. As a group, they have previously negotiated the purpose of the project to be to model where the water molecules are and how they are interacting 
with the chromophore center of the GFP. Evidence for accountability to the enterprise is seen when professor Prakul asks Hal about measuring the angle between the water molecule and the chromophore in voice turn 7. Having multiple observable variables measured supports a robust analysis of water interacting with the chromophore. It is common practice for scientists to be responsible for conducting multiple tests and simulations and having all possible avenues explored before any conclusive statement is made of the observed phenomena. As such, it was important to have Prakul suggest an alternative variable to test. The episode does not show evidence that Hal did not have the ability to contribute such an idea, but I again see the professors making the suggestions in this interaction. As a student, Hal has more practice with the daily technical routines of the computer simulations and sees the problem from a technical perspective. Having the opportunity to share the technical aspects of the project, as well as the fundamental physics behind the project with his mentors, guides Hal towards envisioning the problem from a wider scientific perspective.

Hal also has the ability to interpret and make use of the group's repertoire. In this specific case, the episode shows evidence of how Hal negotiates the capacities and limits of the simulation programs that are commonly used by the group. Hal is able to determine how well the CHARMM program informs them about the hydrogen bond by measuring the distance. Since the distance measures were not enough, Hal was able to consider Prakul's suggestion of measuring angle and knew what simulation program is able to complete the task, in voice turn 13 . Hal has the competency to navigate multiple computational software programs that enhance his analysis and results. Like Ike, Hal has become a trusted member on the project and works well with his mentors to generate 
ideas. Hal's mentors see him as a student able to recognize the limitations of the analytical tool and who is aware of other tools that can be used instead.

From the analysis of the three types of competencies in this interaction I characterize Hal as a member that has mastered how to effectively communicate with his mentors and is competent in his ability to negotiate the common tools used by the group, especially the CHARMM program. As the project progresses, we observed Hal building upon his experiences to further develop his competencies and therefore his full membership.

\section{Communicating ideas}

The third episode focuses on a student editing and reviewing his presentation for a national conference. Udit's presentation addresses his study of water penetrating into florescent proteins under different pressures. Like Hal, Udit has learned to use the CHARMM program to run molecular dynamic simulations of the florescent proteins, but he differs from Hal in that Udit looks at the proteins under different physical pressures.

Although Udit has presented at national conferences before, this is the first time he will communicate his results on the topic of florescent proteins under different physical pressures. In this episode, Udit has just given a practice talk to his research group and he was over the time limit. He and his mentors are trying to figure out the best way to edit the presentation without missing any important points. We see how Udit's mentors, Prakul and Matthew, question and guide Udit to best edit his presentation. We also see Udit defending the choices he made for the presentation.

To better understand the dynamics of the interaction, I first unpack the physics that each participant is defending. The introductory slide to Udit's topic of interest is about pressure and volume effects on florescent protein structure. At this point in the project, 
the group is only concerned with modeling protein "deformations" without specifying whether the protein is folding or unfolding. Denaturation is the process by which the protein loses its secondary or tertiary structure as a consequence of applied pressure or exposure to a strong acidic or basic solute. Denaturation is a phenomenon that the group is not considering for their project. Udit included information about denaturation in his talk to educate his audience and as an introduction to pressure effects on protein structure. His mentors, in efforts to focus Udit's talk and have it under the time limit, feel that these details can be left out.

1. Prakul: This one also you can shorten. You spend a lot of time here. But, these were nice slides actually.

2. Matthew: [They work nicely]

3. Prakul: [... they are too familiar.] 4. Matthew: Yeah. You know, but you won't have - you don't have time to go into detail for these. You can read each of these points.

5. Prakul: And besides, this is more about folding than unfolding. We are not doing folding and unfolding.

6. Matthew: Well you see that, that's just it - - uh. These are nice slides but... it's not what we are looking at here.

7. Udit: But what I am connecting is to the pressure

8. Ida: [Isn't that-]

9. Prakul: [To the volume.

10. Udit: The pressure on- the change of volume this, this, we are looking at this. 11. Matthew: But we are not looking at denage ratio [really.] 12. Prakul: [Yeah] we can't. $<$ Prakul turns to Ida $>$. You had a [question.] 13. Udit: [But] what we are looking at the water penetration [while] protein folding. 14. Matthew: [Yes.]

15. Ida: Yeah, that's what I thought. I was like "oh the connects with-" 16. Udit: And the deformation also we are looking, we are saying we are trying to look at...

17. Prakul: "tends to deform" so, forget about unfold, worry about deform.

18. Udit: [I, I put it in.]

19. Prakul: "[Tends to deform] with increasing pressure." Ok remove unfold. Uh, and put temperature effect, the [pressure effect].

20. Udit: [But] it also unfolds so, at different pressures. We may not be able to go that high but-

21. Prakul: Exactly but, we are not doing unfolding, that's why... You don't want to distract people. You give an impression that, you know, you are doing simulations to show protein denaturation and you don't show any denaturation later on.

22. Matthew: I am going to... All this is true but I am going to remove this whole line. $<$ deletes line at the computer $>$ 
Udit's competence to be mutually engaged is characterized by having all participants in the interaction work towards negotiating the appropriate slide representation needed to get the right point across. Specifically, the mentors are first interpreting the slides and evaluating what can be reduced or deleted in voice turns 4,5 , and 6 . Udit tries to defend why he has included the points about pressure effects in voice turns 7, 10, and 13, later in the interaction the negotiation unfolds. In voice turn 17, Prakul suggests that Udit stay away from mentioning "unfolding" under pressure and that he just focuses on "deformation." Udit retorts by claiming that the proteins do unfold at higher pressures, which is a phenomenon their project could potentially analyze. Udit is bringing his own style and ideas of how the project can be presented. His mentor Prakul argues against not including the unfolding (voice turn 21) so that they will not distract the audience from the main point. The negotiation of ideas from both student and mentor is the fundamental point of mutual engagement, which allows them to generate useful knowledge in the interaction.

For the second type of competence, accountability to the enterprise, Udit defends the points on his slide in voice turns 7, 10,13, and 20. He defends his points for the purpose of including information on pressure effects to educate his audience. Evidence also shows his mentors arguing for the valued standards of the community to not go over the allotted time of the presentation and to keep the information focused on the specific topic. The entire discussion in this episode is representative of all participants comporting themselves as accountable to the enterprise.

Udit used PowerPoint software to write his talk, a common tool used by the research group, and in many cases, by the community at large. Aside from his ability to use 
PowerPoint for presentations, Udit's competence to negotiate to repertoire can also be seen by his understanding and use of research-specific terminology such as "folding," "unfolding," "denaturation," and "denage ratio." Language and jargon interchanged in conversation between participants to further explain their meaning requires all participants, in this case Udit, to have the ability to recognize critical elements of the practice.

As a whole, I characterize Udit in this interaction to be an almost fully competent member. He is at an advanced stage of his project, preparing to communicate his results to the larger biophysics community, indicating his ability to perform all the expected duties and requirements of the project. Similar to Ike and Hal, Udit has been able to show competence of mutual engagement and negotiability of the repertoire. In addition to mutual engagement and negotiability of the repertoire, Udit has also been able to explicitly show individual evidence of his accountability to the enterprise by defending the information on his slides as important for the audience. Having shown explicit evidence of all three competencies I characterize Udit to have a robust membership identity in this interaction. In the following section, we will focus on how the development of each student's membership competencies compare at different stages. The comparison will also help characterize an individual's "paradigmatic" trajectory towards expert membership.

\section{TRAJECTORY TOWARDS EXPERT MEMBER IDENTITY}

Developing an expert identity is temporal in nature. Identity formation requires both the development of a competent membership and the guidance of "paradigmatic trajectories" (p. 154) [10]. Paradigmatic trajectories combine the mentors' own past, the 
student's present, and the future of the research group to inform the student's perception of a trajectory towards specific expertise. Following from their own experience in graduate school in physics, the mentors in this biophysics research group designed a way for the students to become specific experts by contributing research to the scientific community [24]. Along the way, the students also develop their specific expert membership competencies. The students can also see the importance of learning from the paradigmatic trajectories available for them and can create a trajectory with their own individual choices. In this biophysics research group, each student has their individual project on which they work and with that comes specific expertise in software manipulation and specific literature readings. In addition, the students are guided through their projects in stages represented in the above episodes: designing an experiment, testing any and all factors that influence the experiment, and being ready to communicate their contributions to the scientific community [24].

Table 1. Competencies developed during learning trajectory.

\begin{tabular}{|c|c|c|c|}
\hline \multirow{2}{*}{$\begin{array}{c}\text { Paradigmatic } \\
\text { Trajectory Stages }\end{array}$} & \multicolumn{3}{|c|}{ Competencies } \\
\hline & $\begin{array}{l}\text { Mutuality of } \\
\text { Engagement }\end{array}$ & $\begin{array}{l}\text { Negotiability of } \\
\text { Repertoire }\end{array}$ & $\begin{array}{l}\text { Accountability to } \\
\text { Enterprise }\end{array}$ \\
\hline $\begin{array}{l}\text { Designing an } \\
\text { Experiment (Ike) }\end{array}$ & $\begin{array}{l}\text { Negotiates the } \\
\text { proposal to change } \\
\text { the rate constants }\end{array}$ & $\begin{array}{l}\text { Uses model fitting } \\
\text { programs and } \\
\text { argumentation during } \\
\text { presentation }\end{array}$ & \\
\hline $\begin{array}{l}\text { Testing } \\
\text { Experimental } \\
\text { Factors (Hal) }\end{array}$ & $\begin{array}{l}\text { Shows technical } \\
\text { knowledge } \\
\text { complemented by } \\
\text { his mentors' wider } \\
\text { physics resources }\end{array}$ & $\begin{array}{l}\text { Knows the limits and } \\
\text { parameters of } \\
\text { CHARMM and other } \\
\text { simulation programs } \\
\text { like the VMD }\end{array}$ & \\
\hline $\begin{array}{l}\text { Communicating } \\
\text { and contributing } \\
\text { to the field (Udit) }\end{array}$ & $\begin{array}{l}\text { Negotiates the } \\
\text { important points to } \\
\text { present to his } \\
\text { audience within the } \\
\text { time limits }\end{array}$ & $\begin{array}{l}\text { Uses PowerPoint and } \\
\text { communicates using } \\
\text { jargon and language } \\
\text { common to the group } \\
\text { practice }\end{array}$ & $\begin{array}{l}\text { Defends his } \\
\text { presentation points } \\
\text { in order to educate } \\
\text { his audience on } \\
\text { pressure effects }\end{array}$ \\
\hline
\end{tabular}


I summarize the competencies developed by each student at their individual stage of the paradigmatic trajectory in Table 1 . The table highlights the evidence shown by each student in developing their competencies at each of their interactions with mentors. At the first and second stage of the trajectory, all three students show explicit evidence of being able to mutually engage with their mentors and peers, as well as effectively use the simulation tools for analysis that is part of the group's repertoire. In the third stage of the paradigmatic trajectory, the table shows the case of Udit preparing his presentation for a national conference. Udit shows evidence for all three types of membership competencies. From the analysis of his interaction with his mentors, I characterize Udit to be a competent member in this interaction well on his way towards developing a specific expert identity. Udit shows evidence of being accountable to the enterprise when he defends his choice of slides because he considered the information important for his audience. Even though his mentors advise Udit to focus and delete this information, Udit is already at a stage in his identity development where his decision and perspective reflect his individual interpretation of the biophysics and science enterprise.

Udit differs from the other two students in the number of projects to which he has contributed. Udit's episode occurred at a time in his graduate experience where he is working on his second project with the group. The difference indicates that this biophysics research group has their graduate students contribute to at least two projects or manuscripts before they graduate and therefore exposes their students to multiple cycles of the paradigmatic trajectory. For the participant biophysics research group, specific 
expert identity is developed through competent membership learned by participating in multiple cycles of their paradigmatic trajectory of contributing to the field.

The paradigmatic trajectory consists of first designing the project and running preliminary simulations, then compiling multiple factors to present as graphs, and lastly to interpret the results of the project for the larger community of research audience. Udit has gone through the paradigmatic trajectory of contributing to a project more than once. The episode showing all three membership competencies is selected at a point in his second project that is ready to be presented to the larger research field. Findings on the growth of expertise of graduate students were shown in Feldman et al.'s [41] study of chemistry graduate students. Feldman et al. found that those students that develop the "intellectual proficiency to create, disseminate or defend new knowledge" (p. 235) developed their competency through direct participation in the practice. In the cases of both chemistry and biophysics graduate students, participating in the writing of proposals and manuscripts, contributing to the field, and preparing for presentations at national conferences are the experiences that develop expert identity. 


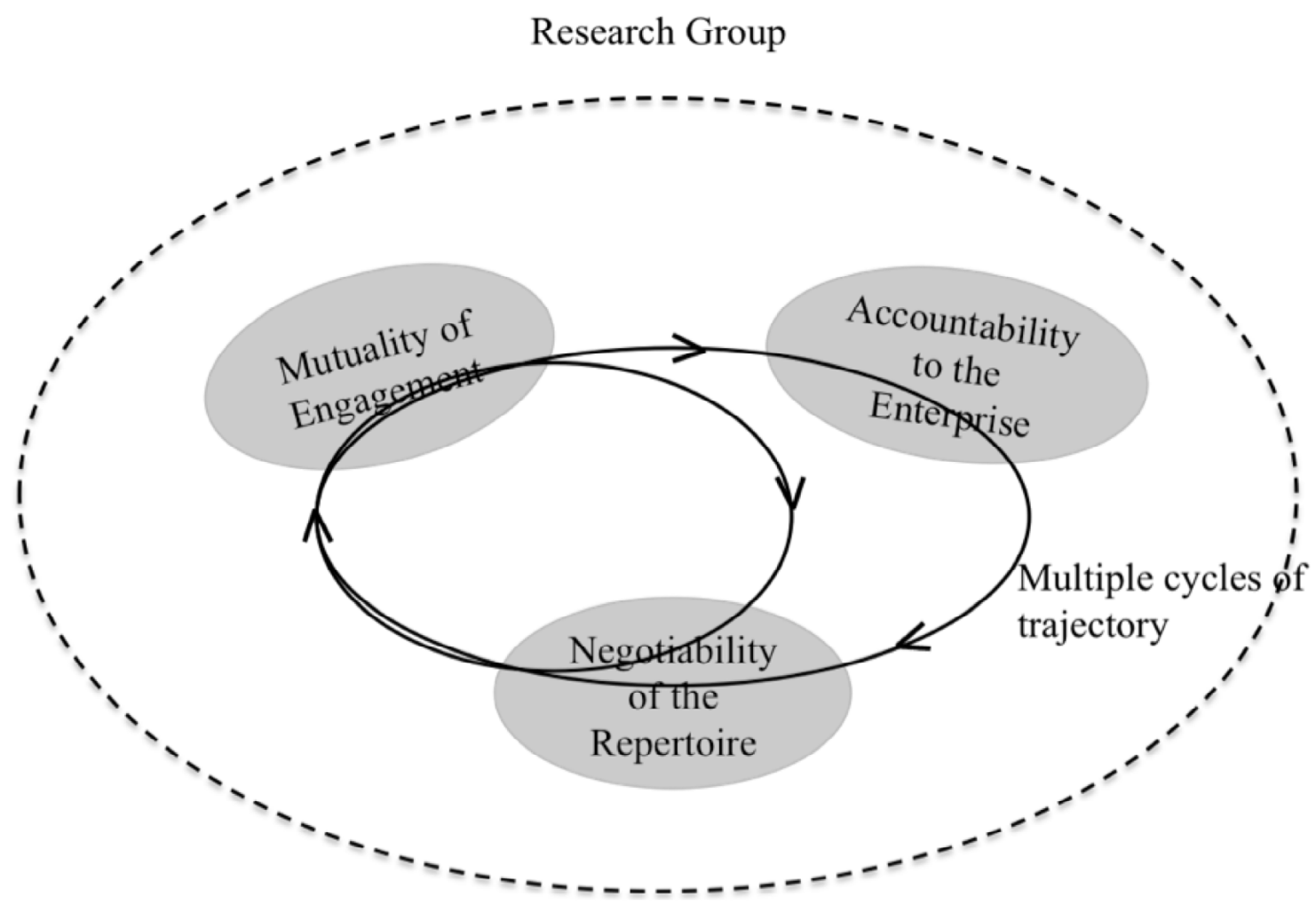

Figure 3. Paradigmatic learning trajectory developing specific expert identity

In Figure 3 I adapt a representation of the trajectory model from Feldman et al. [41] to visually show how a typical student in the biophysics research group develops a specific expert identity. The representation is different from Feldman et al., in that it only shows paradigmatic trajectories for those students on an inbound trajectory [10] towards expertise instead of showing all the possible peripheral and boundary trajectories. The large oval represents the boundaries of the small community of practice: the biophysics research group. Within the research group, the students participate in the practice developing their membership competencies, in particular during discussion and interactions with mentors. As the students finishes a project and goes through one cycle of the paradigmatic trajectory of contributing to research, they may only show evidence for some competencies represented by the smaller circular trajectory. As the student 
continues to work on group projects, his/her experiences can develop membership competencies, represented by the larger trajectory.

\section{IMPLICATIONS AND CONCLUSION}

The present study illustrates how expertise in a community of practice is a matter of identity formation through competent membership and chosen trajectories. With the support of the theoretical perspective of socially constructed expert identity development through the apprenticeship model of learning $[10,22,23]$ the study expands the literature on physics expertise beyond the cognitive realm. The complementary findings from cognitive expertise research and the social interaction research from my study help build a model of how physics expertise is developed both cognitively and socially. I argue that an expansive expertise model can inform us of how physics experts behave in different contexts such as classrooms, solving problems, or in a research setting. An expansive physics expertise model can also teach us what the cognitive and moment-to-moment experiences that characterize expertise in physics. My study identifies the social interactions that are effective for the individuals in this biophysics research group and provides a mechanistic perspective on how students develop their specific physics expert identities through competencies and paradigmatic trajectories.

In the specific community of practice of the participant biophysics research group, the journey to specific physics expertise is guided by paradigmatic trajectories of successful physicists. The biophysics research meetings serve as a platform for advising students on their specific project and any issues they face. Students observe their peers' problems and all the issues dealt with at different stages of their project. Students also have the opportunity to listen to stories of past experiences from experienced members in the 
practice. These experiences from the past, present, and future create a set of possibilities for a new student to negotiate in the formation of their own identity. As a form of individuality, each student in the biophysics group has their own topic of expertise; Ike specialized in protein structural changes from alpha helix to fibrils, Hal specialized in molecular dynamics simulations of green florescent proteins with the use of CHARMM, and Udit specialized on pressure and volume effects on protein structural changes.

The present study focuses on student development of expertise in the specific context of their physics projects. I do not expect that every physics research group will follow the same practices as the participant biophysics group. Every group, as a community of practice, has their own specific norms and their own way of doing things standard to its members. Findings in this study are meant to guide students, mentors, and instructors on practices that could work for them. In particular, moment to moment practices of discussions that promote membership competency development such as reminders of how and why it is important to be accountable to the enterprise. The participant biophysics group serves as a specific model of effective graduate student practices during student and mentor interactions. As the students in this research group develop their specific expert identities, the study explores what kinds of experiences help them achieve their graduate career goals. For example, access to legitimate work gives the students a sense of ownership over their specific topics of interest and a final product of publication to contribute to the larger biophysics community. The explicit and continuous feedback from mentors on the project and student expectations make the relationship between students and mentors in this biophysics research group transparent. 
Aside from a healthy student-advisor relationship needed for success in graduate school [14,15], it is important to have professional development experiences [13]. My study illustrates how the membership competencies of mutual engagement, accountability to the enterprise, and negotiability of the repertoire are developed socially and are related to professional development skills that student needs beyond content knowledge. For example, for the students in this biophysics research group, the ability to manage one's own project, analytically design and test experiments, and effectively communicate results in writing and presentations are professional skills useful in addition to content knowledge. These skills are necessarily useful in different contexts within and beyond the academic research world. Therefore, I aver that a socially constructed model of physics expertise through identity formation complements the established cognitive abilities of physics experts. 


\section{REFERENCES}

[1] W. G. Chase and H. A. Simon, Cognit. Psychol. 4, 55 (1973).

[2] M. T. H. Chi, P. J. Feltovich, and R. Glaser, Cognitive Science 5, 121 (1981).

[3] J. Larkin, J. McDermott, D. P. Simon, and H. A. Simon, Science 208, 1335 (1980).

[4] A. Mason and C. Singh, Phys Rev. STPER 7 (2011).

[5] K. A. Ericsson, The road to excellence: The acquisition of expert performance in the arts and sciences, sports, and games. (Lawrence Erlbaum Associates, Inc, Mahwah, NJ, 1996).

[6] G. Taasoobshirazi and M. Carr, J. Educ. Psychol. 101, 630 (2009).

[7] G. Taasoobshirazi and M. Carr, Educational Psychology Review 20, 149 (2008).

[8] B. Rogoff, Apprenticeship in Thinking: Cognitive Development in Social Context, 1990).

[9] J. Lave and E. Wenger, Situated Learning; Legitimate Peripheral Participation (Cambridge University Press, 1991).

[10] E. Wenger, Communities of practice: Learning, meaning, and identity (Cambridge University Press, New York, 1998).

[11] E. Brewe, V. Sawtelle, L. H. Kramer, G. O'Brien, I. Rodriguez, and P. Pamela, Phys Rev. STPER 6 (2010).

[12] A. Sfard, Educational Researcher 22, 4 (1998).

[13] AIP Statistical Research Center, (Graduate Student Statistics 2013), 2013.

[14] G. Potvin, Thinking Seriously about Doctoral Education in Physics, 2012), 21, p. Back Page.

[15] G. Potvin and R. H. Tai, Journal of Chemical Education 89, 21 (2012).

[16] C. M. Golde, Beginning graduate school: Explaining first-year doctoral attrition (Wiley Online Library, San Francisco, 1998), 1998, p. 55.

[17] C. M. Golde and T. M. Dore, At Cross Purposes: What the Experiences $f$ Today's Doctoral Students Reveal about Doctoral Education (A report prepared for the Pew Charitable Trust, Philadelphia, PA, 2001). 
[18] B. E. Lovitts, Leaving the Ivory Tower: The causes and consequences of departure from doctoral study (Rowman \& Littlefield Publishers, Inc, Lanham, MD, 2001).

[19] J. Tate, T. Hodapp, M. Thoennessen, and C. Singh, Gradaute Education if Physics: Which Way Forward. A Conference to Discuss the Status and Future of Gradaute Education in Physics (APS, College Park, MD, 2008).

[20] R. Diehl, T. Hodapp, C. Singh, M. Thoennessen, S. Turley, and L. Wolf, Graduate Education Conference 2013 (APS, College Park, MD, 2013).

[21] J. L. Lemke, Journal of Research in Science Teaching 38, 296 (2001).

[22] J. D. Bransford, A. L. Brown, and R. R. Cocking, How people learn: Brain, mind, experience, and school (National Academies Press, Washington, D.C., 2000).

[23] J. S. Brown, A. Collins, and P. Duguid, ER 18, 32-41 (1989).

[24] I. Rodriguez, R. M. Goertzen, E. Brewe, and L. H. Kramer, in Physics Education Research Conference 2011, Omaha, NE, 2011), p. 319.

[25] S. Traweek, Beamtimes and Lifetimes: The World of High Energy Physicists (Harvard University Press, Cambridge, MA, 1988).

[26] A. P. Stucky, Empiral grounding of the nature of scientific inquiry: A study of developing researchers (University of Kansas, Lawrence KS, 2005).

[27] J. Lave, Situating learning in communities of practice (American Psychological Association, 1991), 2, p. 63.

[28] K. Handley, A. Sturdy, R. Fincham, and T. Clark, Journal of Management Studies 43, 641 (2006).

[29] E. H. Erikson, Identity; Youth and Crisis (W.W. Norton \& Company, Inc., New York, NY, 1968).

[30] J. V. Wertsch, Culture Psychology 3, 5 (1997).

[31] J. E. Cote and C. G. Levine, Identity Formation, Agency, and Culture: A Social Pscychological Synthesis (Lawrence Erlbaum Associates, Mahwah, New Jersey, 2002).

[32] D. Holland, W. Lachiotte Jr., D. Skinner, and C. Cain, Identity and Agency in Cultural Worlds (Harvard University Press, Cambridge, MA, 1998).

[33] J. P. Gee, Review of research in education 25, 99 (2000). 
[34] N. W. Brickhouse, P. Lowery, and K. Schultz, Journal of Research in Science Teaching 37, 441 (2000).

[35] N. W. Brickhouse and J. T. Potter, Journal of Research in Science Teaching 38, 965 (2001).

[36] H. B. Carlone and A. Johnson, JRST 44, 1187 (2007).

[37] Z. Hazari, G. Potvin, R. H. Tai, and J. Almarode, Phys Rev. STPER 6, 010107-1 (2010).

[38] S. E. Lewis and J. E. Lewis, JRST 45, 749 (2008).

[39] H. B. Carlone, Journal of Research in Science Teaching 41, 392 (2004).

[40] Z. Hazari, G. Sonnert, P. M. Sadler, and M. Shanahan, Journal of Research in Science Teaching 47, 978 (2010).

[41] A. Feldman, K. A. Divoll, and A. Rogan-Klyve, Science Education 97, 218 (2013).

[42] E. Wenger, Organization 7, 225 (2000).

[43] J. W. Creswell, Qualitative inquiry \& research design: Choosing among five approaches (Sage Publications, Inc, Thousand Oaks, CA, 2007).

[44] J. A. Maxwell, Qualitative research design: An interactive approach (Sage, Thousand Oaks, CA, 2005).

[45] S. B. Merriam, Qualitative Reserach in Practice; Examples for discussion and analysis (Jossey-Bass, San Francisco, CA, 2002). 


\title{
CHAPTER V
}

\section{THE GLOBAL COMMUNITY OF PHYSICS INFLUENCE ON A BIOPHYSICS RESEARCH GROUP'S CULTURAL SHIFT AND INDIVIDUAL EXPERTISE}

\begin{abstract}
In this chapter I explore how the global trends of the larger biophysics research community influence a cultural shift in a local biophysics research group research techniques and individual member's expertise. Using a practice-focused analysis of a biophysics research group interacting with a chemistry research group for a period of four weeks, I describe the ways in which knowledge is shared across community boundaries. Community boundaries are defined within Wenger's theory of Communities of Practices and guide my understanding of the shared boundary objects, boundary encounters, and brokering experienced between the two research groups. I also examine how the boundary interactions between the biophysics and chemistry group shift individual graduate student research projects and expertise as a result of trends in the larger biophysics community. Analysis of different forms of brokering practiced by the research group's mentor show to facilitate and expedite the flow of knowledge between the chemistry and biophysics group. The evaluation of the influence of global community research trends on graduate student expertise development informs the literature of a factors in the graduate student experience that encourage graduate students to persist in their physics careers.
\end{abstract}

\section{INTRODUCTION}

The purpose of this study is to better understand how the global enterprise of physics influences the individual's development of expertise within the local communities of research groups. I explore this phenomenon in the context of biophysics graduate 
students developing specific expertise within a biophysics research group. To understand the interaction between local and global influences I utilize the perspective of practice. Practice-focused analysis lets me talk about the ways in which the social and historical resources of a community sustain member engagement in the action of doing work (Brown \& Duguid, 2001; Wenger, 1998). Although many have studied how science is done in practice, particularly in the laboratory (K. D. Knorr-Centina, 1983; Latour \& Woolgar, 1979) they have looked at how scientists structure scientific theories, the histories of ideas, and the institutional setting of science (K. Knorr-Centina, 1999). Studies of the science laboratory (Dunbar, 1995; N. J. Nersessian, 2006; N. J. Nersessian, 2005; Osbeck, Nersessian, Malone, \& Newstetter, 2011) focus on the cognitive problem solving strategies embedded in the social practices of scientific research. These studies of science practice in laboratories have not looked at the global and cultural influences the broader scientific practice has on graduate student development of expertise.

My interest in physics graduate students developed because of their high attrition rates compared to all the other sciences (Committee to Assess Research-Doctorate Programs, 2010). About half of all physics graduate students do not finish their Ph.D. programs with nine years of study (AIP statistical research center, 2013). The high attrition rate becomes an alarming problem for those who have invested the time and resources it takes to graduate a physics Ph.D. (Potvin \& Tai, 2012). Students, faculty, and physics departments share the responsibility in creating effective physics graduate programs. My study on the practices of a biophysics research group teaching graduate students how to engage in the larger biophysics field can elucidate how students develop autonomy and agency beyond their research groups. The study also speaks to how the 
students' mentors are involved and how they motivate graduate students to become physics experts.

One way to understand how graduate students develop physics expertise is to use the idea of expertise being constructed within a community of practice. I define expertise not as the amount of knowledge stored in the head or the number of years of deliberate practice (Ericsson, 1996), but as an expert identity constructed by participating in a community of practice (Lave \& Wenger, 1991; Rodriguez, Goertzen, Brewe, \& Kramer, 2013 submitted; Wenger, 1998). A community of practice is a group of people that share resources and engage with each other in a common goal of creating knowledge in a craft or profession (Lave \& Wenger, 1991; Wenger, 1998). The theory of communities of practice offers a particular perspective on practice that lets me investigate knowledge and identity formation and therefore expertise development in action.

Of particular interest is how a community of practice, such as a biophysics research group, makes it possible for students and members to learn relevant topics and analysis techniques widely used in the larger biophysics field. The evolution and adoption of these techniques leads the group and the graduate students in the group to shift their common practice and develop new specific expertise. Using Wenger's (Wenger, 1998) construct of boundary connections between communities of practice, I investigate how a biophysics research group goes beyond their boundaries of knowledge and learn how to use a popular analysis technique from another research group.

Research methods consist of ethnographic case study techniques to observe and record the daily practices of a biophysics research group over a period of eight months. I focus on the culture shift in the practices of the group after they engage in conversations 
with members of a local, but distinct, chemistry research group for a period of five weeks and how this culture shift influenced the development of individual students' expertise. In the following sections I review the literature on scientific research groups and graduate students for the context of the study. Next I review the theoretical concepts of epistemic cultures (K. Knorr-Centina, 1999), knowledge networks (Brown \& Duguid, 2001), and constellations of communities of practice (Wenger, 1998) to frame and understand how a local research group is part of a larger biophysics enterprise. I then define Wenger's theoretical constructs of boundary connections between communities of practice to analyze the interactions between two research groups negotiating knowledge of a computer simulation program that changes the way the biophysics group analyzes data.

\section{RESEARCH GROUP AND GRADUATE STUDENTS}

Literature that studies the scientific practices of research groups is often set within science research laboratories. A section of this literature focuses on how science is done in practice (Collins, 1985; Dunbar, 1995; Latour \& Woolgar, 1979; N. J. Nersessian, 2006; N. J. Nersessian, 2005; A. Pickering, 1995; A. Pickering, 1992) and recognizes the importance of social and cultural aspects of the environment on knowledge production, problem solving, and scientific cognitive abilities. Nersessian's (N. J. Nersessian, 2005) ethnographic case studies treat biomedical engineering research groups as "cognitive systems." In her study she describes the integration of cognitive perspectives of knowledge and the social-cultural perspectives of knowledge to understand how biomedical engineers optimize experimentally controlled models of analysis. The fusing of both cognitive perspective and social perspective of knowledge led Nersessian (N. J. Nersessian, 2006; N. J. Nersessian, 2005) to consider a research group as a "cognitive 
partnership" within the "problem space." These concepts are similar to Wenger's (Wenger, 1998) concepts of mutual engagement and participation within a community of practice where members build relationships with each other and their devices and artifacts as they practice science. Over time these relationships evolve to produce new knowledge and differences in participation. Similar to Nersessian, Dunbar's (Dunbar, 1995) research in a similar setting of biomedical research laboratories focuses on the scientific thinking processes that scientist produce together to generate new models, modify old models, and solve problems. The science in practice (in laboratories) literature focuses more on the cognitive evolution of ideas and knowledge in relation to individuals interacting with each other and artifacts or objects in the laboratory. Little research in laboratories addresses the scientific practices that help shape the individual newcomers' understanding of these cultural practices. Neither do they address the influences these practices have on their development of expertise as understood through their expert identity (Rodriguez et al., 2013 submitted) and expert participation in the laboratory (Feldman, Divoll, \& Rogan-Klyve, 2013).

Studies that do address education of new graduate student scientist in research group practices are few (Feldman et al., 2013). Studies of graduate student training reviewed in this chapter mostly focus on expected practices learned throughout students' research careers with some highlighting the importance of cultural experiences. The seminal ethnographic study of high-energy physics (Traweek, 1988) dedicated a chapter to the training of new physicists in the laboratory and revolved around the work students are expected to be doing during different stages of their career. The range of expected activities from undergraduate students to postdoctoral fellows vary from learning the 
fundamentals of physics from their traditional schooling to devising new questions to investigate in the field. Bond-Robison and Stucky (Bond-Robinson \& Stucky, 2005) found that students also learned the language and culture of the research group in the research group meetings. They learned skills such as specific research methods, how to use complex equipment, and how to document and disseminate their work (BondRobinson \& Stucky, 2005; Feldman et al., 2013). These findings convey the importance of cultural practices to the graduate student learning experience. Feldman, et al. (Feldman et al., 2013) also found that graduate students in science and engineering research groups develop specific methodological and intellectual proficiencies as they grow in expertise. Feldman et al. compared the learning trajectories of different students at different levels of their graduate career to better understand student participation in research groups and successful scientific research.

Although the studies reviewed in this section give a better understanding of student training and participation in research groups, they do not address the influence of the larger community trends and research directions on the individual group practices and expertise development. This chapter addresses the mechanisms of effective group practices and enculturation processes that help gradate students learn the wider research community norms, culture, and global research trends. To better understand how the larger community of research is linked with local research groups and therefore the individual members, in the next section I review the literature on knowledge in communities from both the interaction of local and global perspectives. 


\section{KNOWLEDGE IN A COMMUNITY OF PRACTICE}

Knowledge in a community of practice is embedded in the practice and effectively shared between the members of the community (Brown \& Duguid, 1998; Brown \& Duguid, 2001; Carlile, 2002; Lave \& Wenger, 1991; Lindkvist, 2005; Wenger, 1998). Members of a community of practice are also simultaneously members of a larger organization or enterprise to which they contribute (Brown \& Duguid, 2001). The knowledge produced locally in their groups becomes the means by which individuals demonstrate their competency to the larger enterprise. In scientific communities such as physics, contributing research to the field in the form of publications is a common practice to share locally produced knowledge to the larger field (Rodriguez, Goertzen, Brewe, \& Kramer, 2011; Rodriguez et al., 2013 submitted). The ability to share knowledge beyond the boundaries of the local community of practice requires the local communities to learn the discourse, style and culture of the larger enterprise (Feldman et al., 2013; Wenger, 1998). To understand how communities of practice share knowledge collectively we consider Knorr-Centina's concept of "epistemic cultures." (K. KnorrCentina, 1999)(see (Haas, 1992) for a similar term “epistemic communities”).

Epistemic cultures are "cultures where knowledge is practiced within structures, processes, and environments that make up that specific knowledge society" (p. 8) (K. Knorr-Centina, 1999). In her analysis of two knowledge societies in science, high-energy physics and molecular biology, Knorr-Cetina distinguishes the differences of their epistemic cultures in creating knowledge and warranting knowledge in their domains. Some of the epistemic differences were the ways physics locates data at the intersection of simulations and theory versus molecular biology experimental conceptions of data as 
being measured. High-energy physics and molecular biology also differ in their beliefs on power structures, physics has community-shared power structures and molecular biology shares individual sense of power (p.246). These differences in practice can translate to how communities of practice develop ways of communicating globally (K. Knorr-Cetina, 1999). Some practices can create effective local communications but create barriers to global communications (Brown \& Duguid, 2001). In a case where effective group coherence creates knowledge is beneficial for the group. Yet, if the group does not practice communications with outside communities, knowledge created in small group can stay bounded within the group alone. Thus, the boundary between local and global communities of practice becomes a space of intersecting views, beliefs, histories, and cultures.

Groups or communities of practice that do not share strong ties between members or ways of doing things, but share similar conditions, artifacts, and historical roots have an opportunity to share knowledge as well. Structures referred to as "networks of practice" (Brown \& Duguid, 2001) are also considered to be "knowledge communities," (Lindkvist, 2005) or "constellations" (Wenger, 2000). The biophysics and chemistry groups in my study can be considered a part of a network of practice. How these social configurations are able to share knowledge is understood through Wenger's concept of boundary connections. Boundary connections are practices that occur at the boundaries between communities of practice, where the boundary defines what, who, and how things belong in the community and what, who, and how things do not belong in the community. Boundaries can distinguish practices between one group and another, as well as distinguish knowledge between groups and their members. In the following section I 
explain Wenger's construct of boundaries to understand what kinds of practices link communities to each other that allow knowledge to flow and how each community is linked to the larger research enterprise to which they belong.

\section{BOUNDARIES OF A COMMUNITY OF PRACTICE}

A community of practice is comprised of a group of people that share a craft or profession. Physics as a community of practice is composed of a large field of professionals with distinct specialties who therefore create smaller communities of practice. Each subfield creates its own definitions and norms in the pursuit of knowledge of how the world works and of what it is made. A community of practice can also be defined by its boundaries, what belongs and does not belong in the community. Boundaries distinguish one community from another and define communities such that they do not exist in isolation from the rest of the world. For example, a small community of practice such as a biophysics research group will be distinguished by what they do and the culture of the group. The small biophysics group also shares connections with the many other subgroups of physics and, by its interdisciplinary nature, with biology and other sciences as well. For example, the biophysics research group may share the same analytical tools and programs as a chemistry research group. Wenger (Wenger, 1998) discusses the types of connections made across boundaries as creating continuities and discontinuity between communities as boundary connections. This chapter explores Wenger's boundary connections of boundary object, brokering, and boundary encounters.

Boundary objects are artifacts, documents, terms, and concepts with which different communities of practice can manage their interconnections. A boundary object serves as 
an intersection of perspectives. Boundary object is a term first used by Star and Griesemer (Star \& Griesemer, 1989) in their analysis of cooperation and negotiation between scientific professionals and museum curators. Boundary objects connect people, ideas, and practices from different worlds and have thus been widely used in business and organizations literature (Brown \& Duguid, 1998; Brown \& Duguid, 2001; Carlile, 2002) as well as in science education on the partnership between a museum and local school (Kisiel, 2009). Wenger's definition of boundary object adopts the original definition by Star and Greisemer (Star \& Griesemer, 1989) and explains how boundary objects are used and developed in practice. For example, when several different members use the object, each member only has partial control over the interpretation of the object in their local setting. The biophysics research group uses a specific computer simulation program for analysis of theoretical models, and a chemistry research group may use the same program but uses different aspects of the program necessary for their local group needs. The biophysics and chemistry group share the same analytical artifact but interpret the program for their personal use. The analytical program may hold a different purpose or meaning for those who use it in their local communities. Therefore, managing connections between communities of practices may not only require a boundary object but someone to facilitate interactions between perspectives.

Boundary objects are ways in which communities connect with one another, but the work in connecting the communities of practices is done by boundary brokers (Brown \& Duguid, 2001; Star \& Griesemer, 1989). Brokering is a common feature of the relation of a community of practice with the outside. Brokers create connections with the outside world and across communities, enable coordination, and open possibilities for new 
meanings. In the example a broker was needed to establish the connection between the biophysics group and chemistry group. One lead professor sought the other and evaluated the benefit of such a union. A broker is involved in the process of translation, coordination, and alignment between perspectives. A broker also needs to have enough legitimacy to influence the development of the practice and address conflicting interests (p. 109) (Wenger, 1998).

Boundary encounters such as meetings, conversations, and visits can take many forms and serve several different purposes (p.112) (Wenger, 1998). Wenger describes three types of boundary encounters: one-on-one, immersion, and delegations. One-on-one conversations between two members of two different communities only need the established relationship between them. The two people can speak frankly about their own practices in an effort to advance the boundary relation. For example, two professors from different research groups may speak frankly about the status of each of their research groups in order to figure out how to help each other. The second kind of encounter is an immersion encounter. One way the two professors from different research groups can help each other is for one professor to visit the other's research group. This kind of immersion provides a broader exposure to the community of practice being visited and to how its members engage with one another. The visit may only prove informative for the visitor and not for the hosting community, as they do not witness the visitor's home practice. The third type of boundary encounter is a delegation, when a number of participants from each community are involved in the encounter. Delegations provide an environment to negotiate meanings between members and across community boundaries. The only problem that delegations could face is that participants may cling to their own 
internal relations, perspectives, and ways of thinking. For example, in discussing the differences in practices between the biophysics and chemistry groups, each group may cling to their ways of doing things and not expand their vision beyond their group practice.

The boundary connections (objects, brokers, and encounters) defined here comprise a mechanistic analysis of how negotiations between two research groups produce new knowledge and influence individual student expertise. I draw upon the literature reviewed on research groups, graduate students, and knowledge in communities of practice, and boundary connections as an analytical framework to address how the global community influences individual graduate student expertise development.

\section{METHODS}

\section{A. Data Collection}

The data in this study are collected as part of an ethnographic case study of a small community of practice. Ethnography, historically practiced by anthropologists (Creswell, 2007; Traweek, 1988), is a qualitative research design investigating the culture of a group. Researchers describe and interpret the shared values, beliefs, behaviors, and language of the group (p.68) (Creswell, 2007). A case study focuses the study on a specific phenomena within the bounded system, in this case a small community of practice of a biophysics research group. Data are collected through participant observation, video recording of the group's research meetings, and individual interviews with participants.

Participant observation requires the researcher to be granted access to the participant group's day-to-day activities. This study focuses observations on group interaction during 
their weekly research meetings. The biophysics research group meets every Friday afternoon for about four to five hours to discuss student research progress. I attend the weekly research meetings, and video record the meetings for the months of January 2011 through June 2011. After six months, I return to the research meetings and record two months in January and February 2012 to assess the development of students' research projects. I also conduct individual hour-long, open-ended guided interviews on relevant topics of expertise, student development, and group practices with each of the participants (Bogdan \& Biklen, 2007). Interviews are conducted throughout the data collection period and a second interview is conducted with each participant in the second year of data collection.

\section{B. Researcher and Validity Measures}

I serve as the primary researcher for this study. My participant observations of the research group meetings are recorded in my fieldnotes. Fieldnotes are time-stamped collection of notes and reflection recorded during observation. Fieldnotes serve as a first analytical tool where I record interesting interactions, quotes, and personal feelings observed. At the time of the data collection, I am physics graduate student. My experience with physics not only helps me understand group conversations and research topics, it gradually increases my rapport with the participant group and permits me to participate in the group's discussions. Although I do not partake in any research projects with the biophysics group, I am able to ask questions and make suggestions during the research meetings. I acknowledge that my identity as a graduate student influences how participants interact with me and how I interact with the data and analysis. This interaction is referred to as "reactivity" in qualitative research (Maxwell, 2005). 
As a way to address any validity threats related to researcher bias, I implement three validity measures throughout the study. First, I practice "reflexivity" and reflected any feelings and reactions or interpretations of data and analysis in a research journal (Merriam, 2002). I also triangulate multiple data sources to confirm emergent findings (Creswell, 2007; Maxwell, 2005; Merriam, 2002). Data are triangulated between the fieldnotes, video recording of meetings, and individual interviews with participants. To further establish internal validity, I implement peer review of data analysis in which multiple physics education researchers review evidence for claims and checked for multiple and alternative interpretations of data (Merriam, 2002).

\section{Participants}

The research participants in this study are part of a theoretical and computational biophysics research group at an American university. Two faculty professors lead the biophysics research group, Matthew (all names are pseudonyms), a tenured professor, and Prakul, an associate professor whom has been working with the group for six years. The two professors mentor three graduate students and one undergraduate student at the time of data collection. Udit, a fourth year graduate student, focuses his studies on structural fluctuations of proteins at different pressures and volumes. Hal, a third year graduate student, focuses on structural fluctuations of florescent proteins using molecular

dynamics calculations. The third graduate student, Ike, is in his third year and is working on models of the structural transitions of proteins in random coil to beta structure, which is the prevalent structure of several brain disease such as Alzheimer's disease. The undergraduate student, Louis, works on theoretical models calculating the energy of amino acids in alpha helix protein chains. 


\section{Structure of Paper}

The rest of the paper is written as ethnography. Ethnography, as mentioned in the data collection section is a qualitative research design addressing data collection. Ethnography is also the method in which to present and write ethnographic data and analysis. Ethnography as a product is a description of human social life and culture, focusing on patterns of behavior, beliefs and language (Creswell, 2007; Merriam, 2002). Ethnographies are written such that they start by describing the setting of the observed culture, researchers search for patterns and make connections with larger theoretical frameworks and personal experience (Creswell, 2007). The description of a group's culture becomes a first level of analysis imbedded in the writing. This chapter is an ethnography of the cultural shift experienced by a biophysics research group after an extended encounter with members of a chemistry research group. The story highlights practices and student research projects in the biophysics group before the chemistry group encounter. I describe topics and ideas discussed throughout the encounter, and the changes in practices and student research projects after the encounter. I then separate the theoretical analysis of boundary connections after the cultural description to frame an understanding of how the biophysics and chemistry research group shared knowledge and how their interactions evolved to influence student research projects and individual expertise.

\section{CULTURE SHIFT}

\section{A. Research Meetings}

Every week, Matthew comes into the conference room with at least two packs of cookies to share with the students during the research meeting. The cookies are meant to 
show gratitude to the students for attending the long, scheduled weekly research meetings that sometimes go late into the night. Matthew says, "The research meetings are my favorite time of the week, when we all get together to discuss physics." The meetings run every Friday afternoon from 2:30 pm until 6:30 pm on average but sometimes finish as late as $8: 30 \mathrm{pm}$ on special occasions. To lighten the load Matthew not only brings cookies, professor Prakul sometimes shares sodas, and several breaks are taken throughout the meeting. At the start of the meeting, Matthew sits at the end of the left side of the oval conference table and his graduate students are either arriving and sitting around the table or setting up the projector to show graphs, plots, results, or any project progress.

During the meeting, each student has an opportunity to present weekly research progress and results as well as questions and experimental design issues. It is common for one or two students to dominate the meeting time presenting project progress, while the other members of the group contribute helpful tips, probing questions, and positive criticism. If a student did not have more than five minutes to present, their project evaluation and progress would be discussed individually outside the meeting throughout the upcoming week. The following section describes a glimpse into some of the students' personal projects.

\section{B. Students' projects}

Ike, one of the graduate students, is working on a project modeling the protein change from random coil to alpha helix and then to beta fibrils. The change in protein structure from alpha helix to beta fibrils is commonly seen in proteins of patients of Alzheimer's and Parkinson disease. Studying how this process of change happens and under what conditions is a very important question of interest in the biophysics field. Ike and his 
mentors have submitted their first manuscript contribution to a journal in the biophysics field on beta fibrils. The manuscript was reviewed and the reviewers suggested the group add aggregate size of proteins in their rate of change model. The authors agree it is an important addition to the model and decide to conduct the appropriate new research on aggregate size to include it in their model. Ike reads several experimental studies on the change of alpha helix the beta fibrils to include as part of his literature review. Ike's work centers on writing computer code using the equation of state of the protein and creating a computational model to fit all the possible experimental data.

Hal, the third year student, is working on a project with green florescent proteins (GFP). Hal uses a molecular dynamics simulation program to model how atoms and amino acids of the GFP interact with water. His project specifically deals with energy landscapes of water molecules entering into the protein chromophore center within a barrel-like surface. In the research meetings, Hal discusses graphs and figures to be included in his first manuscript contribution on GFPs. GFPs are of particular interest to the biophysics field, as they have the ability to fluoresce light from their center. The proteins can be used in medicine as markers and trackers of malignant cells to which proteins can attach. Hal's project informs the other members of the research group on how the florescent chromophore center is "quenched" by water molecules under certain energies interactions and oxygen diffusion pathways in the protein barrel surface.

To produce detailed results of the water molecules interacting with GFPs, Hal uses a popular molecular dynamics program called CHARMM. The effective use of the Chemistry at HARvard Molecular Mechanics (CHARMM) simulation program in the chemistry and molecular biology fields ignited an interest and its use in the biophysics 
field. CHARMM is a program that simulates force interactions between amino acid molecules of proteins with greater detail than previous analytical methods. Although the program was first developed in the 1980's, most researchers did not trust its initial use in the biophysics community. As technology developed and the program was upgraded year to year, its validity in theoretical computational studies became widespread and researchers began to use CHARMM as an investigative analytical tool. CHARMM simulations program became a valuable research tool to Hal and his biophysics group.

Udit, the third year graduate student was initially working with modeling pressure and volume effects of the trigger sequence of a leucine zipper protein. His work primarily modeled proteins using the biophysics group's homegrown energy lattice modeling program. After his first project was accepted for publication, Udit is becoming more interested in analysis from CHARMM. While waiting for approval for publication of his work on the lucine zipper, Udit is working on learning more about CHARMM by reading the program manual and working through tutorials of the simulation program. Since Udit's interest is changing, his mentors appoint Udit to work with Hal on an analysis for a grant proposal using CHARMM. In this manner, Udit gets acquainted with the molecular dynamics program and contributes to the group as well.

\section{Problem with CHARMM}

As it is becoming more "popular" in the larger biophysics field to use CHARMM in theoretical analysis of proteins, more interesting questions can be asked in the biophysics field. In the four weeks of observation highlighted in this ethnography, the research group is organizing a pilot study of proteins changing from alpha helix to beta strands for a grant proposal. Matthew has announced to the research team that attaining preliminary 
results of the protein changing from alpha helix to beta strands in the CHARMM program could strengthen the research grant proposal and assure funding for a more intensive study of the process. Matthew appoints Hal and Udit to work on the proposal study since Hal has experience with CHARMM and Udit is showing interest in learning the program for his future projects, while Ike learns from observation.

Hal and Udit's mission is to run simulations of the proteins in water solvent changing shape and testing under what pressure and temperature conditions the proteins will start folding from an alpha helix to a beta strand. The ideal analysis would show the proteins forming at least one beta strand in the appropriate nanosecond time scale before they can submit the results as a part of the grant proposal. Studying the process of a protein changing from alpha helix to beta strand fibrils has relevant applications in Alzheimer's disease research and is similar to the field of research to which Ike, the first graduate student introduced, is intending to contribute. Proteins of human brains affected with Alzheimer's disease have been shown to undergo this change from healthy alpha helixes to unhealthy beta strands. Understanding how and under what conditions this process happens is a question of great concern in the biophysics and medical science fields.

Even though Hal has experience with the CHARMM program, and Udit is dedicating most of his time to learning how the program works, both students have come to a technical roadblock when it comes to interpreting CHARMM for this grant proposal study. The proteins are modeled to be inside a box with water in it. To make the calculations quicker, the group has decided to use implicit water instead of explicit water molecules in the interaction. Implicit water treats water as a dielectric field with which the proteins interact, while explicit water incorporates every single water molecule 
interacting with the proteins. Hal has studied the effects of water molecules in his studies of green florescent proteins, but adding pressure and temperature effects seems to slow down calculation time, a luxury the group does not have. The mentor, Matthew, feels that going beyond their group expertise and seeking advice from a neighboring research group with more experience with CHARMM might be appropriate in order to accelerate the analysis in time for the grant proposal deadline.

\section{Encounters Between Groups}

Matthew, as a professor at a research university, shares similar experiences with other university professors. He calls upon a colleague in the chemistry department, who also performs molecular dynamics simulations of proteins using CHARMM. Matthew's colleague, Henderson, meets with Matthew briefly and suggests having his graduate student AJ attend the biophysics research meeting, since AJ is adept at using CHARMM. Matthew finds this to be a great idea and sets up the encounter.

As a delegate of the chemistry research group, AJ comes to the biophysics Friday research meeting ready to present on his personal project where he uses CHARMM. AJ's project uses a combination of two simulations programs, CHARMM and Gaussian. Gaussian is a program that goes beyond the mechanical force interaction of CHARMM and models interactions at a quantum level. AJ's project also models molecules in water, which is of particular interest to Matthew, Hal, and Udit for their proposal study. During AJ's presentation, the section about the molecules interacting with water is when both Hal and Matthew ask the most questions. Hal asks AJ very technical questions about CHARMM program commands, not only for the interest of the pilot study but also for his personal project on green florescent proteins interacting with water. Matthew asks AJ 
questions regarding the physics interpreted from the CHARMM program. He asks about the kinds of force fields used for certain simulations. Matthew asks specific questions on topics or issues his own research group had come across, yet the topics are not always something $\mathrm{AJ}$ has come across in his experience.

The following week after AJ's visit, the biophysics research group does not have any visitors from the chemistry research group, but they have scheduled another encounter for the upcoming week. Matthew and his students still discuss the progress of the pilot study simulations in trying to get the alpha helixes to fold into beta strand fibrils. The simulation holds three alpha helix proteins close to each other so that when they start unfolding the proteins can interact and fold into a beta structure. As Hal has tried to keep the proteins structures very close together, the desired result is not within their grasp. This week, Matthew, Hal, and Udit discuss how they will try to add "amino acid bridges" between the ends of the proteins. This maneuver in the molecular dynamics simulation does not prove to be easy, as the program keeps track of the position of every atom and placing new atoms that were not originally there risks their time constraints. Hal suggests against using the bridges and proposes just shrinking the size of the box containing the proteins. Matthew considers this to be a good idea but has questions about the edge effects the proteins face as they travel to the edge of the box, and whether the box will be big enough to let the proteins unravel. Many times throughout their discussion, Matthew summarizes the conclusions to satisfy questions from Ike. Ike asks many questions about what the protein will physically do, which is dependent on the physical parameters set up in the simulation. The physical parameters discussed are the size of the box, the boundary effects, and the water medium surrounding the proteins. 
In the third week, $\mathrm{AJ}$ returns to the research meeting for a second time, although he is not presenting. Instead, the biophysics group presents their results to AJ. Matthew starts the meeting by introducing $\mathrm{AJ}$ as the expert in molecular dynamics and also points out how his student Hal is also developing real expertise in molecular dynamics. As a way to get everyone up to speed, Matthew summarizes the processes and analysis available from the molecular dynamics program, the purpose and goals of the proposal on alpha helixes changing into beta strand fibrils, and finally relaying the pressing question about implicit water. Recall that implicit water is a strategic use of water as solvent in the molecular dynamics simulation. The advantage of using implicit water is to cut down the run time in the simulation and so they can have an approximate model of how the proteins will behave. Currently, the disadvantage is that Matthew and his research group still have lingering questions regarding how the program deals with implicit water, what the size of the box really means if they use implicit water, and whether periodic boundary conditions will waste calculation time with the use of implicit water. AJ unfortunately has only dealt with explicit water in CHARMM and could not provide any direct feedback.

Alternatively, AJ engages Hal and Udit in a more technical discussion of the CHARMM program code and output files in order to address some of these concerns from the inner workings of the programming code.

The fourth and last week of the encounters between the chemistry and biophysics research group was the delegation kind. Professor Henderson and AJ are both welcomed to the Friday research meeting as the expert guests of honor. At the beginning of the meeting there is a summary of all the problems the biophysics group have been addressing such as what kind of force field, periodic boundary conditions, and most 
critically, implicit water. Professor Henderson starts making suggestions and interpretations of the biophysics groups' questions in order to help. He suggests a specific force field to model the interaction between molecules. Henderson also introduces his knowledge of implicit water by letting the group know that even with periodic boundary conditions, the implicit water behaves as non-continuous fluid. This effect would not yield realistic results of the proteins structural changes under certain pressures. Udit, in charge of analyzing pressure effects for the proposal, shows particular interest in this information and asks many questions regarding pressure manipulations within CHARMM and implicit water. Matthew lets Udit and Hal display their command code on the projector so that they can discuss with Henderson the programming code that deals with the pressure effect commands. As a response, Henderson suggests articles and a specific book for the students to read. The students have read some of the articles but the book on fundamentals is of interest to Udit, who writes down the book's information. As Professor Henderson leaves the meeting, Matthew thanks him and AJ for being a great resource and help.

\section{E. Six months later}

On a typical Friday afternoon six months later, meeting time is the same and all the students come into the conference room to sit around the table waiting to report on their projects. Matthew brings two or three packs of cookies for the group to share during their discussion. Matthew also brings over the projector and asks Udit or Hal to set it up. The greetings, the small talk before all the members are present, and the preparations to talk physics have remained the same. What have changed are the topics of conversations and students' research projects. 
Ike's manuscript on the rate of change model of alpha helixes changing to beta strand fibrils was accepted and published in a journal. His analysis of the aggregate size of different experimental results was a great addition to the manuscript. He is now learning from the online tutorials how to use CHARMM for a deeper analysis of the rate of change of alpha helixes to beta strands. Hal published a manuscript on the CHARMM analysis of green florescent proteins and their oxygen diffusion paths when in contact with water and received high praise from the editors, as his paper is an important contribution to the field. With such great success with CHARMM, Hal is continuing to work on questions pertaining to florescent proteins and their interaction with water molecules. Like Hal, Udit is also working on his own project using CHARMM. After the experience with the proposal study he decided to implement what he learned about pressure and volume effects from the luciene zipper on florescent proteins using CHARMM simulations instead of energy lattice models. His current project includes volume and pressure analysis of florescent proteins using CHARMM simulations.

\section{F. Matthew's perspective on the cultural shift}

It is evident that all the students' projects and personal interest depend upon the use of the CHARMM simulation program. It is a pattern that I as a researcher notice and ask Matthew about in his second interview at the end of the second phase of data collection. Matthew mentions that in general the group had done a lot of work with the statistical mechanics and computational lattice models of proteins. "But some very important questions in the field of biophysics over the last ten years have been focusing on really detailed information... and that was not possible until we had a molecular dynamics program." As a mentor, Matthew knows this would be an important field to which to 
contribute and that it would benefit his graduate students to learn it; he just needs to find a way to show his students how to work within CHARMM. As the group's expertise did not reside in molecular dynamics simulations, he decides to bring experts to help. When we ask about what the biophysics group had gained from the interactions with the chemistry group he responds:

We interacted with them so that we could learn as much as we could from them and then it got to the point when we realized that the fact they were using different molecules and asking different questions means they were not going to be able to answer all the questions we were going to have about CHARMM. But the only way to find that out is by talking with them. And it was really useful. - Matthew

Influenced by demands from the larger biophysics field and their interactions with the expert chemistry group on CHARMM, many of the biophysics groups' projects on which the students were working become similar to each other with what Matthew called a natural shift.

I don't know if this has always occurred this naturally or sometimes we just say 'well, I've reached a dead end in this field, I need to find something completely different that I don't know anything about.' Whereas with Ike's work and [Hal's] work, what we are doing keeps leading to interesting questions... It seems kind of nice and seems it's occurring kind of naturally. - Matthew

The work from Ike's project on beta fibrils and the application of CHARMM in Hal's project on florescent proteins provides the group with the background to work on the grant proposal project. This background also helped Udit and the rest of the group learn CHARMM more naturally from a perspective with which they are already familiar. This familiarity with something from previous work is what motivated Udit to take what he 
had learned about pressure effects on the leucine zipper protein to be applied to florescent proteins using CHARMM.

I now turn to a more theoretical analysis of the culture shift using boundary connections (boundary object, brokering, boundary encounters) to interpret how the biophysics and chemistry research group interacted and effectively shared knowledge with each other and influenced the group's expertise.

\section{ROLE OF BOUNDARY CONNECTIONS ON CULTURE SHIFT}

Boundary connections such as boundary objects, boundary encounters, and brokering promote the spread of knowledge between communities of practice (Brown \& Duguid, 1998; Wenger, 1998). In this section I analyze how these boundary encounters facilitate each discussion point about CHARMM. I characterize the purpose and benefit of the encounters for both the chemistry and the biophysics group and I also analyze Matthew's brokering practices during these interactions.

\section{A. Boundary Object}

Recall that a boundary object is an object of interest to each community involved in negotiations but used differently by each of the communities (Brown \& Duguid, 1998; Star \& Griesemer, 1989; Wenger, 1998). In the multiple interactions between the biophysics group and the chemistry group, the shared boundary object is the CHARMM simulation program. Issues with the program initiated the connections in the first place, with Matthew's brokering practice, which we address later. Once it becomes a part of the conversation, the CHARMM program also guides the conversional topics throughout the four weeks of encounters. A type of boundary encounter characterizes each weekly encounter. Each week is also characterized by the specific issues the biophysics group 
was having with CHARMM. For example, in the first meeting with AJ, the group mostly discusses the possible force fields CHARMM could apply to the proteins. In particular, they discussed the F1 force field and how to use it within CHARMM. In the last meeting with Professor Henderson, the group reviews all the issues they've been having, from force fields to dielectric constants and pressure effects to ask the expert. I outline the topics discussed in detail at each encounter in a timeline shown in Figure 4. The issues discussed in the encounters with respect to the boundary object help clarify what each community needs from each other, what they can offer each other, and distinguishes how each group has dealt with these issues themselves.

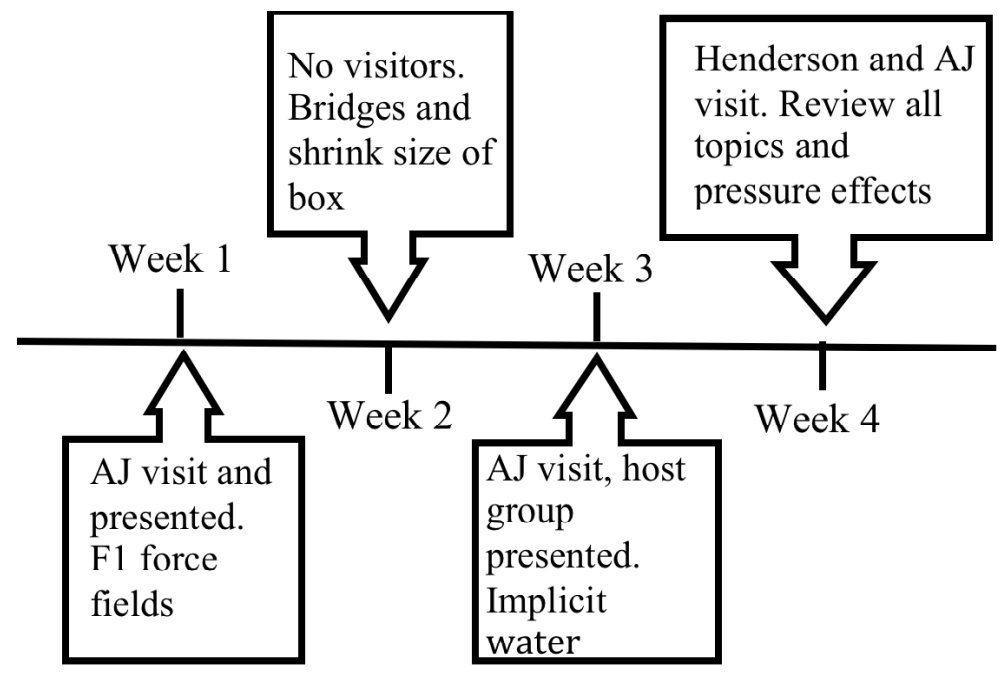

Figure 4. Timeline of topics discussed at each encounter.

\section{B. Boundary Encounters}

In tandem with the boundary object, the types of boundary encounters (Wenger, 1998) are also distinct in purpose and in what is learned in the encounter. Matthew and professor Henderson meet on a one-on-one basis to negotiate how it would be best to share their knowledge about CHARMM simulations. Although it was probably Matthew 
benefiting the most out of interaction to get the help he needs, the encounter serves as the first step in negotiations between the two groups.

The second type of encounter experienced by the participants is an immersion encounter, in which $\mathrm{AJ}$ from the chemistry group visits the biophysics research meeting to present on his work. While it is AJ that comes to visit the biophysics community and witnesses their common practices during the meeting, the immersion served the biophysics group's purpose of extracting knowledge from AJ's presentation. Matthew comments in his second interview that to take advantage of other's expertise he had to "do it in a reasonable fashion." He tells the chemistry group, "Just come and tell us about the calculations on the molecules you are doing and we will just listen. And periodically you'll just say something that is relevant to us and then we might ask you questions." AJ presents his project on a much smaller protein than the biophysics is interested in, but the techniques of using similar force fields and water molecule simulations is of great interest to the biophysics group.

The third is also an immersion encounter, when AJ visits and listens to Hal explain their results. In this boundary encounter knowledge about CHARMM flows from the biophysics group to the chemistry group representative instead in the first immersion, where knowledge flows from the chemistry group representative to the biophysics group. Since the host group will not have the opportunity to witness the chemistry research meetings, each immersion in these interactions show to be informative for each of the research groups. In the first visit with AJ, the biophysics group witnesses a glimpse of the kind of work the chemistry group does and how their work relates to each other. When AJ visits again, it is Hal explaining results from the biophysics research group to AJ, as a 
representative of the chemistry group. AJ learns what the biophysics group does and can decipher what aspects of his work could help the biophysics group from the questions they were asking.

The last of the encounters is of the delegation type, where two or more participants from each community are involved. In the last encounter, both AJ and Professor Henderson visit the biophysics research group meeting. Wenger (Wenger, 1998) states that delegations provide two-way connections between participants, yet the interactions with Professor Henderson were very similar to the interactions the biophysics group had with $\mathrm{AJ}$ in the immersion encounters. First, I notice that $\mathrm{AJ}$ does not speak or contribute to the discussion on the last day and Professor Henderson answers the questions. Since the previous interactions with $\mathrm{AJ}$ share similar characteristics the encounter with Professor Henderson serves the same purpose as an immersion encounter. The biophysics group is fortunate to host multiple encounters with the chemistry group and learn aspects of CHARMM that were critical to their proposal project.

\section{Boundary Broker}

Brokering across boundaries of the two communities of practice takes a certain skill to frame the interest of one group in terms of the other's perspective (Brown \& Duguid, 1998). The broker must also have enough legitimacy in the practice to carry meaningful communications. Although there are many ways in which brokering, coordination, and translation took place by multiple participants in the different encounters, I only focus on the specific brokering practices conveyed by Matthew. The first of Mathew's brokering practices is to initiate the discussion with the chemistry group by having an one-on-one encounter with Professor Henderson. After the boundary connection is made, other 
brokering practices during the research meetings facilitate information and knowledge flow. The most common brokering practice Matthew displays is the numerous occasions in which he summarizes the issues and concepts discussed such that everyone involved would reach a common understanding.

A more interesting brokering practice is Matthew's indications of who is an expert and what an expert does. In the first encounter with AJ, Matthew introduces AJ as an advanced graduate student from a chemistry research group working in molecular dynamics that "has real expertise in these programs." In the second encounter, Matthew does the same and includes Hal to be an expert in CHARMM as well. Distinguishing AJ and Hal as experts in molecular dynamics simulations gives everyone the impression of what each participant can contribute and what is expected of them. In the second encounter with AJ, Matthew tells the students a story of the difference in expertise between himself and Professor Henderson and the importance of knowing that difference in order to seek help. Matthew tells his students:

Professor Henderson wandered down to my office a few days ago because he had a nice discussion with AJ after AJ came by two weeks ago. Now, he is an expert on this stuff, I am not. He very politely told me in different words 'Matthew you have no idea what you're doing'... And at that point when you're talking to an expert the best you can say is 'you know Professor Henderson, I am willing to admit I don't know what I'm doing. Please tell how to do it properly.' Which is why he will come next week. At least I showed him that I know what I don't know and it's important to know what you don't know. -Matthew

After this he then identifies Hal as knowing CHARMM very well, Udit to be learning it and Ike, the only graduate student not directly working on the proposal project, "to be at some point heading in that direction." Within this anecdote, Matthew shows to be comfortable pointing out what he does not know in order to seek corresponding help. He 
understands that he alone could not help Hal and Udit with questions about CHARMM and the proposal project. Matthew's own expertise is indicated when he identifies the needs of the group and finding ways of addressing those needs by bringing in an outsider.

AJ is one of the biggest resources Matthew has at his disposal during the weeks the chemistry group visits. It is seen in the previous quote from Matthew, that in the second encounter with AJ, AJ not only serves as a knowledgeable resource on CHARMM technique, but is also a messenger to his group. Relaying information about the biophysics group's goals to his own chemistry group is in its own form, brokering. AJ's own form of brokering did not escape Matthew as he sees it as a resource for his own purposes of working towards the grant proposal. Before Professor Henderson joins them in the next meeting, Matthew request that AJ come with Professor Henderson. "The reason why it is important is because you know more about what we are doing, you might be able to phrase our questions to him better... In other words you'd be able to speak the language more properly." Therefore, AJ now becomes a translator for the biophysics group and has a newfound purpose to come to the research meeting following week. As translator, AJ needs to have sufficient knowledge about the work of both communities involved in negotiations in order to translate (Brown \& Duguid, 1998). The nature of translating positions AJ to be trustworthy as well.

Although the negotiation of meaning and knowledge of CHARMM could have been shared between the biophysics and chemistry groups in innumerable ways, I argue that Matthew's brokering practices of being explicit about the topics being discussed and pointing out who the experts of CHARMM are facilitates and expedites the transfer of knowledge between groups. It is in the biophysics group's interest to understand the inner 
working of CHARMM as quickly as possible for the grant proposal result to be submitted. Matthew's explicit practice proves to be fruitful in more ways than one, as his graduate students evolved in the use of CHARMM in their own projects. Therefore, it is useful during a negotiation of meaning to have someone coordinate summaries of the topics being discussed and identify who has the expertise in a specific task or topic. Being explicit clarifies the boundaries of knowledge between participants, what the shared knowledge is, and how each of the participants can contribute knowledge across the boundaries.

\section{INFLUENCE OF LARGER ENTERPRISE ON INDIVIDUAL EXPERTISE}

The definition of boundaries I use in this chapter transcends varying levels of connections between the global enterprise, local communities, and individual members. The definition of boundaries outlining what belongs and does not belong in the community of practice covers a broad spectrum of objects, concepts, ideas, people, and knowledge that flows through and across boundaries. I discuss three levels of boundary crossing that are explored in the biophysics research group's interaction with the chemistry research group: individual knowledge boundaries, research group boundaries, and local and global community of practice boundaries. Within the discussion of the three levels of boundary crossing, I also address how the directionality from global community practices influence individual knowledge and expertise.

A distinguishable boundary of knowledge is seen in the individual participants of both the chemistry and biophysics research group. Participants have their own knowledge base bounded by their own personal experience. The encounters give the participants the opportunity to share their knowledge with the rest of the group. For example, AJ from the 
chemistry group has experience with CHARMM from his own project of small molecules in explicit water. Although his experience with CHARMM helps the biophysics group with questions about force fields and command lines, the bounds of his knowledge of CHARMM does not include the use of implicit water that the biophysics group needs to learn. Similarly, Hal's knowledge boundaries of CHARMM lead his mentor Matthew to seek out expert help from another group. Although Hal uses the CHARMM program in his analysis of florescent proteins, having to design tests for a different reaction of alpha helix to beta strands requires him to seek out help. Udit, on the other hand, does not have much experience or knowledge of CHARMM and how it works but his knowledge of pressure and volume effects from his previous project helps him formulate probing questions. Given the opportunity to share knowledge with each other in the visits shows each of the students the limits of their own knowledge boundaries, how their boundaries overlap with other's knowledge, and how to expand their own.

The second level of boundaries explored in this chpater is between each research group as a whole. Each research group as their own community of practice has different objects, concepts, ideas, members, and norms within their group boundaries. Their collaborative benefit is in sharing what they have in common. As both the biophysics and chemistry group use the CHARMM program to analyze molecular interactions, they could share their own knowledge and experience with the program. The limits or bounds of their practice is seen in how each group uses the simulation program in research. While the chemistry group uses the program mostly for small molecules, the biophysics group is using it for larger protein structures. Yet both groups are able to cross community boundaries and discuss experiences they have in common. Effective sharing 
of common practices is facilitated with appropriate brokering practices (Brown \& Duguid, 1998; Carlile, 2002; Star \& Griesemer, 1989). Matthew's ability to translate the interest of one group in terms of the other group's perspective is an invaluable aspect of boundary connections under the time constraint.

A more subtle level of boundary connection is between the local research group community and the larger biophysics research community to which they belong. As Wenger (Wenger, 1998) explains it, "knowledge is not just a matter of our own experiences it is also a matter of the positions of our practices with respect to the broader historical, social, and institutional discourse to which we orient our practice" (p.141). The motivation behind all the intergroup interactions between the biophysics and chemistry research groups is not only student preference of learning CHARMM, but the grant proposal as well. Preliminary finding to be submitted to the larger peer review board of proposals situates the biophysics group knowledge within the larger biophysics research community. The biophysics group's wish to pursue preliminary findings for the proposal also illustrates some of the larger community's norms and practices to be adopted by the local communities. It is common practice in the larger biophysics field to have preliminary results in a grant proposal to secure funding. It is this standard that the biophysics research group adopts as their own as well. In a way, members of the local group develop an outlook on the work and a worldview that may reflect the biophysics research enterprise as a whole (Brown \& Duguid, 2001).

The three levels of boundary connections are interrelated. The common thread is how knowledge is invested in practice: the way scientists do things, methods scientists' employ, and the value of the knowledge developed (Carlile, 2002). Lets take a top down 
view or a global to local perspective and effectively see how the global practices and trends of the research enterprise influence the individual's knowledge in practice. In the specific case of Udit, he changes his research project of energy landscapes and trigger sequences of the lucize zipper to pressure and volume effects on florescent proteins using CHARMM. He personally wants to change because he wants to be more "prolific" in his last two years of graduate school (Rodriguez et al., 2011) and florescent proteins is a popular topic in the field. In the second interview with Matthew, he refers to Udit's change as a natural change and in his best interest.

Udit has already a background in the biophysics of protein structural fluctuations and now we can use it in an area that we are getting into with Hal along with the fact that it's a hot area with a lot of interest nationwide and worldwide. There were too many reasons to go in that direction. Matthew

Udit defends his dissertation topic on the structural fluctuations of florescent proteins using the CHARMM analysis. From the global and local perspective of boundaries it can be understood how Udit's knowledge and individual expert identity are influenced by the larger research enterprise. Knowledge in practice is one of the ways the individual group members demonstrate their competencies or expertise (Rodriguez et al., 2013 submitted) to other members inside and outside the community of practice (Carlile, 2002). This leads to an understanding that mastery does not reside in the master but in the organization of the community of practice of which the master is a part (Lave \& Wenger, 1991; Lindkvist, 2005). Since the knowledge developed in practice must go through implicit and explicit procedural authorities such as review panels for conference papers, journal manuscripts, and funding proposals, it is the larger community that publicly acknowledges one's expertise. 


\section{CONCLUSION AND IMPLICATIONS}

The ethnographic study explores the influence of the larger community of biophysics influence on the individual biophysics graduate student development of expertise. I take a practice-based approach to analyzing community norms, standards and culture using an ethnographic research design and Wenger's (Wenger, 1998) constructs of boundaries as an analytical perspective. In the context of a biophysics research group, influence of the larger biophysics community is investigated throughout an exchange of knowledge between the biophysics group and a chemistry research group on a particular simulation program called CHARMM. Analysis of the boundary connections made between the biophysics and chemistry groups show how their exchange of knowledge is facilitated by boundary objects, boundary encounters, and brokering.

The boundary object shared between the two groups is the analytical simulation program CHARMM that guides the topics of conversation. Discussion revolves around specific force fields, commands, and ways to handled proteins interacting with an implicit water medium. The two research groups meet over a period of four weeks and have several different kinds of encounters. The two immersion encounters where a member from one group visits the host research group proves to be beneficial in exchange of information from the chemistry group to the biophysics group and the second encounter lets the knowledge flow from the biophysics group to the chemistry group representative.

To further facilitate information exchange throughout the encounters of the two research groups, Matthew, the biophysics group's lead professor takes on a role of broker. His consistent summary of topics and concepts discussed reminds everyone what is being discussed and the topics they agree upon. Negotiations of meaning and 
information are expedited by this brokering service. Matthew also identifies every participant's expertise and strengths as a way to understanding what is expected from each participant in conversation.

The analytical framework of boundary connections conveys a mechanistic perspective of how a physics research group undergoes a cultural shift. The boundary framework is a guide to explore three levels of knowledge boundaries interacting in these group encounters. The main purpose of holding these meetings with the chemistry group is to learn as much as possible about the inner working of the CHARMM program in reference to the time-sensitive grant proposal on which the biophysics group is working. Grant proposals with preliminary results are valued more than without preliminary results by the norms of the larger biophysics community. This leads the biophysics group to search for help from the chemistry group that had used the analytical program CHARMM before. After the exchange of knowledge, the biophysics research projects are more centered on CHARMM analysis and individual student expertise in using this program also shifts. A top-down perspective of boundaries of the global to local communities shows how trends in the larger community of biophysics research influence the graduate student development of their expert identity. Meeting the research needs of the larger biophysics community leads the local research group and the individual members to shift their expertise to the topics of interest in the larger field.

My study gives a better understanding of how the levels of boundaries between communities of practice from the global community to the local research group influence student development. The biophysics research group's practices in teaching students how to engage in the larger biophysics community through publications (Rodriguez et al., 
2013 submitted) and learning the popular trends and needs of the global research community are skills that transcend the practices of the local research group. Having students develop autonomy and agency in research beyond the scope of their personal research group motivates the student to persist and continue their journey towards physics expertise.

Another motivator in the graduate student's research experience is the mentor. The study conveys how Matthew's brokering practices facilitated knowledge exchange between the groups, but it can also be seen as effective mentoring practices in serving the needs of his group and the students learning. Matthew is aware of his group's individual strengths and takes it upon himself to seek outsider help when necessary. Matthew's brokering practices of summarizing discussion points and making explicit what is expected of the students with certain expertise is also an effective mentoring practice. In a group with different students at different levels of expertise it is important to have clear explanations so that knowledge flows at the different levels. Further investigations are required to explore how different brokering practices, such as language can become effective mentoring practices to help graduate students develop expertise and improve the graduate student experience. 


\section{REFERENCES}

AIP statistical research center. Graduate Student Statistics (2013). Retrieved, 2013, from www.aip.org/statistics

Bogdan, R. C., \& Biklen, S. K. (Eds.). (2007). Qualitative research for education: An introduction to theory and methods (5th ed.). Boston, MA: Pearson Education, Inc.

Bond-Robinson, J., \& Stucky, A. P. (2005 (July 21-24)). Grounding scientific inquiry and knowledge in situated cognition. 27th Annual Meeting of the Cognitive Science Society, Stresa, Italy.

Brown, J. S., \& Duguid, P. (1998). Organizing knowledge. California Management Review, 40(3), 90-111.

Brown, J. S., \& Duguid, P. (2001). Knowledge and organization: A social-practice perspective. Organization Science, 12(2), 198-213.

Carlile, P. R. (2002). A paradigmaticview of knowledge and boundaries: Boundary objects in new product development. Organization Science, 13(4), 442-445.

Collins, H. M. (1985). Changing order: Replication and induction in scientific practice. London: Sage.

Committee to Assess Research-Doctorate Programs. (2010). A data- based assessment of research-doctorate programs in the United States. (). Washington, DC: National Academies Press.

Creswell, J. W. (2007). Qualitative inquiry \& research design: Choosing among five approaches. Thousand Oaks, CA: Sage Publications, Inc.

Dunbar, K. (1995). How scientists really reason: Scientific reasoning in real-world laboratories. In Sternberg, R.J. and Davidson, J. (Ed.), Mechanisms of insight (pp. 365-395). Cambridge, MA: MIT Press.

Ericsson, K. A. (Ed.). (1996). The road to excellence: The acquisition of expert performance in the arts and sciences, sports, and games. Mahwah, NJ: Lawrence Erlbaum Associates, Inc.

Feldman, A., Divoll, K. A., \& Rogan-Klyve, A. (2013). Becoming researchers: The participation of undergraduate and graduate students in scientific research groups. Science Education, 97(2), 218-243. doi:10.1002/sce.21051

Haas, P. M. (1992). Introduction: Epistemic communities and international policy coordination. International Organization, 46(1), 1-35. 
Kisiel, J. F. (2009). Exploring a school-aquarium collaboration: An intersection of communities of practice. Science Education, 94, 95-121. doi:10.1002/sce.20350

Knorr-Cetina, K. D. (1983). The ethnographic study of scientific work: Towards a constructivist interpretation of science. In K. D. Knorr-Cetina, \& M. J. Mulkay (Eds.), Science observed: Perspectives on the social studies of science (). Beverly Hills, CA: Sage.

Knorr-Cetina, K. (1999). Epistemic cultures: How the sciences make knowledge. Cambridge, MA: Harvard University Press.

Latour, B., \& Woolgar, S. (1979). Laboratory life: The social construction of scientific facts. Beverly Hills, California: Sage Publications, Inc.

Lave, J., \& Wenger, E. (1991). Situated learning; legitimate peripheral participation Cambridge University Press.

Lindkvist, L. (2005). Knowledge communities and knowledge collectivities: A typology of knowledge work in groups. Journal of Management Studies, 46(6), 1189-1210.

Maxwell, J. A. (Ed.). (2005). Qualitative research design: An interactive approach [null] (2nd ed.). Thousand Oaks, CA: Sage.

Merriam, S. B. (Ed.). (2002). Qualitative research in practice; examples for discussion and analysis. San Francisco, CA: Jossey-Bass.

Nersessian, N. J. (2006). The cognitive-cultural systems of the research laboratory. Organization Studies, 27(1), 125-145.

Nersessian, N. J. (2005). Interpreting scientific and engineering practices: Integrating the cognitive, social, and cultural dimensions. In M. Gorman, R. Tweney, D. Gooding, \& A. Kincannon (Ed.), Scientific and technological thinking (pp. 17-56). Erlbaum Press: New York.

Osbeck, L. M., Nersessian, N. J., Malone, K. R., \& Newsletter, W. C. (2011). Science as psychology: Sense-making and identity in science practice. New York: Cambridge University Press.

Pickering, A. (1995). The mangle of practice: Time, agency and science. Chicago: University of Chicago Press.

Pickering, A. (Ed.). (1992). Science as practice and culture. Chicago: University of Chicago Press. 
Potvin, G., \& Tai, R. H. (2012). Examining the relationships among doctoral completion time, gender, and future salary prospects for physical scientist. Journal of Chemical Education, 89(1), 21-28. doi:10.1021/ed100555j

Rodriguez, I., Goertzen, R. M., Brewe, E., \& Kramer, L. H. (2011). Communicating scientific ideas: One element of physics expertise. Physics Education Research Conference 2011, Omaha, NE. 319-322.

Rodriguez, I., Goertzen, R. M., Brewe, E., \& Kramer, L. H. (2013 submitted). Developing a physics expert identity in a biophysics research group. Physical Review Special Topics - Physics Education Research,

Star, S. L., \& Griesemer, J. R. (1989). Institutional ecology, 'translations' and boundary objects: Amateurs and professionals in Berkeley's museum of vertebrate zoology, 1907-39. Social Studies of Science, 19, 387-420. doi:10.1177/030631289019003001

Traweek, S. (1988). Beamtimes and lifetimes: The World of High Energy Physicists. Cambridge: Harvard University Press.

Wenger, E. (1998). Communities of practice: Learning, meaning, and identity. New York: Cambridge University Press.

Wenger, E. (2000). Communities of practice and social learning systems. Organization, 7(2), 225-246. doi:10.1177/135050840072002 


\section{CHAPTER VI}

\section{CONCLUSION}

In this chapter I summarize the findings from the previous chapters and describe how they relate to the overall theme of the dissertation of graduate student development of expertise in physics. I address and answer the research questions:

Question 1: What makes a physics expert, from the perspective of university physics professors?

Question 2: How do physics research students develop specific expert identities in a specific physics subfield, i.e., a specific expert trajectory?

Question 3: Within a specific physics research group, what are the characteristics of the general physics experts and how do they develop?

Question 4: How does the larger physics community interplay in the development of specific physics expertise?

I also discuss the implication of my research in addressing physics graduate programs and student retention.

\section{SUMMARY OF FINDINGS}

The focus of the dissertation is to model how one becomes a physics expert in a research group setting. With the use of participationist theories of learning and Lave and Wenger's constructs of Legitimate Peripheral Participation in a Community of Practice $[1,2]$, I build a specific model of the apprenticeship experience of physics graduate students in a biophysics research group. My study uses an ethnographic research design to collect data and to describe the development of physics expertise. From the observations of day-to-day activities in the weekly research meetings to individual 
interviews with all the participants in the group, I build a collective story of the culture and standards of practice in the biophysics research group and how those practices help develop graduate student expert identities and membership in the physics community. I now summarize the major findings of the study, organized to describe how one develops physics expertise.

\section{A. Chapter 2: Constructing a Model of Physics Expertise}

Chapter 2 sets out to discover "what is physics expertise" from the perspectives of physics experts. Findings from this interview study with three physics professors in different fields are the foundation of the model of physics expertise as perceived from within the physics community. The preliminary model of physics expertise addresses the first of my research questions; what makes a physics expert from the perspective of university physics professors. The preliminary model also set up the rest of the research questions and study designs in the particular context of a biophysics research group.

The model of physics expertise as perceived by physics professors has different levels; one is first a specific expert in topic or subfield. One person cannot be an expert in all of physics; they are experts in their particular field of study and even more specific to their topic of study. For example, Leebob, a nuclear physicist, was a wire chamber expert because he built wire chambers. The notion of being identified by the machine the physicist works with is also common in high-energy physics $[3,4]$. Besides the machine that one works with, one can also identify their specific expertise by the specific topic of study. Albert, for example, is a professor with expertise in electroproduction of strange quarks. 
Besides specific expertise in a relatively small area, the model of physics expertise includes developing general expert characteristics. These general characteristics are developed along the way and emerge through the shared practices of the larger physics community. The professors identified how all physics experts, regardless of their specific expertise, should know what's happening in their discipline in terms of the theories, current experiments, and funding. Expert physicists also need to know how to pose interesting research questions and how to approach solving them, which requires one to know the trends and norms of the larger discipline community.

Further, physics experts can also become what I identified as boundary crossers. The professors interviewed in this study revealed that physics experts typically do not stop at one topic of expertise. The field or discipline is constantly changing and for some, it requires the expert to change as well. Boundary crossing is ability to apply what you know to learn something new, especially when it is necessary. Matthew described how physics experts were called upon to meet with engineers to discuss the explosion of space shuttle Challenger. Although the physicists on the Rogers Commission did not have expertise in rockets, they were able to sufficiently learn fundamentals of rocketry to present findings about the Challenger tragedy. Boundary crossing can also be a transition within the discipline from one topic to another. For example, Leebob was first a wire chamber expert but then became an expert in kaon electricproduction within the same subfield of nuclear physics.

The model of physics expertise from the perspective of university physics professors includes specific expertise in a specific subfield, discipline, or topic. Along the way, the physicist develops general physics expert characteristics, and once established as a 
specific expert in one topic, they can cross boundaries and learn something new in the field as boundary crossers. These three related characteristics formed the initial model of a physics expert. The model is utilized and further developed in subsequent chapters, which study the development of expertise in the context of a biophysics research group.

\section{B. Chapter 3: Communicating Scientific Ideas: One Element of Physics Expertise}

In chapter 3 I present the first analysis of the ethnographic case study of a biophysics group's norms and culture. I specifically focus on their internal group perception of what makes an expert and the group practices that help expertise development. I use interview data and research meeting observations to triangulate the biophysics' group perspective on expertise. Findings from this study show how communicating results of scientific research through scientific writing is an important part of the socialization process from novice to expert. Furthermore, contributing publications to the larger biophysics field becomes a marker of expertise for the members of the biophysics research group. The mentor and group leader, Matthew, describes three attributes of a specific physics expert: knowing what research questions to ask, knowing how to approach the research question, and contributing research to the field. The third of these attributes being a critical marker of physics expertise.

Chapter 3 establishes how the participant biophysics group prepares their student novices to communicate and publish research and develop into experts. Communicating research through scientific publications is a critical aspect of developing physics expertise and the participant biophysics research group designed a learning trajectory for their students from which to learn. This learning trajectory has certain stages of contribution. The student first conducts research by running simulations and observing 
how the manuscript is written. After, they can contribute by also building an outline of the manuscript and identifying graphical representations that will present the point of the research. Lastly, the students learn to communicate how their research connects to the larger context of the scientific community.

The learning trajectory designed for students in this biophysics group has an apparent contradiction in which a specific expert is one that has contributed research to the larger community through publications, but Matthew, one of the group mentors, suggests that none of his current students were "really ready." Udit, a third year graduate student had contributed research to the larger biophysics community and was considered a specific expert in the topic he published; yet his learning trajectory is not completed. This leads to the conclusion that students typically go through multiple cycles of contributing to projects and communicating in writing to become experts. In chapter 3 I argue that multiple cycles of the learning trajectory also imply the development of general physics expert characteristics when students truly become "ready." Uncovering the mechanism by which students develop both the specific and general physics expert characteristics through the development of social identities as physics experts is the focus of the study in Chapter 4.

\section{Chapter 4: Developing a Physics Expert Identity in a Biophysics Research Group}

Chapter 4 is an in depth analysis of how graduate students in a biophysics research group develop expertise by socially becoming expert members in their group and in the biophysics community. Being a physics expert carries certain meaning about the kind of person a physics expert is and how they interact within the community of physicists. I take the social perspective of learning as participating in the social world and developing 
an identity, and use Wenger's [2] theoretical framework of identity as membership and trajectory to analyze how students develop expertise.

Guided by the learning trajectory designed to help students contribute research and publish research in chapter 3, I analyze for membership competencies of students at different stages of the learning trajectory. Wenger's [2] membership competencies of mutual engagement, negotiability of the repertoire, and accountability to the enterprise define one's identity as a competent member of the community of practice. Combined with the construct of identity trajectory, the analysis in chapter 4 shows evidence of how membership competencies are seen in interaction and develop throughout three stages of the learning trajectory.

The first stage of the learning trajectory reviewed in chapter 3 is to first contribute to research by running simulations for preliminary data. The episode selected as an example of this stage is of student Ike designing his project after running some preliminary simulations of his computational model. In a discussion with his mentors, second year student Ike, showed evidence of competent membership. Ike was mutually engaged with his mentors and able to negotiate the group's repertoire and use the tools for analysis.

The second stage of the learning trajectory is to create graphs and identify factors that present the point of the manuscript. For the second stage of the learning trajectory, third year student Hal, is testing factors in his experiment and during discussion he showed evidence of mutual engagement and negotiability of the repertoire with overlapping competencies of the project needs with his mentors. Hal was in the testing stages of his experiment and his competence of the analysis tool complemented by his mentor's physical knowledge of the physics phenomena propelled the project forward. 
The third stage of the learning trajectory is to communicate or publish the research in the larger biophysics community. For the third stage of the learning trajectory, the third student Udit was preparing a presentation of his project to communicate at a national conference. During the discussion with his mentors, Udit showed evidence of mutual engagement and negotiability of the repertoire competencies. Udit's episode also showed Udit's ability to distinguish the kind of information that needs to be presented which is evidence of accountability to the enterprise, a responsibility to communicate with his audience. Unlike the other two students, Udit was working on his second project to contribute to the larger biophysics community and therefore had gone through the learning trajectory designed by his mentors at least twice. The analysis shows that multiple cycles of the learning trajectory of contributing research in the form of publication or communication to the larger community of physicists may be necessary to establishing an expert identity.

The analysis of membership competencies at three stages of the learning trajectory to contribute research supports the conclusions in chapter 3 of multiple cycles strengthening the development of general expert characteristics. From the theoretical perspective of the student's developing an expert identity, membership acquired through competencies enables the student to develop their specific expert identity through their specific projects. The combination of findings from both chapters 3 and 4 answer the second and third research questions in my introduction. Question 2: How do physics research students develop specific expert identities in a specific physics subfield, i.e. a specific expert trajectory? Question 3: Within a specific physics research group, what are the characteristics of the general physics experts and how do they develop? For questions 2 
and 3, I show how specific expertise in the biophysics research group is attained after the student has successfully contributed research the field in the form of publications. The learning trajectory to contribute research develops student expert identities through membership competencies and along the way also develops general expert characteristics such as being accountable to the enterprise. For question 3 particularly, I show in chapter 3 that general physics experts, according to this biophysics group, have certain attributes: knowing what research questions to ask, knowing how to approach the research question, and contributing research to the field. In chapter 2 , one of the physics professors also suggested that physics experts should know what is happening in their discipline and what research is being funded. These attributes or general expert characteristics, identified in chapter 3 are shown to develop through a learning trajectory of competent membership in chapter 4 . Yet the attributes all seem to have influence from the larger research community. The exploration of the interaction of the larger physics community with individual student expertise development is addressed in chapter 5 .

\section{Chapter 5: The Global Community of Physics Influence on a Biophysics Research Groups' Cultural Shift and Individual Expertise}

Chapter 5 is a study that explores the influence of the larger biophysics research community on the biophysics research group's cultural practices and the development of individual students' expertise. To investigate the influence on the larger biophysics research field on the local research group, I use Wenger's construct of boundaries and focus on analyzing four weeks of group interactions with a chemistry research group. Using ethnographic study design and presentation techniques, I describe the culture of the biophysics research group before, during, and after the chemistry group encounters and 
exchange of knowledge. The professor from the biophysics group, Matthew, initiates the encounters between the two groups, in order to learn as much as possible about an analytical molecular dynamics simulation program that both research group have in common. Learning how to effectively and efficiently use the molecular dynamics simulations program is meets a perceived need for preliminary results in a grant proposal that needed to be submitted. The outcome of the knowledge exchange between groups, as well as the research trends in the larger community of biophysics to use molecular dynamics simulation analysis shifts the biophysics research group research practices and student projects.

Utilizing Wenger's framework of boundaries in a community of practice [2] I analyze how boundary connections of a boundary object, boundary encounters, and brokering facilitated and expedited the exchange of knowledge between the two research groups. The larger biophysics community of practice has specific trends, norms and standards that members of the specific biophysics community adopt. In this case it is a standard for grant proposals to be funded that include preliminary results and analysis. The standard feeds into the local community of research groups that interpret this community standard as one their own and strive to meet the criteria. In the process, individual members of the research group are influenced in terms of the tools they use and the concepts they learn. The biophysics research group in the present study wanted to contribute work to the popular research topics of florescent proteins using molecular dynamics simulations. An outcome of the global research community trends is the individual graduate student shift in research project and analytical techniques. Udit for example, switched his research project to be centered on these popular research topics. In this way, the larger community 
research trends influenced Udit's expertise development from structural fluctuations of proteins using energy landscapes to fluctuations in florescent proteins using molecular dynamics simulations. Delineating these global and local boundaries and their interactions conveys the subtleties of global community norms on individual expertise development.

In chapter 5 I explore the global and local community boundary interactions influence on expertise development is a response to my last research question: How does the larger physics community interplay in the development of specific physics expertise? As the last piece of the expertise model in chapter 2 is for physics experts to become boundary crossers, when one is able to apply what they know of one topic when learning a new topic. The results from chapter 5 show how one of the graduate students was able to cross project boundaries and apply what he learn in a previous project to a new project, shifting his individual expertise. In the interaction with another expert chemistry research group, the biophysics research group as a whole also shifted their analytical techniques and group expertise. Therefore, boundary crossing for Udit and the research group as a whole is influenced by the larger biophysics community cultural trends.

\section{IMPLICATIONS FOR RESEARCH}

The research implications of this study lie on the overall participationist framework of practice and identity to investigate physics expertise development. This framework adds to the model of physics expertise from a practice and identity perspective that has been traditionally studied from cognitive perspective. In contrast to cognitive model of physics experts, the authentic description of physics expertise development through identity membership and enculturation practices expands the physics expertise model. 
Research in cognitive psychology and cognitive science literature focuses around expert-novice differences in specific problem solving skills. The cognitive literature has addressed how physics experts organize their memory and retrieval mechanisms to solve physics problems based on physics principles [5-9]. Although the cognitive research on physics expertise has contributed substantial knowledge on how people learn, the limited scope of physics experts' cognitive abilities lacks an understanding of how these problem solving skills and overall expertise is developed over time, and developed within the context of the physics community. Further, understanding expert knowledge organization and retrieval mechanisms is interesting but these are far removed from the research laboratory and the practices that support expert development. My research of student expertise development in natural laboratory context describes the social practices that cultivate expert identity development.

Methodologically, physics expertise research on expert thinking is specialized in clinically controlled methods such as verbal protocols, cognitive walkthroughs, and knowledge elicitation techniques such as card sorting and task analysis [7,8,10-12]. Such research approaches limits observations to controlled environments and does not take context into account. An authentic practice perspective such as learning as participating in a community of practice expands the model of physics expertise to include contextual dependence on learning and mechanisms by which expertise is developed in the physics practice. A variety of research methodologies are necessary to investigate questions of development in natural contexts. The present study uses the qualitative ethnographic approach to research physics expertise development. Ethnography, as a qualitative research design, focuses on the cultural practices of a group [13]. The researcher has the 
opportunity to participate in the group's culture and learn about their environment, social organization, developmental cycles, and the group's system of knowledge and skills [3]. The longitudinal observations of day-to-day activities in the group, allows the researcher to describe and interpret the natural setting of the group's culture instead of just the sole perspective of the participants through interviews. My research expands methods of research in the physics expertise literature to in depth qualitative a research design builds a robust model of physics expertise and its development.

\section{IMPLICATIONS FOR INSTRUCTORS AND GRADUATE STUDENTS}

The research practices observed in this participant biophysics research group serve as a guide for graduate students and the mentors alike. My intention is to suggest what experiences could help graduate student develop individual expertise and succeed at their graduate studies. Findings from the present study suggest that contributing research to the physics community in the form of publications is important in developing physics expertise and student autonomy and accountability. Participants from the biophysics group all agreed that expert recognition comes from good research being published as seen in chapter 3 interviews with mentors and students. In order to be recognized as an expert through research publications, graduate students need a form of guidance and training on the process of writing manuscripts and interpreting research for publication. Having mentors explicitly train students through a learning trajectory as the participant biophysics group had in chapters 3 and 4 shows the students how research is conducted and teaches students about the norms of practice of the larger biophysics field.

Analysis of student membership competencies in chapter 4 also suggests how mentors can guide students in moment-to-moment interactions to develop social expert 
identity. In the present study, the mentors of the biophysics graduate students discuss weekly project progress with their students so as to gauge the research and also the students learning and development. Mentors also guide the student by explicitly stating reasons for their suggestions and how each decision is influenced by their local community norms and global research norms. Mentors guidance and explicitly summarizing discussion points and expectations supports a transparent mentor-student relationship, an important factor in graduate student success.

As students in the biophysics research group contribute work through the group's projects, they also developed professional development skills that transcend the graduate experience into the workforce [14]. Skills, such as communicating and presenting research at conferences, teaches students how to properly communicate their message and the significance of their contribution to the field. Participant graduate student Udit showed an example of these professional development skills in chapter 4 analyses of membership competencies. A way of promoting the development of such professional development skills, mentors can encourage and motivate students by stating explicitly the value of these skills and any individual expertise students add to the group. Mentors in the biophysics research group made explicit comments to students' excellent performance and individual expertise. For example, in chapter 5 Matthew presented his student Hal as the group expert in molecular dynamics simulations and peers of the group asked Hal questions they may have about molecular dynamics. The mutual recognition of student's valuable skills motivates students for continued participation [15-17]. 


\section{DIRECTIONS FOR FUTURE RESEARCH}

Future research of this study can branch into multiple directions. One direction centers on extending ethnographic observations to multiple physics research groups from multiple specific disciplines and compare between cultures and practices. Multiple research group populations can also guide the researcher to follow patterns of similarity across the physics disciplines to better understand expertise within the general physics community of practice. Multiple research sites would require a research design with multiple investigators and ample resources. My present study would serve as a guide to initiate questions of social practice and community participation that promote expertise development.

A second research direction from this ethnographic study on student development of physics expertise is to focus the question of development of expertise from the perspective of mentors. Mentors are an important aspect to graduate student success [15]. Research on positive mentoring practices in the laboratory context can also target the problem of physics graduate student attrition. An example of positive mentoring practices is seen in Matthew's brokering practices when collaborating with other research

groups in chapter 5. Brokering practices such as summarizing concepts and ideas during discussion can make both the more advance student and novice students understand the flow of discussions from which both levels can learn. In depth analysis of student-mentor interactions could shed light on moment-to-moment mentoring practices that cultivate a positive graduate student experience and expert identity development within the community of practice. 
A third direction of research is to apply the theoretical perspectives of identity and ask questions of how gender, race, nationality, and language affect the graduate experience and expert identity development. I propose combining previous research of identity factors [18-25] that influence one's science identity and membership competencies explored in my study to create a comprehensive survey of social expert identity development. The survey would consist of statements of ability and performance as perceived by the graduate student and a similar measure as perceived by the mentor. Both students and mentor perceptions on the student's ability and social identity in the community of practice can serve as benchmarks of expertise development. Analysis of the interaction between student beliefs and mentor's perceptions of the student can inform research on student-mentor relationships. Mentors, students, and stakeholders can then make decision on how to guide graduate students through their physics graduate career on the basis of research findings. My purpose in the present study is to contribute further understanding of physics graduate student development from the perspective of expert identity in order to reduce graduate student attrition and increase student participation and retention in physics. 


\section{REFERENCES}

[1] J. Lave and E. Wenger, Situated Learning; Legitimate Peripheral Participation (Cambridge University Press, 1991).

[2] E. Wenger, Communities of practice: Learning, meaning, and identity (Cambridge University Press, New York, 1998).

[3] S. Traweek, Beamtimes and Lifetimes: The World of High Energy Physicists (Harvard University Press, Cambridge, MA, 1988)

[4] K. Knorr-Cetina, Epistemic Cultures: How the Sciences Make Knowledge (Harvard University Press, Cambridge, MA, 1999).

[5] J. Larkin, J. McDermott, D. P. Simon, and H. A. Simon, Science 208, 1335 (1980).

[6] J. H. Larkin, The role of problem representations in physics (Lawrence Erlbaum Associates, Inc., Hillsdale, NJ, 1983).

[7] A. Mason and C. Singh, Phys Rev. STPER 7 (2011).

[8] M. T. H. Chi, P. J. Feltovich, and R. Glaser, Cognitive Science 5, 121 (1981).

[9] W. G. Chase and H. A. Simon, Cognit. Psychol. 4, 55 (1973).

[10] T. Farrington-Darby and J. R. Wilson, Appl. Ergon. 37, 17 (2006).

[11] Ericsson, K. Anders, Jacqui Smith, Prospects and limits of the empirical study of expertise: an introduction (Cambridge University Press, Cambridge, 1991), p. 1.

[12] J. Shanteau, The Psychology of Experts An Alternative View (Springer, New York, 1992), p. 11.

[13] J. W. Creswell, Qualitative inquiry \& research design: Choosing among five approaches (Sage Publications, Inc, Thousand Oaks, CA, 2007).

[14] AIP Statistical Research Center, (Graduate Student Statistics 2013), 2013.

[15] G. Potvin and R. H. Tai, Journal of Chemical Education 89, 21 (2012).

[16] C. M. Golde, Beginning graduate school: Explaining first year doctoral attrition (Wiley Online Library, San Francisco, 1998), 1998, p. 55.

[17] B. E. Lovitts, Leaving the Ivory Tower: The causes and consequences of departure from doctoral study (Rowman \& Littlefield Publishers, Inc, Lanham, MD, 2001). 
[18] H. B. Carlone and A. Johnson, JRST 44, 1187 (2007).

[19] E. Wenger, Organization 7, 225 (2000).

[20] J. P. Gee, Review of research in education 25, 99 (2000).

[21] Z. Hazari, G. Sonnert, P. M. Sadler, and M. Shanahan, Journal of Research in Science Teaching 47, 978 (2010).

[22] J. E. Cote and C. G. Levine, Identity Formation, Agency, and Culture: A Social

Pscychological Synthesis (Lawrence Erlbaum Associates, Mahwah, New Jersey, 2002).

[23] N. W. Brickhouse and J. T. Potter, Journal of Research in Science Teaching 38, 965 (2001).

[24] J. V. Wertsch, Culture Psychology 3, 5 (1997).

[25] E. H. Erikson, Identity; Youth and Crisis (W.W. Norton \& Company, Inc., New York, NY, 1968). 
VITA

\section{IDAYKIS RODRIGUEZ}

1992

2003-2008

2008-2009
Born, Havana, Cuba

Immigrated to the United States

B.S., Physics; Minor in Mathematics

Florida International University

Miami, Florida

Teaching Assistant

Florida International University

Miami, Florida

\section{PUBLICATIONS AND PRESENTATIONS}

Brewe, E., Sawtelle, V., Kramer, L. H., O’Brien, G., Rodriguez, I. Pamela, P. “Towards equitable instruction in introductory university physics." Phys. Rev. Special Topics-PER. 010106 (2010).

Rodriguez, I., Goertzen, R.M., Brewe, E., Kramer, L.H., "Cookies as agents for community membership." Invited paper in Symposia presented at the 2012 Physics Education Research Conference, Philadelphia, (2012).

Rodriguez, I., Brewe, E., Sawtelle, V., Kramer, L.H., "Impact of Equity Models and Statistical Measures on Interpretations of Educational Reform." Phys. Rev. Special Topics-PER. 020103 (2012).

Rodriguez, I., Goertzen, R. M., Brewe, E., Kramer, L., "Communicating Scientific Ideas: One Element of Physics Expertise," Proceedings of the 2011 Physics Education Research Conference, AIP Press. Melville, NY, 319-322 (2011)

Rodriguez, I., Brewe, E., and Kramer, L.H., "Physics as a Community of Practice: Qualitative Interview Study of Three University Physics Professors" Proposal at NARST 2011 Proceedings, Orlando, FL (2011).

Rodriguez, I., Brewe, E., Kramer, L.H., "Constructing a Model of Physics Expertise," Proceedings of the 2010 Physics Education Research Conference, AIP Press. Melville NY, 1289, 277-280, (2010).

Rodriguez, I., Dr., Higinbotham, D. H. "Reviving and Upgrading of the eP device." Journal of Undergraduate Research. Vol 8, (2008). (Selected paper) 


\section{DISTINCTIONS AND AWARDS}

American Physical Society (APS) Graduate Education Conference 2013, Student Discussant, College Park, MD. January (2013)

Southeastern Conference for Undergraduate Women in Physics (SCUWP), Graduate Student Panel Discussant, Orlando, FL. January (2013)

Florida International University $4^{\text {th }}$ Annual Community Leaders Summit, Student Discussant, Coral Gables, FL. October (2012)

Florida International University Dissertation Year Fellowship Award, (100\% Tuition and Stipend) August 2012

$62^{\text {nd }}$ Lindau Nobel Laureate Meeting Young Researcher, Germany, July (2012)

Oak Ridge Associated Universities (ORAU) Nominee to the Lindau Nobel Laureates Meeting, (2012)

FIU News Article. "Mingling with Nobel Laureates in Germany" by Karen Cochrane. August 17, 2012. http://news.fiu.edu/2012/08/mingling-with-nobel-laureates-ingermany $/ 43537$

Congressional Hispanic Caucus Institute (CHCI), Inc. and NBC News Education Nation Latino Education Forum. "Young Latino Perspective - In their own voices". May 21, 2012 http://www.chci.org/news/pub/chci-partners-with-nbc-news-education-nation-forpowerful-education-dialogue-in-miami

FIU News Article. "Physics Student to Meet Nobel Prize Winners in Germany" by Evelyn Perez. April 17, 2012. http://news.fiu.edu/2012/04/physics-student-to-meetnobel-prize-winners-in-germany/38313 